\title{
Mutant analysis of luminescence and autoinduction in a marine bacterium
}

by

\section{Alan Kuo \\ B.A., Harvard University \\ M.S., Massachusetts Institute of Technology}

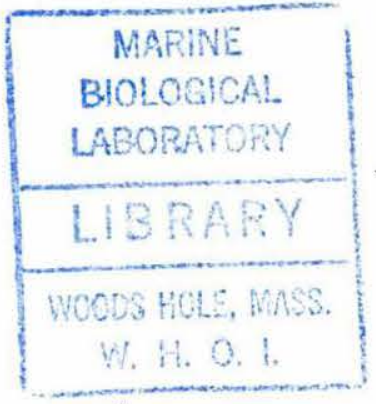

Submitted to the Department of Biology in partial fulfillment of the requirements for the Degree of

\section{Doctor of Philosophy}

at the

Woods Hole Oceanographic Institution and the

Massachusetts Institute of Technology

December 1994

(C)Woods Hole Oceanographic Institution and Massachusetts Institute of Technology, 1994

Signature of Author

Joint Program in Oceanography and Ocean Engineering Woods Hole Oceanographic Institution and Massachusetts Institute of Technology

Certified by

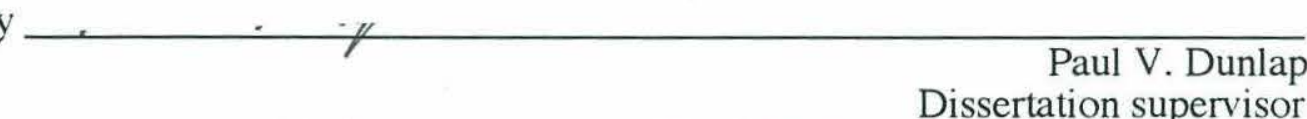

Biology Department, Woods Hole Oceanographic Institution

Accepted by

Donald M. Anderson

Chairman of the Joint Committee for Biological Oceanography Woods Hole Oceanographic Institution and Massachusetts Institute of Technology 


\title{
Mutant analysis of luminescence and autoinduction in a marine bacterium
}

by

\author{
Alan Kuo \\ Submitted to the Department of Biology in partial \\ fulfillment of the requirements for the Degree of \\ Doctor of Philosophy in Biology
}

\begin{abstract}
The marine symbiotic bacterium Vibrio fischeri is striking for its ability both to emit light and to dramatically regulate light emission using a cell-to-cell signalling mechanism called autoinduction. The latter is mediated by a signal molecule called the "autoinducer". The mechanistic bases of both luminescence and autoinduction are well known in $V$. fischeri, but this knowledge is mostly derived from studies of the cloned luminescence and autoinduction genes expressed in Escherichia coli. In this study, luminescence and autoinduction mutations were systematically generated in $V$. fischeri to explore aspects of luminescence and autoinduction not addressable in $E$. coli, such as the adaptive significance of luminescence. Most dramatically, the mutants revealed the presence of multiple autoinducers and autoinducer synthases in $V$. fischeri. One of the autoinducers (autoinducer-2, or AI-2) was chemically purified and shown to be $N$ octanoyl-L-homoserine lactone. The genetic locus encoding the AI-2 synthase was cloned and designated ain (autoinducer). Manipulation of ain and AI-2 in V. fischeri demonstrated that the function of AI-2 appears to be to inhibit rather than to promote autoinduction.
\end{abstract}




\section{ACKNOWLEDGMENTS}

I wish to thank the following people for making this work possible both logistically and intellectually:

Paul Dunlap, for teaching me physiology, and for being simultaneously advisor, professor, ally, critic, and colleague.

Neil Blough, for teaching me chemistry, and enjoying such an onerous task.

Members of my thesis committee, for offering advice and criticism, and for some sharp debates.

Other members of the Woods Hole Oceanographic Institution (WHOI) Biology Department faculty, for being helpful at one time or another.

The staff, students, postdocs, and other denizens of the Redfield and Fye Buildings at WHOI, for being both logistically and intellectually crucial for this work. Many were also crucial for my personal well-being and sanity.

The administrative staff of WHOI, particularly certain extremely helpful individuals in the Departments of Biology and of Education, for their friendliness and competence, and for a willingness to accomodate to one of their more unpredictable clients.

And of course the Woods Hole Oceanographic Institution (WHOI), including the WHOI Ocean Ventures Fund and the WHOI Molecular Biology Fund, for contributing financially to my progress as a Joint Program student.

Finally, I have had no lack of friends, both here in Cape Cod and equally many outside scattered around the world, who have been unflagging in their support, intelligent in their advice, patient in their tolerance, and generous in their supply of the sushi, dark beer, and ice-cream that are necessary for successful completion of a dissertation. Above all, they have been sympathetic in both good moments and bad. The publication of this thesis is a good moment, and I wish to share it with them all. These friends know who they are, so I will name only three: Mom, Dad, and Sis. Thanks. 


\section{TABLE OF CONTENTS}

Abstract

Acknowledgments

Chapter 1 . Introductory remarks

I. Luminescence

A. Mechanism of luminescence $\quad 6$

$\begin{array}{ll}\text { B. Regulation of luminescence } & 6\end{array}$

$\begin{array}{ll}\text { C. Function of luminescence } & 8\end{array}$

$\begin{array}{ll}\text { II. Autoinduction } & 10\end{array}$

A. Autoinduction in Vibrio fischeri 11

1. The signal 11

2. The signal response 13

3. The current model for autoinduction 14

B. Autoinduction in other bacteria 15

1. Autoinduction systems which fit the $V$. fischeri paradigm 15

2. Autoinduction systems which do not fit the paradigm 17

$\begin{array}{ll}\text { C. Why study autoinduction? } & 19\end{array}$

Chapter 2. Construction and characterization of defined lux mutants of Vibrio 26 fischeri

Chapter 3. Multiple $N$-acyl-L-homoserine lactone autoinducers of luminescence in $\quad 45$ the marine symbiotic bacterium Vibrio fischeri

Chapter 4. Negative regulation of luminescence by $N$-octanoyl-L-homoserine lactone, a Vibrio fischeri autoinducer

Chapter 5. Concluding remarks

$\begin{array}{ll}\text { I. Luminescence } & 73\end{array}$

$\begin{array}{ll}\text { II. Pigmentation } & 74\end{array}$

III. Autoinduction 75
A. AI-2
75
B. AI-3
76
C. LuxR
77 


\section{Chapter 1. Introductory remarks}

The marine bacterium Vibrio fischeri has drawn scientific attention for more than fifty years because of its possession of three specialized properties: its ability to emit light, its participation in light organ symbioses with fishes and squids, and its ability to regulate light emission in a cell density-dependent manner involving an extracellular factor (autoinduction). This attention has been rewarded: $V$. fischeri is presently the best developed system for studying both bacterial luminescence and animal-microbe symbiosis, and the current model for autoinduction is based entirely on studies of the $V$. fischeri system. Much of the work on luminescence and most of the work on autoinduction relied on the $V$. fischeri luminescence (lux) genes cloned into Escherichia coli. Surprisingly, a mutant approach in $V$. fischeri has until recently not been systematically used to develop the system further, though recent construction of defined mutants of $V$. fischeri has already revealed novel aspects of regulation of luminescence (Dunlap and Kuo 1992). This dissertation constitutes an additional contribution to the ongoing mutant analysis of $V$. fischeri. The mutant approach applied in this study has allowed the experimental examination of the biological role of the luminescence system in $V$. fischeri, and has revealed exciting and heretofore unknown complexities in the mechanism of autoinduction, including the fact that $V$. fischeri possesses multiple autoinducers and autoinducer synthases. As a prelude to the experiments presented in the subsequent chapters, I will devote the rest of this chapter to a review and discussion of current ideas concerning luminescence (prelude to Chapter 2) and autoinduction (Chapters 3 and 4).

\section{Luminescence}

Luminescence is found in at least eleven species and four genera of bacteria found in a variety of mostly marine habitats (Nealson and Hastings 1991). All are members of the $\gamma$ subgroup of purple bacteria, and all but one belong to the facultatively aerobic enteric group of bacteria. Two species of luminous bacteria are not marine; luminous strains of Vibrio cholerae are isolated from brackish and fresh waters while Photorhabdus luminescens participates in symbioses with certain soil nematodes. However, most species of luminous bacteria are marine, and the most intensively studied of the luminous bacteria - V. fischeri, Photobacterium phosphoreum, Photobacterium leiognathi, and Vibrio harveyi - have been isolated from both the water column and from animals, including the gastrointestinal tracts of those animals. The first three species also 
occur in the light organs of certain fishes and squids in a species-specific manner. Colonization of animals results in high cell densities (106-10 cells $\mathrm{ml}^{-1}$; Nealson and Hastings 1991), far higher than in the surrounding sea water $\left(10^{3-4}\right.$ cells $\left.\mathrm{ml}^{-1}\right)$.

\section{A. Mechanism of luminescence}

Bacterial luminescence is the product of an oxygenation reaction catalyzed by the heterodimeric flavoenzyme luciferase (see Figure). Purified luciferase can cleave $\mathrm{O}_{2}$ and oxygenate both a long-chain aldehyde and a reduced flavin cofactor to the corresponding fatty acid and oxidized flavin (Cormier and Strehler 1953, McElroy et al 1953, Dunn et al 1973); a 4a-hydroperoxyflavin is postulated to combine with the aldehyde to form the light-emitting species (Eberhard and Hastings 1972, Suzuki et al 1983, Vervoort et al 1986). Luciferase can also cleave $\mathrm{O}_{2}^{-} \cdot$ and $\mathrm{H}_{2} \mathrm{O}_{2}$ to yield light via the same light-emitting intermediate if a flavin with the appropriate oxidation state is present (Watanabe and Nakamura 1976, Hastings et al 1979, Kurfurst et al 1983). The fatty aldehyde itself is synthesized from the fatty acid, NADPH, and ATP by a fatty acid reductase complex (Riendeau and Meighen 1979). Each of the two flavin reductases purified from $V$. fischeri is capable of supplying the reducing power necessary for the light-emitting reaction (Zenno et al 1994, Zenno and Saigo 1994).

The two subunits of luciferase are encoded by the chromosomal genes luxA and luxB. The subunits of the fatty acid reductase complex are a reductase, an acyl transferase, and an acyl-protein synthetase, encoded by the genes $l u x C, \operatorname{luxD}$, and $\operatorname{luxE}$, respectively (Boylan et al 1985). The $V$. fischeri lux genes are linked in the order luxCDABE and are cotranscribed from a single promoter; thus luciferase and the fatty acid reductase complex are coregulated (Engebrecht et al 1983, Engebrecht and Silverman 1984). In $V$. fischeri there are three other lux genes linked to luxCDABE: $\operatorname{lux} G$, the function of which is unknown (Swartzman et al 1990) but which has sequence similarity to a known flavin reductase (Andrews et al 1992), and the regulatory genes luxR and $l u x I$, which are described later in this chapter.

\section{B. Regulation of luminescence}

The luminescence of $V$. fischeri is regulated. One form of regulation is a cell density-dependent induction of luminescence called autoinduction, which I discuss in detail later in this chapter. In addition, elimination of the lux operon promoter reveals an autoinduction-independent modulation of luminescence (Dunlap and Kuo 1992). This 


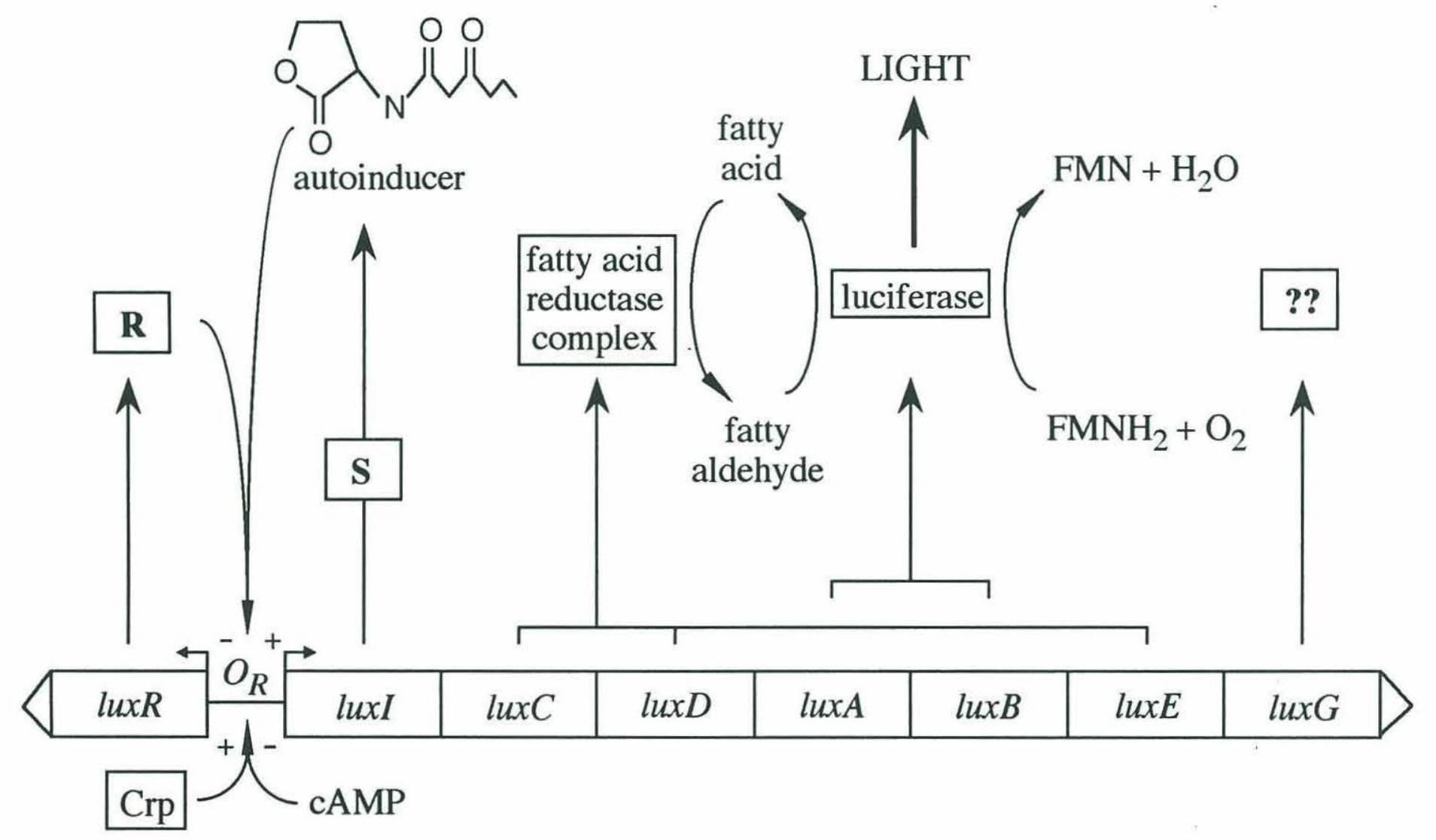

Figure. Classical model of the luminescence system of Vibrio fischeri 
modulation is independent of any known lux regulatory elements, including the lux promoter, and has been proposed to reflect gene-copy changes over the course of batch culture growth (Dunlap 1992).

Luminescence is also subject to control by a number of environmental factors. Low $\mathrm{O}_{2}$ tensions may increase luminescence and luciferase levels (Ruby and Nealson 1976, Nealson and Hastings 1977), as may pure $\mathrm{O}_{2}$, though $V$. fischeri does not grow under the second condition (Colepicolo et al 1992). The mechanism of $\mathrm{O}_{2}$ modulation of lux $A B$ expression is unknown. Induction of luminescence is delayed by the presence of iron (Makemson and Hastings 1982), and iron delays the above-described autoinducerindependent modulation (Dunlap 1992, Dunlap and Kuo 1992). Glucose delays induction, even in the presence of cyclic AMP (cAMP; Ruby and Nealson 1976). Glucose also represses luminescence under phosphate-limited chemostat conditions, and the repression is reversed by cAMP (Friedrich and Greenberg 1983). Consistent with a model of catabolite repression, the E. coli cAMP receptor protein (Crp) activates luxR transcription in the presence of cAMP (Dunlap and Greenberg 1985), luxR has an upstream E. coli Crp-binding site (Engebrecht and Silverman 1987), and V. fischeri mutants analogous to $E$. coli catabolite repression mutants with respect to luminescence can be isolated (Dunlap 1989). Also, cAMP-Crp stimulates transcription of luxICDABEG (Dunlap and Greenberg 1985). However, cAMP-Crp control is insufficient to explain the influence of glucose, since glucose also delays autoinducer-independent modulation in the absence of the Crp-binding site (Dunlap and Kuo 1992).

\section{Function of luminescence}

Significant progress has been made in elucidating the mechanisms of luminescence and its regulation in $V$. fischeri, but the biological function of luminescence in this and other luminous bacteria remains obscure. The luminescence system involves at least five polypeptides, two of which (the luciferase subunits) can comprise up to 5\% of cellular protein (Hastings et al 1965). Also, each light-emitting event ultimately consumes at least two reducing equivalents and one molecule of ATP. Also, the luminescence system is regulated, presumably to ensure that the lux gene products are synthesized only when needed. All of this nurtures the suspicion that the luminescence system is of adaptive significance to the bacteria. A few hypotheses which attempt to explain the adaptive value of the luminesence system are discussed here.

In one hypothesis, luciferase defends the cell against oxygen toxicity by scavenging $\mathrm{O}_{2}$. This hypothesis is based on the ability of luciferase to reduce molecular 
oxygen, even at low $\mathrm{O}_{2}$ tensions. Oxygen metabolism produces $\mathrm{O}_{2}{ }^{-}, \mathrm{H}_{2} \mathrm{O}_{2}, \mathrm{HO}$, and perhaps singlet $\mathrm{O}_{2}$, all of which are highly reactive species that can reduce or oxidize lipids, nucleotides, and proteins, and thus inactivate enzymes, induce mutations, and kill cells (Kanfer and Turro 1981, Imlay and Linn 1988). To protect themselves from these threats, some organisms synthesize enzymes such as catalase and superoxide dismutase that scavenge $\mathrm{H}_{2} \mathrm{O}_{2}$ and $\mathrm{O}_{2}^{-}$, respectively (Fridovich 1978). Such enzymes are often induced by oxidative stresses such as $\mathrm{H}_{2} \mathrm{O}_{2}, \mathrm{O}_{2}^{-}$, or hyperbaric $\mathrm{O}_{2}$ (Gregory and Fridovich 1973, Finn and Condon 1975). Their absence due to null mutation lowers resistance to oxidative stress (Loewen 1984, Farr et al 1986). In the oxygen scavenger hypothesis, luciferase is proposed to protect the bacterium from oxygen toxicity by scavenging molecular oxygen or its derivatives in a fashion analogous to catalase and superoxide dismutase (McElroy and Seliger 1962). In support of this hypothesis, pure $\mathrm{O}_{2}$ induces luciferase synthesis in V. fischeri and P. luminescens (Colepicolo et al 1992). Both of the toxic radicals $\mathrm{O}_{2}^{-} \cdot$ and $\mathrm{H}_{2} \mathrm{O}_{2}$ can be cleaved by purified luciferase to produce light (Watanabe and Nakamura 1976, Hastings et al 1979, Kurfurst et al 1983).

In a second hypothesis, luciferase mediates terminal electron transfers to $\mathrm{O}_{2}$ when cytochrome oxidase cannot. This hypothesis is based on the high $\mathrm{O}_{2}$ affinity of luciferase (Hastings 1952, Lloyd et al 1985). Oxidative phosphorylation depends on the heme enzyme cytochrome oxidase to transfer reducing equivalents from the electron transport chain to $\mathrm{O}_{2}$. In the electron carrier hypothesis, luciferase is proposed to perform the electron transfer function of cytochrome oxidase under conditions where cytochrome oxidase might not function, such as low $\mathrm{O}_{2}$ tension or low iron (Nealson and Hastings 1979, Makemson and Hastings 1982). Respiration and luminescence compete in $V$. harveyi, evidently for reductant (Ulitzur et al 1981, Grogan 1984), luciferase induction promotes growth of $V$. harveyi that are cytochrome oxidase-deficient due to iron limitation (Makemson and Hastings 1986), and iron limitation promotes luminescence (Makemson and Hastings 1982), as may low $\mathrm{O}_{2}$ tensions (Nealson and Hastings 1977). Finally, some luminescence mutants survive poorly under anaerobic conditions (Dieterich and Nealson 1972, Nealson and Hastings 1979).

In another hypothesis, luminescence serves as a mechanism for the dispersal and propagation of luminous bacteria. In this hypothesis, light emission by bacterial aggregations or colonies on particles in the water column attract potential host animals (Nealson and Hastings 1979). Thus, the luminescence system supplies a means by which bacteria defecated from one host colonize new gastrointestinal tracts. Consistent with this hypothesis, fecal pellets and sediment trap particles freshly collected from oceanic 
sources emit light (Andrews et al 1984), as do fecal pellets defecated by fish fed with luminous bacteria (Ruby and Morin 1979).

Additional hypotheses focus on the fact that luciferase is an oxygenase; its oxygenation of fatty aldehydes is proposed to be useful to the bacteria. The fatty acids might be oxidized further (Seliger 1987) or be covalently attached to the oxidized flavin for some unknown purpose (Kasai et al 1991). The fact that luciferase can oxygenate its substrates under low $\mathrm{O}_{2}$ tensions has also been proposed to be advantageous to organisms living under hypoxic conditions (Seliger 1975).

The above-described hypotheses do not necessarily mutually exclude one another. The luminescence system may have multiple functions. Also, it is possible that the adaptive value of the luminescence system has changed over time. It has been suggested that luminescence enzymes evolved initially to protect the strictly anaerobic inhabitants of the primitive earth's anaerobic environment from the toxic effects of low but increasing concentrations of $\mathrm{O}_{2}$, or to perform oxygenations under low $\mathrm{O}_{2}$ tensions; it is suggested that subsequently luminescence was adapted to behavioral or other uses unrelated to oxygen metabolism, or became vestigial (McElroy and Seliger 1962, Seliger 1975, 1987).

\section{Autoinduction}

A growing bacterial cell exists in the presence of its clonal siblings. Perhaps unsurprisingly then, the environmental stimuli to which a bacterium responds sometimes originate from the bacterium's fellow cells. In the laboratory world of pure batch cultures, such stimuli manifest themselves in the observation that many biologically significant activities are cell density-dependent. In many cases the cell density dependence has been shown to be mediated by a protein, such as the peptide phermones of Enterococcus faecalis (Dunny et al 1978), the extracellular differentiation factor of Bacillus subtilis (Grossman and Losick 1988), and the morphogenetic C-factor of Myxococcus xanthus (Kim and Kaiser 1990). In other cases the cell density dependence is mediated by a small membrane-permeable signal molecule. Small signal molecules were first demonstrated to regulate cell differentiation in Streptomyces griseus and then to regulate luminescence in $V$. fischeri, where the mechanism was first named "autoinduction".

Autoinduction is a mode of gene regulation where a bacterium synthesizes a specific small molecule that diffuses freely into the medium and triggers a transcriptional activator of target genes in the same or another bacterium. The most striking aspect of autoinduction is its involvement of the extracellular compartment, for this implies that 
autoinduction is a cell-cell signalling system. Because of this same extracellular aspect, expression of the genes targeted by autoinduction appears to be cell density-dependent. Thus we can view autoinduction as a method for the individual cell to measure local cell density.

\section{A. Autoinduction in Vibrio fischeri}

The term "autoinduction" was first used to describe the spectacular kinetics of light emission in batch cultures of $V$. harveyi, where luminescence per cell first declined until the cells reached the middle of the exponential growth phase $\left(5 \times 10^{7}\right.$ cells ml- $\left.^{-1}\right)$, and then rose 103-4-fold over about 4 cell doublings (Nealson et al 1970). The induction but not the initial decline was attributed to an induction of synthesis of luciferase. Without any known external stimulus, this enzyme induction presumably responded to a stimulus derived from the bacteria themselves, and so was termed "autoinduction".

At first autoinduction was not specifically associated with an extracellular signal. Kempner and Hanson (1968) had earlier performed "conditioned medium" experiments where cells were exposed to medium in which another culture had already been grown. Conditioned medium eliminated the initial decline of luminescence, leading Kempner and Hanson to propose the existence of an inhibitor of luminescence present in fresh medium but subsequently removed by the cells. Nealson et al (1970) rejected the inhibitor hypothesis but proposed that "conditioning" was the stimulus responsible for autoinduction. Finally, Eberhard (1972) showed that the conditioning was due to both removal of an inhibitor and release of a species-specific activator of luminescence, and thus that autoinduction is partly mediated by a signal or "autoinducer".

\section{The signal}

An autoinducer of luminescence should be isolatable from medium conditioned by a dense culture of $V$. fischeri fully induced for luminescence. From such a source, and using a naturally autoinducer-deficient strain of $V$. fischeri as an assay for the $V$. fischeri autoinducer, Eberhard et al (1981) purified a substance that was physically and biologically indistinguishable from synthetic $N$-3-oxohexanoyl-L-homoserine lactone (3oxohexanoyl-HSL). The autoinducer was extractable from medium with ethyl acetate (consistent with the fatty acyl moiety) and labile to base (consistent with the lactone ring). Addition of the autoinducer to a culture of wild-type $V$. fischeri immediately induced luminescence, eliminating the initial decline. 
The most novel feature of autoinduction is its extracellular aspect, which implies that the autoinducer moves from cell to medium. 3-oxohexanoyl-HSL is a small slightly polar molecule that might be capable of freely diffusing through both aqueous and lipid compartments of the cell. Kaplan and Greenberg (1985) showed that equilibration of radioactive autoinducer between cells and media was indeed extremely rapid. Dilution of the autoinducer in the medium to concentrations below $10 \mathrm{nM}$ resulted in disappearance of autoinducer from cells and cessation of induction. This result can be explained by a simple model where the rate of diffusion of autoinducer (when autoinducer in medium < $10 \mathrm{nM}$ ) is greater than the rate of binding of to the putative autoinducer receptor. However, the data do not exclude the possibility that autoinducer might be actively transported across the membrane.

The synthetic precursors to the autoinducer are unknown. Engebrecht et al (1983) cloned a $V$. fischeri locus into $E$. coli which directed $E$. coli to synthesize both luciferase and an autoinducer activity. E. coli without luxI did not produce the autoinducer. Genetic complementation tests, protein synthesis analysis, and sequencing showed that a single $578 \mathrm{bp}$ gene encoded a $22 \mathrm{kD}$ polypeptide that was necessary and sufficient for $E$. coli to synthesize the autoinducer and release it into the medium (Engebrecht and Silverman 1984, 1987). Mutation of the gene, luxI, reduced the synthesis of luciferase; luciferase synthesis was restored by the addition of exogenous autoinducer. LuxI bore no sequence similarity to other known proteins. No attempt was made to show that luxI was necessary for autoinducer synthesis in $V$. fischeri. Significantly, luxI is part of the luxICDABEG operon, implying that the autoinducer is a positive autoregulator. Subsequently, autoregulation was demonstrated directly (Eberhard et al 1991).

That a single gene confers on $E$. coli the ability to produce the autoinducer implies that $E$. coli has most of the metabolic machinery needed for synthesis and that luxI encodes an enzyme that catalyzes a single final step in the synthetic pathway, presumably formation of the amide bond. Indeed, E. coli mutants deficient in the synthesis of the putative homoserine lactone precursor homoserine do not produce an autoinducer activity in the presence of luxI (Roberto Kolter, personal communication). So far, LuxI has not been purified, nor has it been demonstrated to have a synthase activity. Eberhard et al (1991) failed to synthesize the autoinducer by mixing a crude $V$. fischeri lysate with an activated 3-oxohexanoyl-group and homoserine lactone, but succeeded when homoserine lactone was replaced by $S$-adenosylmethionine. This intriguing result raises the possibility that lactonization occurs either concurrently with or after formation of the amide bond, perhaps catalyzed by a lactonizing activity common to both $E$. coli and $V$. fischeri. However, Kolter reports that an E. coli metA mutant, which synthesizes 
homoserine but not $S$-adenosylmethionine, is capable of supporting autoinducer production (personal communication). This result is reconcilable with the Eberhard et al (1986) report if 1) exogenous homoserine lactone added to $V$. fischeri extracts is extremely labile and 2) V. fischeri, like Aerobacter aerogenes (Shapiro and Mather 1958), converts $S$-adenosylmethionine to homoserine lactone.

Nothing is known about the metabolic fate of the autoinducer, whether it is modified or degraded, nor whether such events are relevant to the kinetics of autoinduction.

\section{The signal response}

A simple autoinducer response mechanism could consist of 1) a receptor for the autoinducer and 2) a transcriptional activator that binds at or near the luxICDABEG promoter and interacts with RNA polymerase. Engebrecht and Silverman $(1984,1987)$ cloned and sequenced a single $750 \mathrm{bp}$ gene encoding a $29 \mathrm{kD}$ polypeptide that appeared to perform both tasks. Mutation of the gene, luxR, reduced the synthesis of luciferase; the phenotype was not rescued by the addition of exogenous autoinducer (Engebrecht et al 1983).

If LuxR is the signal receptor, it should bind to autoinducer. So far, active LuxR has not been purified. Random mutagenesis of $l u x R$ defined two functional domains, a "DNA-binding domain" and a "sensing domain" which included mutations that were suppressed by elevated levels of exogenous autoinducer (Slock et al 1990, Shadel et al 1990). Choi and Greenberg (1991) rendered LuxR function independent of autoinducer by deleting its amino-terminus, including the sensing domain, but leaving the DNAbinding domain intact; they argued that the amino-terminus masks the DNA-binding function of LuxR, and that autoinducer interaction with the sensing domain removes the mask.

The ligand requirements of LuxR are poorly defined. $V$. fischeri responded to a limited number of synthetic $N$-acyl-L-HSLs other than 3-oxohexanoyl-HSL (Eberhard et al 1986). These inducers varied principally in the structure of the fatty acyl moiety, while most changes in the lactone ring abolished activity. The results implied that the recognition constraints on fatty acyl structure are substantially less than those on the amino acyl moiety. Whether there are separate binding sites for the two moieties is unknown. The observation that LuxR is membrane-associated despite its lack of membrane-spanning domains (Kolibachuk and Greenberg 1993) raises the possibility that 
the amino acyl moiety is recognized by LuxR while the fatty acyl moiety controls localization of the autoinducer to the cytoplasmic membrane and access to LuxR.

In addition, Eberhard et al (1986) observed nonlinear kinetics of the luminescence response, and thus proposed that LuxR binds to multiple autoinducer molecules (presumably in a cooperative fashion), and that there is cooperativity between LuxR molecules. This is consistent with genetic dominance experiments that imply the existence of a multimerization domain (Choi and Greenberg 1992b). It should be noted that Choi and Greenberg $(1991,1992 b)$ do not show that the putative multimerization is necessary for activation of luxICDABEG.

The domain studies place the DNA-binding domain toward the carboxyl-terminus of LuxR. The carboxyl terminus of LuxR is similar to the carboxyl termini of the response regulator members of the family of two-component signal transduction proteins (Henikoff et al 1990). Members of this family possess a characteristic carboxyl-terminal "helix-turn-helix" motif that has been implicated in DNA binding. The presumptive lux operator is a 20 bp palindrome that is 30 bp upstream from the luxICDABEG transcriptional start site, mutation of which eliminated transcriptional activation by autoinducer (Devine et al 1989). Specific binding of purified LuxR to the operator has not been demonstrated. Finally, the extreme carboxyl-terminus appears to activate RNA polymerase, presumably after LuxR is bound to DNA (Choi and Greenberg (1992a).

While activating transcription of luxICDABEG, LuxR also represses its own synthesis. luxR is divergently transcribed from luxICDABEG, and is $147 \mathrm{bp}$ from the lux operator (Engebrecht and Silverman 1983, 1987). Inbetween lies the putative Crpbinding site. Autorepression requires autoinducer (Engebrecht and Silverman 1986, Dunlap and Ray 1989), the DNA-binding domain and the extreme amino-terminus of LuxR (Choi and Greenberg 1991), the lux operator, and an undefined locus in the luxIC region (Shadel and Baldwin 1991). Whether autorepression is effected by steric hindrance of RNA polymerase or Crp binding by LuxR binding is unknown. LuxR may also stimulate its own synthesis at low autoinducer concentrations (Shadel and Baldwin 1991).

\section{The current model for autoinduction}

The above experiments, almost all with the cloned $l u x$ genes in E. coli, lead to a remarkably simple and elegant model for autoinduction (see Figure). At low cell density, luxR transcription is stimulated by cAMP-Crp, while luxICDABEG is transcribed at a low level, allowing the slow accumulation of LuxI and thus of autoinducer in both the cells 
and the medium. At a higher cell density, autoinducer reaches a threshold concentration that allows it to bind to the sensor domain of LuxR, which then binds with the lux operator via its DNA-binding domain. Binding to the operator allows LuxR to both stimulate transcription from the luxICDABEG promoter and to block Crp access to the luxR promoter. Stimulated transcription of $l u x I$ initiates a positive feedback loop of autoinducer synthesis that is limited only by repression of $l u x R$ transcription.

The adaptive significance of this system is unclear. Most authors have assumed that the purpose of autoinduction is to measure cell density. One difficulty with this assumption is that it is not clear that there is any benefit to the organism of linking luminescence to cell density, especially since the adaptive significance of luminescence itself is not established. A second difficulty is that the actual occurrences of both luminescence and cell density of $V$. fischeri outside of the artifactual confines of the laboratory are poorly documented. It is possible that the membrane-permeable property of the autoinducer is an incidental function of its dual amino acyl-fatty acyl structure, and that the primary purpose of this structure is to reflect the status of amino acid and fatty acid metabolic pools. Since the adaptive significance of autoinduction per se is not a central concern of this dissertation, I shall from now on simply assume that a system to monitor local cell density is useful to the bacterium.

\section{B. Autoinduction in other bacteria}

For years autoinduction was treated as the unique specialization of a small group of bacteria. Recently, however, autoinduction systems homologous to that of $V$. fischeri have been discovered in other species of bacteria. Naturally, the $V$. fischeri model described above has been the intellectual paradigm for dissecting these other systems. In contrast, the autoinduction systems of $V$. harveyi and $S$. griseus, of which significant understanding has come only relatively recently, are not homologous to their $V$. fischeri counterpart.

\section{Autoinduction systems which fit the $V$. fischeri paradigm}

Agrobacterium tumefaciens is a plant pathogen well known for its ability to induce tumors in its host by injecting a fragment of a tumor-inducing plasmid (pTi) into host cells. pTi can be transfered from one bacterium to another, but only in the presence of a diffusible signal called "conjugation factor" (CF; Zhang and Kerr 1991). Synthesis

of and response to $\mathrm{CF}$ require the pTi genes traI and traR, respectively, and traR activates 
transcription of the conjugal transfer gene traA (Piper et al 1993, Fuqua and Winans 1994). CF is $N$-3-oxooctanoyl-L-HSL (Zhang et al 1993), Tral has $31 \%$ identity with LuxI, and TraR has $20 \%$ identity with LuxR.

Pseudomonas aeruginosa is an opportunistic human pathogen that exports an elastase, an alkaline protease, and an exotoxin as virulence factors. Expression of these enzymes is cell density-dependent, and requires lasI and lasR (Frank and Iglewski 1988, Gambello and Iglewski 1991, Passador et al 1993). LasR has 27\% identity with LuxR while LasI has 35\% identity with LuxI. lasI directs the synthesis of $\mathrm{N}$-3-oxododecanoylL-HSL, which is required for LasR to activate transcription of the elastase gene las $B$ (Pearson et al 1994). A 20 bp palindrome similar to the lux operator is upstream from lasB (Gray et al 1994). Also, another luxR homologue, $r h l R$, regulates synthesis of elastase, a phenazine antibiotic, and rhamnolipid surfactants (Ochsner et al 1994).

Erwinia carotovora is a plant pathogen that exports a cellulase, a polygalacturonase, a protease, and lyases as virulence factors, as well as a carbapenem antibiotic. Synthesis of the carbapenem requires either a diffusible factor, which turns out to be 3-oxohexanoyl-HSL (Bainton et al 1992), or carI, which encodes a protein with $25 \%$ identity with LuxI (Swift et al 1993). Expression of the virulence factors is induced upon stationary phase, and requires expI, which encodes a protein with $30 \%$ identity with LuxI (Pirhonen et al 1993).

Published homologues of LuxR are: SdiA, which positively regulates cell division in $E$. coli (Wang et al 1991); RhiR, which is required for expression of the rhizospherespecific Rhizobium leguminosarum genes rhiABC (Cubo et al 1992); and PhzR, which is required for the cell density-responsive regulation of phenazine synthesis in Pseudomonas aureofaciens (Pierson et al 1994). Other components of these autoinducer systems, if that is indeed what they are, have not been identified. Also, autoinducer activities have been detected in a number of other bacteria, though in most cases the target of autoinducer regulation is not known. An example of the latter is the autoinducer activity of Enterobacter agglomerans, which has a gene eagI homologous to luxI (Swift et al 1993). Finally, a homoserine lactone-based signal has been proposed to mediate the starvation response in $E$. coli (Huisman and Kolter 1994).

The above list of autoinduction system components in diverse proteobacteria leads to the suspicion that autoinduction may be a ubiquitous and perhaps fundamental mode of regulation in the proteobacteria. If so, one can expect autoinduction to be the mechanism of regulation in numerous other cell density-dependent processes. Perhaps the ability to sense local cell density has been crucial to the manifest success of the proteobacterial group. But despite the variety of autoinducer-regulated functions 
identified so far, in no case is the adaptive value of connecting the autoinducer-regulated function with cell density unequivocally clear, though one might make the argument that extracellular virulence factors are effective only when employed in massive, instantaneous doses.

\section{Autoinduction systems which do not fit the paradigm}

The $V$. harveyi autoinducer is structurally similar to its $V$. fischeri counterpart. Cao and Meighen (1989) purified the $V$. harveyi autoinducer and found it to be physically and biologically indistinguishable from $N$-3-hydroxybutanoyl-L-HSL. Two autoinducerdeficient mutants responded much more to the D-3-hydroxy isomer than to the L-3hydroxy isomer (Cao and Meighen 1993). This result suggested that the fatty acyl moiety of the autoinducer is diverted from the synthetic rather than degradative pathways of fatty acid metabolism, since classical fatty acid synthesis involves D-isomer intermediates while degradation involves only L-isomers. Blockage of fatty acid synthesis also inhibited autoinducer production.

In contrast to the autoinducer, the genes involved in synthesis of and response to the $V$. harveyi autoinducer appear to be completely different from their $V$. fischeri counterparts, luxI and luxR. Bassler et al (1993) cloned a locus that complemented a spontaneous mutant deficient in luminescence. Mutagenesis of the locus followed by mapping and recombination into the chromosome revealed two distinct loci corresponding to two distinct phenotypes, neither of which, curiously, was deficient in luminescence. The LuxM- phenotype synthesized a reduced but still significant amount of autoinducer activity, and responded to both wild-type-conditioned media and to synthetic autoinducer. The LuxN- phenotype responded to conditioned media but not to synthetic autoinducer. The authors concluded that the $\mathrm{LuxM}^{-}$and $\mathrm{LuxN}^{-}$phenotypes reflected losses of an autoinducer synthase and receptor, respectively. The ability of all mutants to condition media at a reduced but significant level suggested the presence of a second autoinducer of luminescence distinct from 3-hydroxybutanoyl-HSL. The ability of all mutants to respond to this putative second autoinducer implied a separate and specific receptor for the second autoinducer. Subsequently, mutants deficient in response to this as yet unidentified second autoinducer were isolated and called LuxQ- (Bassler et al 1994b).

Sequencing of the luxMN locus revealed three open reading frames. The LuxNmutations fell within the $\operatorname{luxN}$ gene, which encodes a protein related to members of the two-component family of sensors and response regulators. LuxN has the "histidine 
kinase" motif characteristic of the sensors, as well as the "Asp-57" phosphorylation site characteristic of the response regulators, but lacks the helix-turn-helix motif. The LuxMmutations fell within two contiguous open reading frames, $\operatorname{lu} x L$ and $M$, neither of which was similar to other known genes. Neither complementation tests nor protein synthesis analyses has been done with $\operatorname{lux} L M$. The LuxQ- mutations fell within the genes $\operatorname{lux} P$ and $Q ; \operatorname{lux} Q$ encodes a homologue of $\operatorname{luxN}$ and $\operatorname{lu} x P$ encodes a homologue of $E$. coli and Salmonella ribose-binding proteins. Each of these genes possesses its own candidate promoter and ribosome-binding sites. None of these genes is a luxI or luxR homologue. Hybridization, random mutagenesis, and sequencing near the $l u x C D A B E$ genes have failed to identify $l u x I$ or $l u x R$ homologues, though complementation of $V$. fischeri lux mutations has not yet been attempted.

A second luminescence-complementing locus was cloned, mutagenized, and sequenced. luxO encodes a protein related to the two-component response regulators, this time with both the Asp-57 and helix-turn-helix motifs (Bassler et al 1994a). Surprisingly, luxO mutants were fully and constitutively luminescent. This independence from autoinduction led to the conclusion that LuxO is a repressor of luminescence that is inactivated by autoinducer. However, the ability of luxO to complement luminescencedeficient mutants is difficult to reconcile with a repressor model.

Finally, the $S$. griseus autoinduction system, also found in variant form in some other Streptomyces sp., differs even more radically from that of $V$. fischeri (Horinouchi and Beppu 1994). S. griseum colonies produce an autoinducer that controls the timing of both sporulation and antibiotic production. This autoinducer or "A-factor" is 2-(6'methylheptanoyl)-3R-hydroxymethyl-4-butanolide which, like the autoinducers described above is a $\gamma$-butyrolactone, but is not a $N$-acyl-homoserine lactone. Structurally similar autoinducers are produced by other Streptomyces sp. A-factor synthesis requires afsA, the product of which is not homologous to any known protein, including LuxI (Hara et al 1983, Horinouchi et al 1989). A-factor binds specifically to a protein in the absence of which sporulation and antibiotic production commence aberrantly early (Miyake et al 1989, Miyake et al 1990). Thus the A-factor receptor is a negative regulator rather than a positive regulator like LuxR. The primary structure of the autoinducer receptor of the closely related Streptomyces virginiae system has been reported to resemble not LuxR but the E. coli antiterminator NusG, but this report has since been retracted by its authors (Okamoto et al 1992, Horinouchi and Beppu 1994).

Despite the structural similarities between the autoinducers, the two Vibrio autoinduction systems clearly and dramatically differ from each other and from the Streptomyces systems. The dissimilarities render the conservatism of the autoinducers 
themselves even more striking. This might be a case of convergent evolution. If so, the common $\gamma$-butyrolactone motif must be of specific utility to the bacteria. The physicalchemical properties of the structure may make it an ideal extracellular messenger (one that diffuses through both hydrophilic and hydrophobic compartments), or the structure may result from a need for autoinduction to reflect the state of fatty acid metabolism in the cell.

\section{Why study autoinduction?}

Autoinduction is interesting and important because 1) it is an apparently common regulator of significant cellular functions, possibly including many functions of which we are presently not aware. 2) it might inform us of the importance of intercellular communication as an environmental signal relevant to those cellular functions. 3 ) it is an interesting signal transduction system in its own right, involving a number of novel mechanistic elements. The study of autoinduction, until recently the exclusive province of students of vibrios and streptomycetes, is now of broader and more general interest than ever before. Since the $V$. fischeri system is through historical accident the bestknown and effectively paradigmatic example of autoinduction, it is both imperative and convenient to explore the $V$. fischeri system even more thoroughly than has been done. To this end P. Dunlap brought basic genetic techniques to bear on the $V$. fischeri system, both confirming the classical model of autoinduction as developed with $V$. fischeri genes cloned into $E$. coli, as well as revealing novel elements in cell density-dependent regulation (Dunlap and Kuo 1992). In the course of these studies, Dunlap encountered phenomena that could be interpreted as evidence for a second autoinducer of luminescence in $V$. fischeri (personal communication). Since a second autoinducer has potentially significant ramifications with respect to the classical model of autoinduction, I have continued that line of research in my dissertation. 


\section{REFERENCES}

Andrews, CC, DM Karl, LF Small and SW Fowler. 1984. Metabolic activity and bioluminescence of oceanic faecal pellets and sediment trap particles. Nature 307:539541.

Andrews, SC, D Shipley, JN Keen, JBC Findlay, PM Harrison and JR Guest. 1992. The haemoglobin-like protein (HMP) of Escherichia coli has ferrisiderophore reductase activity and its $\mathrm{C}$-terminal domain shares homology with ferredoxin NADP+ reductases. FEBS 302:247-252.

Bainton, NJ, P Stead, SR Chhabra, BW Bycroft, GPC Salmond, GSAB Stewart and P Williams. 1992. $N$-(3-oxohexanoyl)-L-homoserine lactone regulates carbapenem antibiotic production in Erwinia carotovora. Biochem. J. 288:997-1004.

Bassler, BL, M Wright, RE Showalter and MR Silverman. 1993. Intercellular signalling in Vibrio harveyi: sequence and function of genes regulating expression of luminescence. Mol. Microbiol. 9:773-786.

Bassler, BL, M Wright and MR Silverman. 1994a. Sequence and function of LuxO, a negative regulator of luminescence in Vibrio harveyi. Mol. Microbiol. 12:403412.

Bassler, BL, M Wright and MR Silverman. 1994b. Multiple signalling systems controlling expression of luminescence in Vibrio harveyi: sequence and function of genes encoding a second sensory pathway. Mol. Microbiol. 13:273-286.

Boylan, M, AF Graham, and EA Meighen. 1985. Functional identification of the fatty acid reductase components encoded in the luminescence operon of Vibrio fischeri. J. Bacteriol. 163(3):1186-1190.

Cao, J-G, and EA Meighen. 1989. Purification and structural identification of an autoinducer for the luminescence system of Vibrio harveyi. J. Biol. Chem. 264:2167021676.

Cao, J-G, and EA Meighen. 1993. Biosynthesis and stereochemistry of the autoinducer controlling luminescence in Vibrio harveyi. J. Bacteriol. 175:3856-3862.

Choi, SH, and EP Greenberg. 1991. The C-terminal region of the Vibrio fischeri LuxR protein contains an inducer-independent lux gene activating domain. Proc. Natl. Acad. Sci. USA 88:11115-11119.

Choi, SH, and EP Greenberg. 1992a. Genetic dissection of DNA binding and luminescence gene activation by the Vibrio fischeri LuxR protein. J. Bacteriol. 174:4064-4069.

Choi, SH, and EP Greenberg. 1992b. Genetic evidence for multimerization of LuxR, the transcriptional activator of Vibrio fischeri luminescence. Mol. Mar. Biol. Biotechnol. 1:408-413.

Colepicolo, P, VCCP Camarero, J Eckstein and JW Hastings. 1992. Induction of bacterial luciferase by pure oxygen. J. Gen. Microbiol. 138:831-836.

Cormier, MJ, and BL Strehler. 1953. The identification of KCF: requirement of long-chain aldehydes for bacterial extract luminescence. J. Am. Chem. Soc. 75:48644865.

Cubo, MT, A Economou, G Murphy, AWB Johnston and JA Downie. 1992. Molecular characterization and regulation of the rhizosphere-expressed genes rhiABCR that can influence nodulation by Rhizobium leguminosarum biovar viciae. J. Bacteriol. 174:4026-4035.

Devine, JH, GS Shadel and TO Baldwin. 1989. Identification of the operator of the lux regulon from the Vibrio fischeri strain ATCC7744. Proc. Natl. Acad. Sci. USA $86: 5688-5692$.

Dieterich, A, and K Nealson. 1972. A study of the survival of dark mutants of marine luminous bacteria under anaerobic conditions. Biol. Bull. 143(2):458. 
Dunlap, PV, and EP Greenberg. 1985. Control of Vibrio fischeri luminescence gene expression in Escherichia coli by cyclic AMP and cyclic AMP receptor protein. J. Bacteriol. 164(1):45-50.

Dunlap, PV. 1989. Regulation of luminescence by cyclic AMP in cya-like and crp-like mutants of Vibrio fischeri. J. Bacteriol. 171:1199-1202.

Dunlap, PV, and JM Ray. 1989. Requirement for autoinducer in transcriptional negative autoregulation of the Vibrio fischeri luxR gene in Escherichia coli. J. Bacteriol. 171:3549-3552.

Dunlap, PV. 1992. Mechanism for iron control of the Vibrio fischeri luminescence system: involvement of cyclic AMP and cyclic AMP receptor protein and modulation of DNA level. J. Biolum.Chemilum. 7:203-214.

Dunlap, PV, and A Kuo. 1992. Cell density-dependent modulation of the Vibrio fischeri luminescence system in the absence of autoinducer and LuxR protein. J. Bacteriol. 174:2440-2448.

Dunn, DK, GA Michaliszyn, IG Bogacki and EA Meighen. 1973. Conversion of aldehyde to acid in the bacterial bioluminescent reaction. Biochem. 12:4911-4918.

Dunny, GM, BL Brown and DB Clewell. 1978. Induced cell aggregation an mating in Streptococcus faecalis: evidence for a bacterial sex pheromone. Proc. Natl. Acad. Sci. USA 75:3479-3483.

Eberhard, A. 1972. Inhibition and activation of bacterial luciferase. J. Bacteriol. 109:1101-1105.

Eberhard, A, and JW Hastings. 1972. A postulated mechanism for the bioluminescent oxidation of reduced flavin mononucleotide. Biochem. Biophys. Res. Comm. 47(2):348-353.

Eberhard, A, AL Burlingame, C Eberhard, GL Kenyon, KH Nealson and NJ Oppenheimer. 1981. Structural identification of autoinducer of Photobacterium fischeri luciferase. Biochem. 20:2444-2449.

Eberhard, A, CA Widrig, P McBath and JB Schineller. 1986. Analogs of the autoinducer of bioluminescence in Vibrio fischeri. Arch. Microbiol. 146:35-40.

Eberhard, A, T Longin, CA Widrig and SJ Stranick. 1991. Synthesis of the lux gene autoinducer in Vibrio fischeri is positively autoregulated. Arch. Microbiol. 155:294-297.

Engebrecht, J, K Nealson and M Silverman. 1983. Bacterial bioluminescence: isolation and genetic analysis of functions from Vibrio fischeri. Cell 32:773-781.

Engebrecht, J, and M Silverman. 1984. Identification of genes and gene products necessary for bacterial bioluminescence. Proc. Natl. Acad. Sci. USA 81:4154-4158.

Engebrecht, J, and M Silverman. 1986. Regulation of expression of bacterial genes for bioluminescence. JK Setlow and A Hollaender (ed.), Genetic engineering. Vol. 8. Plenum, New York.

Engebrecht, J, and M Silverman. 1987. Nucleotide sequence of the regulatory locus controlling expression of bacterial genes for bioluminescence. Nucleic Acids Res. 15:10455-10467.

Farr, SB, R D'Ari and D Touati. 1986. Oxygen-dependent mutagenesis in Escherichia coli lacking superoxide dismutase. Proc. Natl. Acad. Sci. USA 83:82688272.

Finn, GJ, and S Condon. 1975. Regulation of catalase synthesis in Salmonella typhimurium. J. Bacteriol. 123(2):570-579.

Frank, D, and BH Iglewski. 1988. Kinetics of toxA and regA mRNA accumulation in Pseudomonas aeruginosa. J. Bacteriol. 170:4477-4483.

Fridovich, I. 1978. The biology of oxygen radicals. Science 201:875-880.

Friedrich, WF, and EP Greenberg. 1983. Glucose repression of luminescence and luciferase in Vibrio fischeri. Arch. Microbiol. 134:87-91. 
Fuqua, WC, and SC Winans. 1994. A LuxR-LuxI type regulatory system activates Agrobacterium Ti plasmid conjugal transfer in the presence of a plant tumor metabolite. J. Bacteriol. 176:2796-2806.

Gambello, MJ, and BH Iglewski. 1991. Cloning and characterization of the Pseudomonas aeruginosa lasR gene, a transcriptional activator of elastase expression. J. Bacteriol. 173:3000-3009.

Gray, KM, L Passador, BH Iglewski and EP Greenberg. 1994. Interchangeability and specificity of components from the quorum-sensing regulatory systems of Vibrio fischeri and Pseudomonas aeruginosa. J. Bacteriol. 176:3076-3080.

Gregory, E. M., and I. Fridovich. 1973. Induction of superoxide dismutase by molecular oxygen. J. Bacteriol. 114(2):543-548.

Grogan, DW. 1984. Interaction of respiration and luminescence in a common marine bacterium. Arch. Microbiol. 137:159-162.

Grossman, AD, and R Losick. 1988. Extracellular control of spore formation in Bacillus subtilis. Proc. Natl. Acad. Sci. USA 85:4369-4373.

Hara, O, S Horinouchi, T Uozumi and T Beppu. 1983. Genetic analysis of Afactor synthesis in Streptomyces coelicolor A3(2) and Streptomyces griseus. J. Gen. Microbiol. 129:2939-2944.

Hastings, JW. 1952. Oxygen concentration and bioluminescence intensity. J. Cell. Comp. Physiol. 39(1):1-30.

Hastings, JW, WH Riley and J Massa. 1965. The purification, properties, and chemiluminescent quantum yield of bacterial luciferase. J. Biol. Chem. 240(3):14731481.

Hastings, JW, S-C Tu, JE Becvar and RP Presswood. 1979. Bioluminescence from the reaction of $\mathrm{FMN}, \mathrm{H}_{2} \mathrm{O}_{2}$ and long chain aldehyde with bacterial luciferase. Photochem. Photobiol. 29:383-387.

Henikoff, S, JC Wallace and JP Brown. 1990. Finding protein similarities with nucleotide sequence databases. Meth. Enzymol. 183:111-132.

Horinouchi, S, H Suzuki, M Nishiyama and T Beppu. Nucleotide sequence and transcriptional analysis of the Streptomyces griseus gene (afsA) responsible for A-factor biosynthesis. J. Bacteriol. 171:1206-1210.

Horinouchi, S, and T Beppu. 1994. A-factor as a microbial hormone that controls cellular differentiation and secondary metabolism in Streptomyces griseus. Mol. Microbiol. 12:859-864.

Huisman, GW, and R Kolter. 1994. Sensing starvation: a homoserine lactonedependent signaling pathway in Escherichia coli. Science 265:537-539.

Imlay, JA, and S Linn. 1988. DNA damage and oxygen radical toxicity. Science 240:1302-1309.

Kaplan, HB, and EP Greenberg. 1985. Diffusion of autoinducer is involved in regulation of the Vibrio fischeri luminescence system. J. Bacteriol. 163:1210-1214.

Kanfer, S, and NJ Turro. 1981. Reactive forms of oxygen, p. 47-64. DL Gilbert (ed.), Oxygen and living processes. Springer-Verlag, New York.

Kasai, S, S Fujii, R Miura, S Odani, T Nakaya and K Matsui. 1990. Structure of $\mathrm{FP}_{390}$ including its prosthetic group (Q-flavin): physiological significance of light emitting reaction in luminous bacteria. Flavins and flavoproteins 1990.

Kempner, ES, and FE Hanson. 1968. Aspects of light production by Photobacterium fischeri. J. Bacteriol. 95:975-979.

Kim, SK, and D Kaiser. 1990. C-factor: a cell-cell signalling protein required for fruiting body morphogenesis of M. xanthus. Cell 61:19-26.

Kolibachuk, D, and EP Greenberg. 1993. The Vibrio fischeri luminescence gene activator LuxR is a membrane-associated protein. J. Bacteriol. 175:7307-7312. 
Kurfurst, M, S Ghisla and JW Hastings. 1983. Bioluminescence emission from the reaction of luciferase-flavin mononucleotide radical with $\mathrm{O}_{2}^{-}$. Biochem. 22:15211525 .

Lloyd, D, CJ James and JW Hastings. 1985. Oxygen affinities of the bioluminescence systems of various species of luminous bacteria. J. Gen. Microbiol. 131:2137-2140.

Loewen, PC. 1984. Isolation of catalase-deficient Escherichia coli mutants and genetic mapping of katE, a locus that affects catalase activity. J. Bacteriol. 157(2):622626.

Makemson, JC, and JW Hastings. 1982. Iron represses bioluminescence and affects catabolite repression of luminescence in Vibrio harveyi. Curr. Microbiol. 7:181186.

Makemson, JC, and JW Hastings. 1986. Luciferase-dependent growth of cytochrome-deficient Vibrio harveyi. FEMS Microbiol. Ecol. 38:79-85.

McElroy, WD, JW Hastings, V Sonnenfield and J Coulombre. 1953. The requirement of riboflavin phosphate for bacterial luminescence. Science 118:385-386.

McElroy, WD, and HH Seliger. 1962. Origin and evolution of bioluminescence, p. 91-101. M Kasha and B Pullman (ed.), Horizons in biochemistry. Academic Press, Inc, New York.

Miyake, K, S Horinouchi, M Yoshida, N Chiba, K Mori, N Nogawa, N Morikawa and T Beppu. 1989. Detection and properties of A-factor-binding protein from Streptomyces griseus. J. Bacteriol. 171:4298-4302.

Miyake, K, T Kuzuyama, S Horinouchi and T Beppu. 1990. The A-factorbinding protein of Streptomyces griseus negatively controls streptomycin production and sporulation. J. Bacteriol. 172:3003-3008.

Nealson, KH, T Platt and JW Hastings. 1970. Cellular control of the synthesis and activity of the bacterial luminescence system. J. Bacteriol. 104:313-322.

Nealson, KH, and JW Hastings. 1977. Low oxygen is optimal for luciferase synthesis in some bacteria. Arch. Microbiol. 112:9-16.

Nealson, KH, and JW Hastings. 1979. Bacterial bioluminescence: its control and ecological significance. Microbiol. Rev. 43:496-518.

Nealson, KH, and JW Hastings. 1991. The luminous bacteria. A Balows, HG Truper, M Dworkin, W Harder and K-H Schleifer (ed.), The prokaryotes, 2nd ed. Springer-Verlag, New York.

Ochsner, UA, AK Koch, A Fiechter and J Reiser. 1994. Isolation and characterization of a regulatory gene affecting rhamnolipid biosurfactant synthesis in Pseudomonas aeruginosa. J. Bacteriol. 176:2044-2054.

Okamoto, S, T Nihira, H Kataoka, A Suzuki and Y Yamada. 1992. Purification and molecular cloning of a butyrolactone autoregulator receptor from Streptomyces virginiae. J. Biol. Chem. 267:1093-1098.

Passador, L, JM Cook, MJ Gambello, L Rust and BH Iglewski. 1993. Expression of Pseudomonas aeruginosa virulence genes requires cell-to-cell communication. Science 260:1127-1130.

Pearson, JP, KM Gray, L Passador, KD Tucker, A Eberhard, BH Iglewski and EP Greenberg. 1994. Structure of the autoinducer required for expression of Pseudomonas aeruginosa virulence genes. Proc. Natl. Acad. Sci. USA 91:197-201.

Pierson, LS, 3rd, VD Keppenne and DW Wood. 1994. Phenazine antibiotic biosynthesis in Pseudomonas aureofaciens 30-84 is regulated in response to cell density. J. Bacteriol. 176:3966-3974.

Piper, KR, SB von Bodman and SK Farrand. 1993. Conjugation factor of Agrobacterium tumefaciens regulates Ti plasmid transfer by autoinduction. Nature 362:448-450. 
Pirhonen, M, D Flego, R Heikinheimo and ET Palva. A small diffusible signal molecule is responsible for the global control of virulence and exoenzyme production in the plant pathogen Erwinia carotovora. EMBO J. 12:2467-2476.

Riendeau, D, and E Meighen. 1970. Evidence for a fatty acid reductase catalyzing the synthesis of aldehydes for the bacterial bioluminescent reaction. J. Biol. Chem. 254:7488-7490.

Ruby, EG, and KH Nealson. 1976. Symbiotic association of Photobacterium fischeri with the marine luminous fish Monocentris japonica: a model of symbiosis based on bacterial studies. Biol. Bull. 151:574-586.

Ruby, EG, and JG Morin. 1979. Luminous enteric bacteria of marine fishes: a study of their distribution, densities, and dispersion. Appl. Environ. Microbiol. 38:406411. 21:355-361.

Seliger, HH. 1975. The origin of bioluminescence. Photochem. Photobiol.

Seliger, HH. 1987. The evolution of bioluminescence in bacteria. Photochem. Photobiol. 45:291-297.

Shadel, GS, R Young and TO Baldwin. 1990. Use of regulated cell lysis in a lethal genetic selection in Escherichia coli: identification of the autoinducer-binding region of the LuxR protein from Vibrio fischeri ATCC 7744. J. Bacteriol. 172:39803987.

Shadel, GS, and TO Baldwin. 1991. The Vibrio fischeri LuxR protein is capable of bidirectional stimulation of transcription and both positive and negative regulation of the luxR gene. J. Bacteriol. 173:568-574.

Shapiro, SK, and AN Mather. 1958. The enzymatic decomposition of Sadenosyl-L-methionine. J. Biol. Chem. 233:631-633.

Slock, J, D VanRiet, D Kolibachuk and EP Greenberg. 1990. Critical regions of the Vibrio fischeri LuxR protein defined by mutational analysis. J. Bacteriol. 172:3974 3979.

Suzuki, K, T Kaidoh, M Katagiri and T Tsuchiya. 1983. $\mathrm{O}_{2}$ incorporation into a long-chain fatty acid during bacterial luminescence. Biochim. Biophys. Acta 722:297301.

Swartzman, E, S Kapoor, AF Graham and EA Meighen. 1990. A new Vibrio fischeri lux gene precedes a bidirectional termination site for the lux operon. J. Bacteriol. 172:6797-6802.

Swift, S, MK Winson, PF Chan, NJ Bainton, M Birdsall, PJ Reeves, CED Rees, SR Chhabra, PJ Hill, JP Throup, BW Bycroft, GPC Salmond, P Williams and GSAB Stewart. A novel strategy for the isolation of luxI homologues: evidence for the widespread distribution of a LuxR:LuxI superfamily in enteric bacteria. Mol. Microbiol. 10:511-520.

Ulitzur, S, A Reinhertz and JW Hastings. 1981. Factors affecting the cellular expression of bacterial luciferase. Arch. Microbiol. 129:67-71.

Vervoort, J, F Muller, J Lee, WAM van den Berg and CTW Moonen. 1986. Identification of the true carbon-13 nuclear magnetic resonance spectrum of the stable intermediate II in bacterial luciferase. Biochem. 25(24):8062-8067.

Wang, X, PAJ de Boer and LI Rothfield. 1991. A factor that positively regulates cell division by activating transcription of the major cluster of essential cell division genes of Escherichia coli. EMBO J. 10:3363-3372.

Watanabe, T, and T Nakamura. 1976. Studies on luciferase from Photobacterium phosphoreum. VIII. FMN- $\mathrm{H}_{2} \mathrm{O}_{2}$ initiated bioluminescence and the thermodynamics of the elementary steps of the luciferase reaction. J. Biochem. 79:489495. 
Zenno, S, K Saigo, H Kanoh and S Inouye. 1994. Identification of the gene encoding the major NAD(P)H-flavin oxidoreductase of the bioluminescent bacterium Vibrio fischeri ATCC 7744. J. Bacteriol. 176:3536-3543.

Zenno, S, and K Saigo. 1994. Identification of the genes encoding NAD(P)Hflavin oxidoreductases that are similar in sequence to Escherichia coli Fre in four species of luminous bacteria: Photorhabdus luminescens, Vibrio fischeri, V. harveyi, and $V$. orientalis. J. Bacteriol. 176:3544-3551.

Zhang, L, and A Kerr. 1991. A diffusible compound can enhance conjugal transfer of the Ti plasmid in Agrobacterium tumefaciens. J. Bacteriol. 173:1867-1872. Zhang, L, PJ Murphy, A Kerr and ME Tate. 1993. Agrobacterium conjugation and gene regulation by $N$-acyl-L-homoserine lactones. Nature 362:446-448. 


\title{
Chapter 2. Construction and characterization of defined lux mutants of Vibrio fischeri
}

\begin{abstract}
Luminescence in Vibrio fischeri requires $\mathrm{O}_{2}$, luciferase (encoded by $\operatorname{lux} A B$ ), reduced flavin mononucleotide, and the aldehyde product of a reaction catalyzed by a fatty acid reductase complex (encoded by $\operatorname{lux} C D E$ ). Expression of the operon luxICDABEG is dependent on luxR and luxI; luxI is required for the synthesis of an autoinducer molecule ( $N$-3-oxohexanoyl-L-homoserine lactone) while $\operatorname{luxR}$ is required for

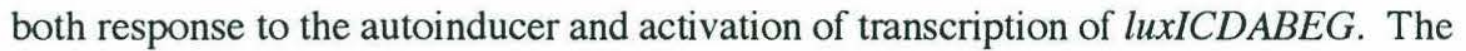
hypothesis that luminescence plays a role in protecting the cell from oxidative stress was examined by generating defined lux mutations in $V$. fischeri. The mutants were constructed using plasmid conjugation and gene replacement techniques, and then were tested for resistance to treatment with the toxic oxygen species $\mathrm{H}_{2} \mathrm{O}_{2}$. Both large lux deletion mutants ( $\triangle l u x R I C D$ and $\triangle l u x D A B E G)$ and mutants with small nonpolar mutations in individual lux genes were constructed. These included mutants deficient in luciferase, fatty acid reductase complex, luxI, and $l u x R$. The mutants did not differ from the $l u x^{+}$parent strain in resistance to $\mathrm{H}_{2} \mathrm{O}_{2}$ toxicity, indicating that luminescence is not involved in resistance to $\mathrm{H}_{2} \mathrm{O}_{2}$. The mutants also did not differ from the wild-type in any obvious phenotype, including growth rate, except in the predicted luminescence-related functions, and in the accumulation of a yellow pigment typical of $V$. fischeri. The distribution of pigment phenotypes among the mutants suggested that luxG is linked to the yellow pigment.
\end{abstract}




\section{INTRODUCTION}

Luminescence in the marine enteric symbiont Vibrio fischeri and other bacteria requires two enzymatic activities, those of a luciferase and a multienzyme fatty acid reductase complex. Luciferase catalyzes the light-emitting reaction, which involves the cleavage of molecular oxygen and the oxidation of reduced flavin mononucleotide (FMN) and a fatty aldehyde to the corresponding FMN and fatty acid (McElroy et el 1953, Cormier and Strehler 1953, Dunn et al 1973). The fatty acid reductase complex generates the aldehyde (Riendeau and Meighen 1979). The two subunits of luciferase are encoded by the genes $\operatorname{lux} A$ and $B$, while the subunits of the fatty acid reductase complex are encoded by the genes $\operatorname{lux} C, D$, and $E$ (Engebrecht and Silverman 1984). In $V$. fischeri, synthesis of these enzymes is activated by a putative transcriptional regulatory protein LuxR upon binding with a small membrane-permeable molecule, $\mathrm{N}$-3oxohexanoyl-L-homoserine lactone (autoinducer), synthesis of which requires the luxI gene (Eberhard et al 1981, Engebrecht et al 1983, Engebrecht and Silverman 1984). The lux genes are organized into a single chromosomal locus which is sufficient to support luminescence when cloned into Escherichia coli; in this locus luxR is divergently transcribed from the operon $\operatorname{lu} I C D A B E G$, and between the two transcriptional units lies the lux operator (Engebrecht et al 1983, Devine et al 1989, Swartzman et al 1990). The function of $\operatorname{lux} G$ is unknown, but the gene product has sequence similarity to the $E$. coli flavin reductase Fre/FsrC (Andrews et al 1992).

Bacterial luminescence involves the consumption of reducing equivalents and ATP (to reduce FMN and synthesize aldehyde) and of $\mathrm{O}_{2}$ (to reoxidize the reduced substrates), as well as the synthesis of at least seven gene products. The adaptive significance of these activities to $V$. fischeri and other luminescent bacteria is not understood. One hypothesis is that luciferase helps defend the cell against oxidative stress (McElroy and Seliger 1962, Colepicolo et al 1992). Aerobic metabolism generates, through successive single-electron reductions of $\mathrm{O}_{2}$, superoxide anion $\left(\mathrm{O}_{2}^{-} \cdot\right)$, hydrogen peroxide $\left(\mathrm{H}_{2} \mathrm{O}_{2}\right)$, and hydroxyl radical (HO) $)$, each a highly reactive molecule that can oxidize or reduce lipids, proteins, and DNA, thus causing mutation and cell death (Fridovich 1978, Kanfer 1981, Imlay and Linn 1988). Oxidative stresses are exacerbated by increased partial pressures of $\mathrm{O}_{2}$, exposure to radical-generating agents, and direct treatment with $\mathrm{H}_{2} \mathrm{O}_{2}$. Luciferase, which is capable of catalyzing the light-emitting reaction by cleaving $\mathrm{O}_{2}, \mathrm{H}_{2} \mathrm{O}_{2}$, or $\mathrm{O}_{2}^{-} \cdot$. (Watanabe and Nakamura 1976, Hastings et al 1979 , Kurfurst et al 1983), is hypothesized to protect the cell against oxidative stress by eliminating excess $\mathrm{O}_{2}$ or one of the other toxic oxygen species. 
Alternative hypotheses for the biological role of the luminescence system include the notion that luciferase is an alternate electron acceptor to cytochrome oxidase under conditions where the latter does not function (Seliger 1975, Nealson and Hastings 1979, Ulitzur et al 1981, Makemson and Hastings 1986, Guerrero and Makemson 1989), that luciferase is a sink for excess reducing equivalents that presumably arise when cells move from a nutritionally replete environment to growth-restricted conditions (from gut tract to sea water or light organ; Keynan et al 1963, Dunlap 1984), that the fatty acid product of the reaction has some metabolic significance independent of luminescence (Seliger 1987, Kasai et al 1990), and that luminescence attracts potential host animals to the free-living bacterium (Ruby and Morin 1979, Andrews et al 1984). None of these hypotheses has been directly tested through the analysis of luminescence mutants. Luminescence variants have been isolated from a number of species of bacteria (Rogers and McElroy 1955, Keynan and Hastings 1961, Nealson and Markovitz 1970, Cline and Hastings 1971). In one instance the variants were physiologically compared to the wild-type and reported to be less tolerant of excess reducing equivalents than the wild-type (Keynan et al 1963). The genotypes of the above variants have not been defined.

To address these hypotheses I have generated the first defined lux deletion mutants of $V$. fischeri, using a gene transfer system described previously (Dunlap and Kuo 1992). In this study the lux mutants were tested for resistance to $\mathrm{H}_{2} \mathrm{O}_{2}$ toxicity. My results suggest that the lux genes, luciferase, and luminescence are not involved in resistance to $\mathrm{H}_{2} \mathrm{O}_{2}$. I also show that the yellow pigment typical of $V$. fischeri (Baumann et al 1984) is dependent on a gene downstream of luxICDABE, presumably luxG. 


\section{MATERIALS AND METHODS}

Strains, plasmids, and culture methods. $V$. fischer $i$ and $E$. coli strains used in this study are described in Table 1 and Figure 1. MJ-100 is a spontaneously naladixic acid-resistant $\left(\mathrm{Nx}^{\mathrm{r}}\right)$ isolate of $V$. fischeri $\mathrm{MJ}-1$, which originated from the light organ of the fish Monocentris japonicus (Ruby and Nealson 1976). MJ-112 and MJ-141 are, respectively, luxR and luxICD mutants of MJ-100 (Dunlap and Kuo 1992). Of the E. coli strains, JM83 was used for most cloning procedures (Yanisch-Perron et al 1985), while S17-1 carries transfer functions $\left(\mathrm{tra}^{+}\right)$that allow conjugation of mobilizable $\left(\mathrm{mob}^{+}\right)$ plasmids from S17-1 into a variety of proteobacteria, including $V$. fischeri (Simon et al 1986, Dunlap and Kuo 1992). pJE202 is the entire MJ-1 lux region cloned into the Inc(pMB1) plasmid pBR322 (Engebrecht et al 1983). pNL121 is the same lux region cloned into the $\mathrm{mob}^{+}$, chloramphenicol resistant ( $\mathrm{Cm}$ r), Inc(p15A) plasmid pSUP102 (Simon et al 1986, Dunlap and Kuo 1992). pWH112 and pWH141 are derivatives of pNL121 with mutations in, respectively, luxR and luxICD (Dunlap and Kuo 1992). These and other plasmids are described in Table 1.

Except where otherwise indicated, MJ-100 and its derivatives were maintained on $1.5 \%$ agar plates of LBS medium ( $1 \%$ tryptone, $0.5 \%$ yeast extract, $2 \% \mathrm{NaCl}, 0.3 \%$ glycerol, $50 \mathrm{mM}$ Tris, pH 7.5; Dunlap 1989) with $20 \mathrm{mg} \mathrm{l}^{-1} \mathrm{Nx}$, and grown in liquid culture by shaking in $3 \mathrm{~mL} \mathrm{LBS}$ at $28^{\circ} \mathrm{C}$. Growth of liquid cultures was monitored by measuring optical density at $660 \mathrm{~nm}\left(A_{660}\right)$. For minimal medium experiments, cells were grown in an artificial seawater medium $\left(300 \mathrm{mM} \mathrm{NaCl}, 50 \mathrm{mM} \mathrm{MgSO}_{4}, 10 \mathrm{mM}\right.$ $\mathrm{KCl}, 10 \mathrm{mM} \mathrm{CaCl}_{2}, 1 \mathrm{~g} \mathrm{l}^{-1} \mathrm{NH}_{4} \mathrm{Cl}, 100 \mathrm{mg} \mathrm{l}^{-1} \alpha$-glycerophosphate, $20 \mathrm{mg} \mathrm{l}^{-1}$ ferric ammonium citrate, $25 \mathrm{mM}$ HEPES, pH 7.5; Friedrich and Greenberg 1983) with $10 \mathrm{mM}$ glucose but without $\mathrm{Nx}$ at $28^{\circ} \mathrm{C}$. E. coli strains were grown on LB, LBS, or SOB medium with appropriate antibiotics at $\mathrm{pH} 7.5$ and $28^{\circ} \mathrm{C}$ (conditions necessary for luminescence in E. coli). To select or screen for presence or absence of the appropriate genetic marker, antibiotics were added to medium to the following concentrations: $34 \mathrm{mg} \mathrm{l}^{-1} \mathrm{Cm}, 50 \mathrm{mg} \mathrm{l}^{-}$ 1 ampicillin (Ap), $20 \mathrm{mg} \mathrm{l}^{-1}$ kanamycin (Km), $200 \mathrm{mg} \mathrm{l}^{-1}$ neomycin (Nm), $12 \mathrm{mg} \mathrm{l}^{-1}$ tetracycline (Tc). When used, $2 \mathrm{mg} 5$-bromo-4-chloro-3-indolyl- $\beta$-D-galactoside was applied to the surface of a plate, while synthetic autoinducer was added to liquid medium to $5 \mathrm{mg} \mathrm{l}^{-1}$.

Construction of mutants: general procedures. All mutants were generated by enzymatically manipulating the cloned MJ-1 lux genes (cloned into pSUP102), transforming the plasmid bearing the resulting lux mutation into S17-1, transconjugating the plasmid into $\mathrm{MJ}-100$, and screening for nonluminescent (Lux-) recombinants. 
Table 1. Strains and plasmids used in this study. Constructions are detailed in the Materials and Methods.

Strain or plasmid Relevant genotypic and phenotypic characters

Source

E. coli JM83 recA

Yanisch-Perron et al 1985

E. coli S17-1 RP4 tra ${ }^{+}$

Simon et al 1986

V. fischeri $\mathrm{MJ}-1$

MJ-100 MJ-1 that is spontaneously $\mathrm{Nx}^{\mathrm{r}}$

Ruby and Nealson 1976

MJ-112

MJ-100 with luxR::Mu dII734, $\mathrm{Nm}^{\mathrm{r}}$

MJ-141

MJ-100 with luxI::Mu dI1734', $\triangle$ luxICD, $\mathrm{Nm}^{\mathrm{s}}$

MJ-201

MJ-112 with $\triangle l u x R I C D, \triangle \mathrm{Mu}$ dI $1734, \mathrm{Nm}^{\mathrm{s}}$

MJ-203

$\mathrm{MJ}-100$ with in-frame $\Delta l u x A$

Dunlap and Kuo 1992

Dunlap and Kuo 1992

Dunlap and Kuo 1992

This study

This study

MJ-207

MJ-100 with $\triangle l u x R I C D$

This study

This study

MJ-208 MJ-100 with in-frame $\Delta l u x R$

MJ-209 MJ-100 with nonpolar 4 bp insertion in luxD

MJ-210 MJ-100 with $\triangle$ luxDABEG

MJ-211 MJ-100 with nonpolar $\Delta l u x I$

This study

This study

This study

pBR322 Inc(ColE1), $\mathrm{Ap}^{\mathrm{r}} \mathrm{Cm}^{\mathrm{r}} \mathrm{Tc}^{\mathrm{r}}$

pJE202 pBR322 with MJ-1 luxRICDABEG, Tc ${ }^{\mathrm{s}}$

pAK004 pJE202 with $\triangle$ luxBEG

pACYC184 Inc(p15A), $\mathrm{Cm}^{\mathrm{r}} \mathrm{Tc}^{\mathrm{r}}$

pSUP102 pACYC184 with RP4 $\mathrm{mob}^{+}$

Simon et al 1986

pNL121 pSUP102 with MJ-1 luxRICDABEG, Tc ${ }^{\mathrm{s}}$

Dunlap and Kuo 1992

pWH112 pNL121 with luxR::Mu dI1734, Km ${ }^{r}$

Dunlap and Kuo 1992

pWH141 pNL121 with luxI::Mu dI1734' $\triangle$ luxICD, $\mathrm{Km}^{\mathrm{s}}$

Dunlap and Kuo 1992

pWH201 pWH112 with $\triangle l u x R I C D, \Delta \mathrm{Mu}$ dI1734, Km ${ }^{\mathrm{s}}$

This study

pAK203 pNL121 with in-frame $\triangle l u x A$

This study

pAK207 pNL121 with $\triangle l u x R I C D$

This study

pAK208 pNL121 with in-frame $\Delta l u x R$

This study

pAK209 pNL121 with nonpolar 4 bp insertion in luxD

This study

pAK210 pNL121 with $\triangle$ luxDABEG

This study

pAK211 pNL121 with nonpolar $\triangle l u x I$ 


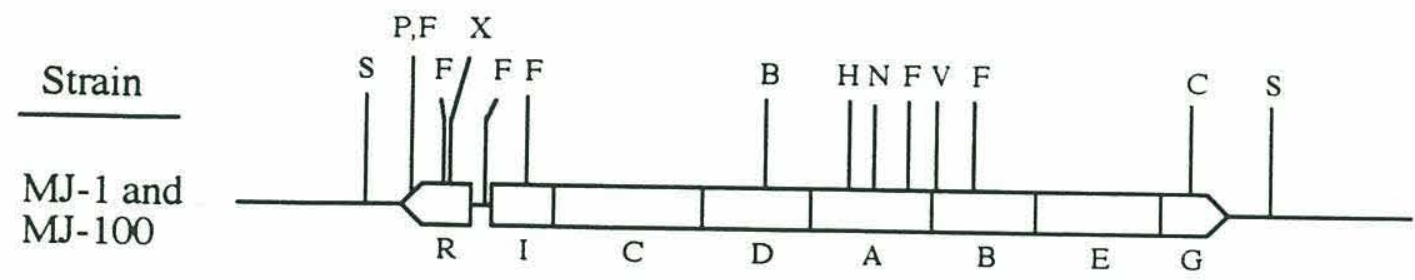

MJ-201

MJ-203

MJ-207

MJ-208

MJ-209

$\Delta$

MJ-210

MJ-211

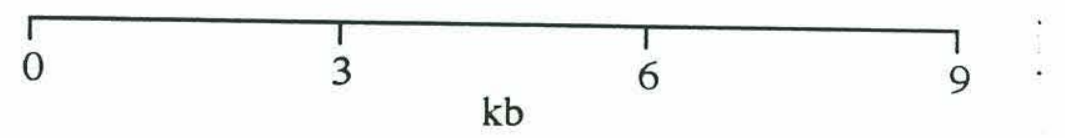

Figure 1. Physical and genetic maps of the lux region of Vibrio fischeri MJ-1 and MJ-1derived lux deletion mutants constructed in this study. Letters above the map indicate restriction sites exploited in this study and recognized by the following enzymes: S, Sall; P, PstI; F, SfcI; X, XbaI; B, BglII; H, XhoI; N, NheI; V, PvuII; C, NcoI. Letters below the map indicate the lux genes. The lux promoters and operator are located between the luxR and luxICDABEG operons. Black bars ( $\square$ ) indicate stretches of DNA deleted from each mutant. Triangle $(\Delta)$ indicates a $4 \mathrm{bp}$ insertion into $l u x D$. Square (口) indicates $1.4 \mathrm{~kb} \mathrm{Mu}$ dI $1734 \mathrm{DNA}$, including the $\mathrm{Mu} c$ gene and the promoter for neo, interrupting the lux region of MJ-201. The construction of each mutant is detailed in the Materials and Methods. 
Restriction digests, blunt-ending reactions (using DNA polymerase I large (Klenow) fragment), and ligations followed standard procedures, as did transformations into $E$. coli. The desired ligation products were detected by culturing transformed $E$. coli in the presence of $\mathrm{Cm}$ at $28^{\circ} \mathrm{C}$, screening for $\mathrm{Lux}^{-}$colonies, isolating plasmid, and performing an appropriate restriction analysis. To mate strains, the plasmid-bearing donor S17-1 and the recipient MJ-100 were separately cultured at $28^{\circ} \mathrm{C}$ in LBS without antibiotics to $A_{660}$ $=0.5$, and $10 \mu \mathrm{L}$ each culture was aliquoted onto an LBS plate. After overnight incubation, the mixture was cultured on LBS in the presence of $\mathrm{Cm}$ and Nx. Doublyresistant transconjugants were purified and then cultured in the absence of $\mathrm{Cm}$. Because pSUP102-derived plasmids appear to be unstable in MJ-100 in the absence of selection (Dunlap and Kuo 1992), double recombinants (in which the enzymatically altered lux region on the plasmid had replaced the wild-type lux region on the MJ-100 chromosome) were recovered by screening for $\mathrm{Lux}^{-} \mathrm{Cm}^{\mathrm{s}} \mathrm{Nx}^{\mathrm{r}}$ colonies. Recombinants arose at frequencies of $0.02-1.0 \%$. In some cases loss of the plasmid was confirmed by examining plasmid extracts on agarose gels.

The putative mutants were then purified and characterized. Luminescence was quantified as described previously (Rosson and Nealson 1981) in $3 \mathrm{ml} \mathrm{LBS}$ cultures using a Pacific Instruments Digital Photometer Model 124. Luciferase activity was measured in crude lysates of centrifuged $1 \mathrm{ml}$ cultures at $A_{660}=1$ using a single-turnover assay as described previously (Rosson and Nealson 1981). Aldehyde deficiency was determined by exposing a colony of the strain in question to vapors of $95 \% n$-decanal for $5 \mathrm{~min}$, and scoring for luminescence (Nealson and Markovitz 1970). Autoinducer synthesis was assessed by measuring the ability of the strain in question to condition medium to prematurely induce luminescence in MJ-100 (Eberhard 1972). Conversely, ability to respond to autoinducer was assessed by culturing the strain in question in either medium that had been conditioned by MJ-100 and then filter-sterilized, or in unconditioned medium with synthetic autoinducer. Complementation tests were performed using the transformation or transconjugation protocols described above and scoring for luminescence. All mutants were verified by Southern analysis. V. fischeri genomic DNAs were extracted as previously described (Dunlap and Kuo 1992), DNA probes were prepared and purified on low-melting point agarose electrophoretic gels following standard procedures, and Southern hybridizations were conducted with a Nonradioactive DNA Labeling and Detection Kit (Boehringer Mannheim).

Details pertaining to each mutant are presented in the following text, and in Table 1 and Figure 1. 
Construction of the luxRICD mutant MJ-201. The lux deletion plasmid pWH201 was generated by treating pWH112 with BglII (one site in luxD and two sites in Mu dI 1734) and ligase. pWH201 thus lacks $2.8 \mathrm{~kb}$ lux DNA, including luxI, luxC, the 5' ends of $l u x R$ and $l u x D$, and the lux promoters and operator, but retains $1.4 \mathrm{~kb}$ Mu dI 1734 DNA (including the Mu $c$ gene and the promoter for neo; Castilho et al 1984). pWH201 was used to construct the lux deletion mutant MJ-201. MJ-201 emitted no detectable light, expressed a low but detectable level of luciferase activity ( $0.02 x$ level of MJ-100), failed to respond to either exogenous autoinducer or aldehyde, and failed to prematurely induce luminescence in MJ-100. Southern hybridizations showed that the $2.8 \mathrm{~kb}$ fragment deleted from pWH201 was also lacking in MJ-201, and that the lux sequences flanking the deletion were intact (data not shown).

Construction of the luxR mutant MJ-208. Complete digestion of pNL121 with PstI, followed by partial digestion with $\mathrm{XbaI}$ (one site in $l u x R$ and one in pSUP102), blunt-ending, and ligation yielded pAK208. This plasmid theoretically has a $450 \mathrm{bp}$ (150 aa) deletion in luxR that is in-frame (according to the published sequence; Engebrecht and Silverman 1987). This luxR deletion plasmid complemented the mutant MJ-141 (which has a functional luxR but no functional luxICD) but not MJ-112 (which is defective in luxR). pAK208 was used to construct the luxR deletion mutant MJ-208. MJ-208 was complemented for luminescence by pWH141 (luxR ${ }^{+} \Delta$ luxICD) but not by pWH112 (luxR::Mu dI1734). Southern analysis showed that MJ-208 lacked the XbaI site in luxR. MJ-208 was expected to express luxICDABEG, but only at low levels, and in fact emitted $0.0006 \mathrm{x}$ the level of light emitted by MJ-100 at $A_{660}=1.5$. Also as expected, addition of autoinducer to the medium had no effect on luminescence.

Construction of the luxRICD mutant MJ-207. pNL121 was digested with BglII and PstI, blunt-ended, and ligated. The resulting plasmid, pAK207, possessed a $3.5 \mathrm{~kb}$ deletion extending from the PstI site in $l u x R$ to the $B g l \mathrm{II}$ site in $l u x D$, and was used to construct MJ-207.

Construction of the luxI mutant MJ-211. pNL121 was first partially digested with $S f c I$; singly-cut plasmid was purified by low-melting point agarose gel electrophoresis. A set of deletions was generated using the Erase-a-Base System (Promega); the procedure involved sequential treatment of the DNA with exonuclease III, $\mathrm{S} 1$ nuclease, Klenow, and T4 DNA ligase. The exonuclease digestion was conducted at $25^{\circ} \mathrm{C}$ for $0.5-2 \mathrm{~min}$. Transformants were screened for responsiveness to autoinducer by picking poorly luminescent colonies and coculturing them with MJ-203 (luxI+ $\Delta l u x A$; see below). Four plasmids with nonpolar mutations in luxI were detected in this manner, recovered, and shown by restriction analysis to carry $\sim 200-300$ bp deletions. One 
plasmid with a $\sim 250$ bp deletion, pAK211, was used to construct the luxI deletion mutant MJ-211. At $A_{660}=1.5$, MJ-211 emitted $0.0002 x$ the amount of light emitted by MJ-100, but in the presence of synthetic autoinducer light emission was $0.2 \mathrm{x}$ the level of MJ-100. Thus exogenous autoinducer promoted luminescence in MJ-211 1000-fold at $A_{660}=1.5$. The presence and size of the deletion in MJ-211 was confirmed by Southern analyses.

Construction of the luciferase (luxA) mutant MJ-203. Complete digestion of pNL121 with XhoI (one site in $\operatorname{luxA}$ ) and partial digestion with NheI (one site in luxA and two sites in pSUP102) followed by blunt-ending and ligation yielded pAK203. pAK203 theoretically has a $168 \mathrm{bp}$ (56 aa) deletion within luxA that is in-frame and therefore nonpolar (based on the published sequence; Foran and Brown 1988). To demonstrate that the deletion was indeed nonpolar, the luxRICDAB' plasmid pAK004 was constructed by digesting the $l u x^{+}$plasmid pJE202 with PvuII (one site in $l u x B$ and one site in pBR322) and ligating, thus truncating $l u x B$ and deleting $l u x E$. Neither pAK203 nor pAK004 alone was capable of supporting luminescence in JM83, but together the plasmids complemented one another for luminescence, demonstrating that pAK203 expressed both $l u x B$ and $l u x E$. pAK203 was then used to construct the nonpolar luxA deletion mutant MJ-203. MJ-203 emitted no detectable light, nor expressed any detectable luciferase activity, but did condition medium in our autoinducer assay. Southern analysis showed that MJ-203 lacked the XhoI site in luxA.

Construction of the aldehyde (luxD) mutant MJ-209. pAK209 was constructed by digesting pNL121 with BglII, filling-in the resulting 4 bp overhangs with Klenow, and ligating. These manipulations theoretically generate a 4 bp insertion and thus a frameshift in $l u x D$. S17-1 transformed with pAK209 was Lux-. However, transformants were physiologically complemented by exogenous aldehyde, demonstrating that the insertion was nonpolar. pAK209 was used to construct the luxD mutant MJ-209, the luminescence of which was also responsive to aldehyde. Without aldehyde, MJ-209 emitted light at 0.0001x the level of MJ-100 at $A_{660}=1.5$. Southern hybridization showed that MJ-209 lacked the BgII site in luxD.

Construction of the luxDABEG mutant MJ-210. Complete digestion of pNL121 with $B g l$ II, followed by partial digestion with $N c o$ I (one site in luxG, one site in pSUP102), blunt-ending, and ligation, yielded pAK210, which lacked $4.0 \mathrm{~kb}$ DNA containing $\operatorname{lu} x A B E$, the 3 ' end of $\operatorname{lu} x D$, and the 5' end of $l u x G$. S17-1 transformed with pAK210 did not luminesce. pAK210 was used to construct the lux mutant MJ-210, which emitted no detectable light. A $8.8 \mathrm{~kb}$ Sall fragment of pNL121 (containing all of lux) hybridized to a single $4.8 \mathrm{~kb}$ fragment of a Sall-BglII digest of MJ-210 DNA while 
hybridizing to 4.8 and $4.0 \mathrm{~kb}$ fragments of similarly digested MJ-100 DNA, indicating that MJ-210 lacked $4.0 \mathrm{~kb}$ lux DNA.

Measurement of resistance to $\mathrm{H}_{2} \mathrm{O}_{2}$. Strains were tested for $\mathrm{H}_{2} \mathrm{O}_{2}$ resistance in two ways. In the liquid culture test, cells were grown in minimal medium for $>12$ hours. Before reaching stationary phase $\left(A_{660}<1\right)$ cultures were diluted into fresh minimal medium at least 100 -fold. The dilute cultures were monitored for growth over the course of exponential phase; at $A_{660}=0.2, \mathrm{H}_{2} \mathrm{O}_{2}$ was added to $40 \mu \mathrm{M}$, and growth was monitored for several more hours. In the top agar test, cells were grown in LBS without antibiotics for $24 \mathrm{hrs}\left(A_{660}>2\right)$ and then diluted with fresh LBS to $A_{660}=0.5 ; 100 \mu \mathrm{l}$ of the dilute culture was mixed with $5 \mathrm{ml}$ molten top agar (LBS with $0.75 \%$ low-melting point agarose at $37^{\circ} \mathrm{C}$ ) and poured onto a hardened LBS agar plate. After $30 \mathrm{~min}$, a concentration blank was placed on the center of the plate and $10 \mu \mathrm{l} 30 \% \mathrm{H}_{2} \mathrm{O}_{2}$ was applied to the blank. Plates were incubated at room temperature overnight and diameters of the resulting clear circular zones of growth inhibition were measured with a ruler. Alternatively, the zones of inhibition were outlined with a marker and photocopied onto paper, and the resulting images were cut out and weighed on a balance. 


\section{RESULTS}

Low resistance of the lux mutant $\mathrm{MJ}-201$ to $\mathrm{H}_{2} \mathrm{O}_{2}$. In all media tested, the $\triangle$ luxRICD mutant MJ-201 grew more slowly than did MJ-100. In the liquid culture assay for resistance to $\mathrm{H}_{2} \mathrm{O}_{2}$, the growth of both $\mathrm{MJ}-100$ and MJ-201 was inhibited by the addition of $\mathrm{H}_{2} \mathrm{O}_{2}$, but cultures of MJ-100 were inhibited only temporarily while cultures of MJ-201 were inhibited much more strongly (Fig. 2a). This result was confirmed with the top agar assay for $\mathrm{H}_{2} \mathrm{O}_{2}$ resistance; $\mathrm{H}_{2} \mathrm{O}_{2}$ left a consistently and significantly larger zone of growth inhibition in a confluent layer of MJ-201 than in a layer of MJ-100 (data not shown).

Normal resistance of the luxR mutant to $\mathrm{H}_{2} \mathrm{O}_{2}$. To provide further evidence that the $\mathrm{H}_{2} \mathrm{O}_{2}$ sensitivity of MJ-201 was due to the low expression of lux genes, I tested the in-frame $\Delta l u x R$ mutant MJ-208 for resistance to oxidative stress. Unlike MJ-201, MJ208 exhibited a growth curve no different from that of MJ-100, and exhibited no greater sensitivity to $\mathrm{H}_{2} \mathrm{O}_{2}$ than did MJ-100 in either the liquid or the top agar assay (data not shown). Varying the concentration of $\mathrm{H}_{2} \mathrm{O}_{2}$ from 20 to $80 \mu \mathrm{M}$ did not affect the result of the liquid assay. To confirm these results, $\mathrm{H}_{2} \mathrm{O}_{2}$-resistance of MJ-208 was quantitated in a third manner. Cells were cultured as in the top agar assay. However, instead of diluting the culture, I challenged $1 \mathrm{ml}$ aliquots of the dense culture with a range of $\mathrm{H}_{2} \mathrm{O}_{2}$ concentrations (from $200 \mu \mathrm{M}$ to $88.2 \mathrm{mM}$ ), incubated the cultures for $5 \mathrm{~min}$, and then diluted the cultures for spreading on LBS plates. The viability of the cultures after treatment with $\mathrm{H}_{2} \mathrm{O}_{2}$, as measured by the number of colonies arising after $\mathrm{H}_{2} \mathrm{O}_{2}$ treatment relative to the number of colonies without $\mathrm{H}_{2} \mathrm{O}_{2}$ was not different between MJ-208 and MJ-100 (data not shown). These results suggest that low lux expression was in fact not responsible for the heightened sensitivity of MJ-201 to $\mathrm{H}_{2} \mathrm{O}_{2}$.

Normal resistance of the lux mutant $\mathrm{MJ}-207$ to $\mathrm{H}_{2} \mathrm{O}_{2}$. One difference between the luxR mutant and MJ-201 is that the former presumably synthesises the fatty acid reductase complex at a low level, while the latter lacks $l u x C$ and $D$. Also, MJ-201 lacks luxI and the lux promoters and operator, which were retained in the construction of MJ208. Finally, MJ-201 differs from MJ-208 in possessing exogenous insert DNA, consisting of the Mu $c$ gene (encoding the Mu phage repressor) and the promoter of neo. To ask if the $\mathrm{H}_{2} \mathrm{O}_{2}$ sensitivity of MJ-201 was due to the absence of any of certain lux sequences or to the presence of the exogenous DNA, I constructed a mutant that was similar to MJ-201 in its lack of $\operatorname{luxI}, \operatorname{luxC}$, the 5' ends of $\operatorname{luxR}$ and $\operatorname{luxD}$, and the $l u x$ promoters and operator, but differed from MJ-201 in its lack of any Mu DNA. The resulting $\triangle l u x R I C D$ mutant, MJ-207, grew at the same rate as MJ-100, and exhibited the 

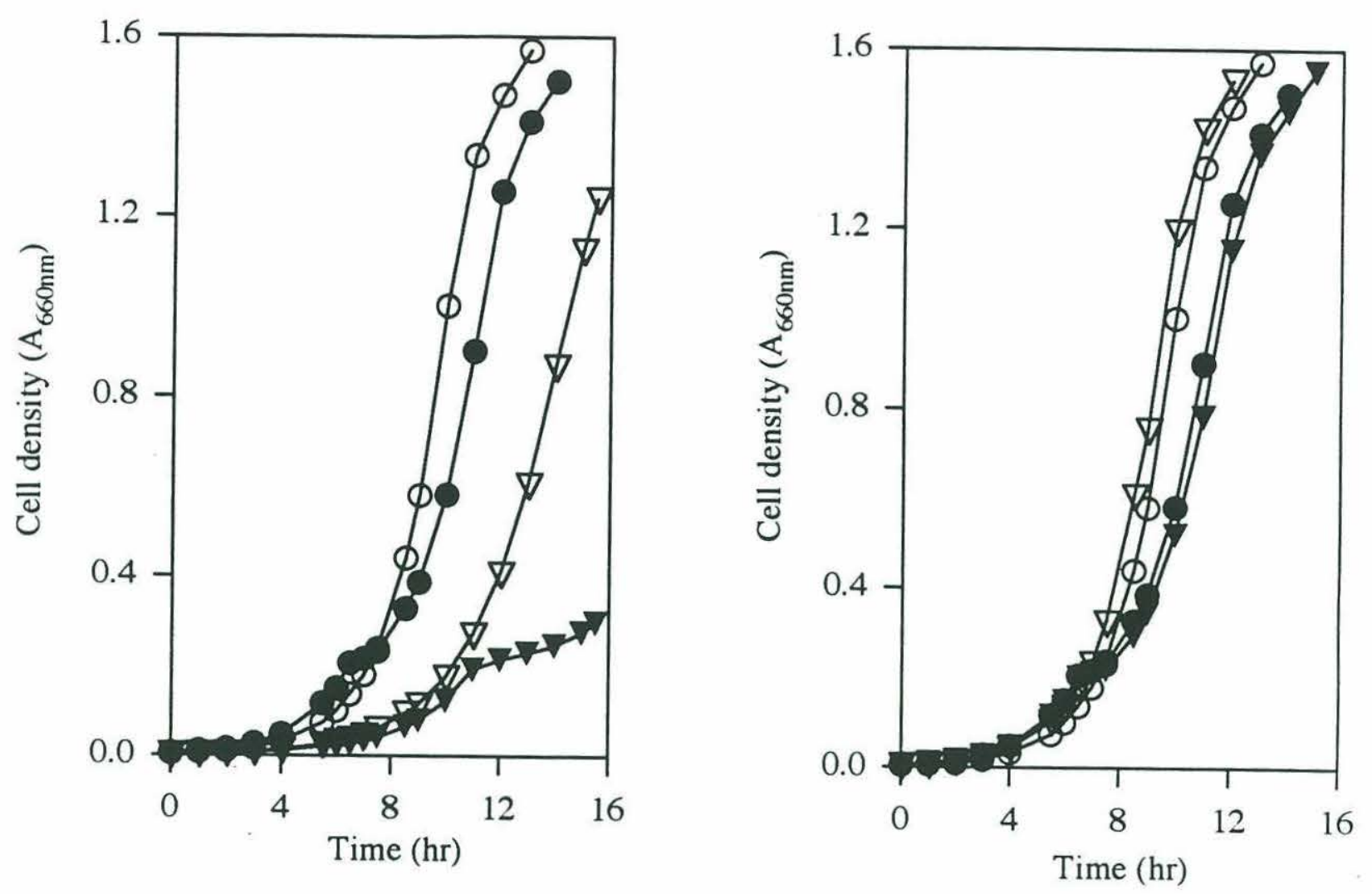

Figure 2. Growth and resistance to $\mathrm{H}_{2} \mathrm{O}_{2}$ of $l u x$ mutants. Strains were cultured in a minimal medium and treated with $\mathrm{H}_{2} \mathrm{O}_{2}$ at $A_{660}=0.2$, as detailed in the Materials and Methods. Filled symbols denote $\mathrm{H}_{2} \mathrm{O}_{2}$-treated cultures, unfilled symbols denote untreated cultures. a) Strains areMJ-100 (O) and the $\Delta l u x$ mutant MJ-201 ( $\nabla)$. b) Strains are MJ-100 (O) and the $\Delta l u x R I C D$ mutant MJ-207 ( $\nabla)$. MJ-201 differs from MJ207 in its possession of Mu dI1734 DNA. 
same resistance to $\mathrm{H}_{2} \mathrm{O}_{2}$ as that of the wild-type (Fig. 2b). I conclude that the low growth rate and low resistance of $\mathrm{MJ}-201$ are due to the presence of Mu DNA rather than to lux mutation.

Pigment production by the luxI mutant. Each of the above mutants, but not the wild-type MJ-100, was deficient in the accumulation of a yellow pigment characteristic of $V$. fischeri. This pigment is visible in colonies and stationary-phase liquid cultures, and in the cell-free supernatants of such cultures. The fact that each of the mutants lacked luxR clearly indicates that the pigment-deficient phenotype is dependent on luxR. To confirm that pigment synthesis is coregulated with luminescence, I examined the nonpolar $\Delta l u x I$ mutant MJ-211. MJ-211 emitted a relatively low level of light compared to the wild-type, and concomitantly failed to produce visible amounts of pigment. Both luminescence and pigmentation were rescued by growth in the presence of exogenous autoinducer (Table 2). Furthermore, neither luminescence nor pigmentation were rescued by the addition of exogenous autoinducer to the $\Delta l u x R$ mutant MJ-208. These results demonstrate that pigment accumulation is, like luminescence, regulated by autoinduction.

Normal pigmentation of the luciferase and aldehyde mutants. One possible reason that pigmentation and luminescence are induced together is that pigment synthesis reflects the activities of one of the luminescence enzymes. To ask if the flavoenzyme luciferase is involved in pigment production, I examined the in-frame $\Delta l u x A$ mutant $M J$ 203. The luciferase mutant did not obviously differ from MJ-100 in either growth characteristics or pigmentation. Similarly, the nonpolar luxD mutant MJ-209, while deficient in aldehyde production, was normally pigmented. These results do not implicate either luminescence or fatty acid reduction in pigmentation.

Deficient pigmentation of the luxG mutant. The above results do not exclude the possibility that pigment accumulation is directed by genes not involved in luminescence but which are nevertheless regulated by autoinducer and LuxR. One such gene is $\operatorname{lux} G$, which is not necessary for luminescence in E. coli (data not shown). It is also possible that autoinducer and LuxR regulate pigmentation genes outside of the lux operon. To assess this possibility, I constructed a luxG mutant. There is no known phenotype or protein associated with $\operatorname{lux} G$, so there is no way to phenotypically detect a $V$. fischeri mutant with a simple deletion internal to luxG. However, a luxG deletion could be detected if linked to the deletion of other genes with known functions. Thus I constructed MJ-210, which lacks $\operatorname{luxABE}$, the $3^{\prime}$ end of $\operatorname{luxD}$, and the $5^{\prime}$ end of $\operatorname{luxG}$. MJ210 was deficient in pigment production, implying that accumulation of the yellow pigment is directed by $\operatorname{lux} G$. 
Table 2. Yellow pigment production of lux mutants

\begin{tabular}{|c|c|}
\hline Strain & Yellow pigment \\
\hline MJ-100 (lux $\left.x^{+}\right)$ & + \\
\hline MJ-201 ( $\triangle l u x R I C D)$ & - \\
\hline MJ-207 (AluxRICD) & - \\
\hline MJ-203 ( $\Delta l u x A)$ & + \\
\hline MJ-209 (luxD-) & + \\
\hline MJ-211 ( $(\Delta l u x I)$ & - \\
\hline MJ-211 + autoinducer & + \\
\hline MJ-208 ( $\Delta l u x R)$ & - \\
\hline MJ-208 + autoinducer & - \\
\hline MJ-210 ( $\triangle l u x D A B E G)$ & - \\
\hline
\end{tabular}




\section{DISCUSSION}

In this study, defined mutations of the lux genes were constructed in $V$. fischeri. To test whether luminescence protects the cell against $\mathrm{H}_{2} \mathrm{O}_{2}$ toxicity, the effects of the mutations on cellular resistance to $\mathrm{H}_{2} \mathrm{O}_{2}$ were measured. Mutations in lux had no apparent effect on resistance to $\mathrm{H}_{2} \mathrm{O}_{2}$, nor on growth, but certain mutations did affect pigmentation.

There has been only one previous report of the construction of defined mutants of a luminescent bacterium (Dunlap and Kuo 1992). In this study I introduced enzymatically altered genes into $V$. fischeri, moved the altered genes into the chromosome through gene replacement, and documented the gene replacements by complementation and Southern analysis. This genetic methodology provides a powerful and general approach to studying the $V$. fischeri lux genes in $V$. fischeri, as opposed to in $E$. coli, as well as any other cloned $V$. fischeri genes. I stress the importance of performing such studies in $V$. fischeri, since it is known that aspects of lux regulation such as autoinducer-independent modulation differ between $V$. fischeri and $E$. coli (Dunlap and Kuo 1992).

Both the lower growth rate and the greater $\mathrm{H}_{2} \mathrm{O}_{2}$ senstivity of MJ-201 relative to MJ-100, MJ-208, and MJ-207 imply that the insertion of $1.4 \mathrm{~kb}$ Mu dI1734 DNA into the lux locus has a substantial physiological affect on V. fischeri. The foreign DNA includes the $\mathrm{Mu} c$ gene (encoding the Mu phage repressor) and the promoter of the $\mathrm{Km}^{\mathrm{r}}$ determinant neo. The reason for the adverse effect of the Mu DNA is unknown; it is possible that the promoters for $c$ or neo may affect the expression of flanking $V$. fischeri genes. Alternatively, it is possible that the expression of $c$ function causes the observed phenotype. Given that Mu-derived constructs are commonly used in transposon mutagenesis and the generation of transcriptional and translational fusions, and that neo cassettes are of ten used to construct selectable insertions, the effect of exogenous DNA reported here may serve as a cautionary note.

This study is the first systematic use of a genetic approach to assess the physiological role of luminescence in bacteria. The mutant phenotypes confirmed the functions of the individual lux genes as established in studies with the cloned genes in $E$. coli (Engebrecht and Silverman 1984). Given the complexity and energetic requirements of luminescence (reducing power, $\mathrm{O}_{2}$, ATP, protein synthesis), it is perhaps surprising that the lux mutants (excepting MJ-201) did not differ from MJ-100 in growth rate or yield. Estimates of the magnitude of the impact of luminescence on total cellular metabolism vary widely, from as high as $20 \%$ of respiration to as low as $0.007 \%$ of total 
energy expenditure (Dunlap 1985, Makemson 1986, Makemson and Gordon 1989). My results support the view that luminescence is not an enormous energetic burden on the cell.

My inability to detect a clear effect of $l u x$ mutation on $\mathrm{H}_{2} \mathrm{O}_{2}$ resistance is inconsistent with the hypothesis that the function of luciferase is to detoxify $\mathrm{H}_{2} \mathrm{O}_{2}$. However, this result does not prove that luciferase function does not involve elimination of $\mathrm{O}_{2}{ }^{-}$. or excess $\mathrm{O}_{2}$. The luxA mutant generated in this study could be employed to directly address these possibilities. Similarly, the luxA mutant could be used to test some of the other hypotheses of the adaptive function of luminescence, especially the hypothesis that luciferase acts as an alternate electron acceptor. Utilizing the lux mutants to investigate the role of luminescence in symbiosis may be more difficult, because the only known cultivable host of $V$. fischeri, the squid Euprymna scolopes, cannot establish a successful symbiosis with MJ-1, the strain used in this study (Ruby and McFall-Ngai 1992). However, the mutation approach used in this study might be applicable to still other strains of $V$. fischeri that can infect E. scolopes (McFall-Ngai and Ruby 1991).

Even though neither the deletions in $l u x R$ and $l u x A$ nor the broad deletion from luxR to luxD had a demonstrable effect on growth or $\mathrm{H}_{2} \mathrm{O}_{2}$ resistance, there was a clear pattern relating yellow pigment to the lux locus. The pattern is consistent with the notion that development of the yellow pigment is a product not of luciferase function or fatty acid reduction but of LuxG. E. coli with the intact lux operon does not appear to synthesize the yellow pigment, and I have not constructed a $V$. fischeri strain with a mutation in luxG alone. Before this study, LuxG had no demonstrated function, but has sequence similarity to Fre, an $E$. coli flavin reductase involved in the generation of the free radical functional group of ribonucleotide reductase (Fontecave et al 1987, Spyrou et al 1991, Andrews et al 1992). Known NAD(P)H-flavin oxidoreductases in luminescent bacteria are not encoded by luxG (Zenno et al 1994, Zenno and Saigo 1994). Similarly, the nature and function of the pigment are unknown. Its solubility in water and flourescence in ultraviolet have led to the suggestion that it is riboflavin (Giese 1943). Such a suggestion is tempting if LuxG is indeed a flavin reductase. The mutants and genetic techniques described in this study, together with chemical identification of the pigment, should clarify the functional role of $\operatorname{luxG}$. 


\section{ACKNOWLEDGMENTS}

I thank EP Greenberg for synthetic autoinducer, and the Woods Hole Oceanographic Institution (WHOI) for a WHOI Ocean Ventures Fund Award.

\section{REFERENCES}

Andrews, CC, DM Karl, LF Small and SW Fowler. 1984. Metabolic activity and bioluminescence of oceanic faecal pellets and sediment trap particles. Nature 307:539541.

Andrews, SC, D Shipley, JN Keen, JBC Findlay, PM Harrison and JR Guest. 1992. The haemoglobin-like protein (HMP) of Escherichia coli has ferrisiderophore reductase activity and its $\mathrm{C}$-terminal domain shares homology with ferredoxin NADP+ reductases. FEBS 302:247-252.

Baumann, P, AL Furniss and JV Lee. 1984. Genus I. Vibrio Pacini $1854,411^{\mathrm{AL}}$, p. 518-538. NR Krieg and JG Holt (ed.), Bergey's manual of systematic bacteriology. Williams and Wilkins, Baltimore.

Castilho, BA, P Olfson and MJ Casadaban. 1984. Plasmid insertion mutagenesis and lac gene fusion with mini-Mu bacteriophage transposons. J. Bacteriol. 158:488-495.

Cline, T, and JW Hastings. 1971. Temperature-sensitive mutants of bioluminescent bacteria. Proc. Natl. Acad. Sci. USA 68:500-504.

Colepicolo, P, VCCP Camarero, J Eckstein and JW Hastings. 1992. Induction of bacterial luciferase by pure oxygen. J. Gen. Microbiol. 138:831-836.

Cormier, MJ, and BL Strehler. 1953. The identification of KCF: requirement of long-chain aldehydes for bacterial extract luminescence. J. Am. Chem. Soc. 75:48644865 .

Devine, JH, GS Shadel and TO Baldwin. 1989. Identification of the operator of the lux regulon from the Vibrio fischeri strain ATCC7744. Proc. Natl. Acad. Sci. USA 86:5688-5692.

Dunlap, PV. 1984. Physiological and morphological state of the symbiotic bacteria from light organs of ponyfish. Biol. Bull. 167:410-425.

Dunlap, PV. 1985. Osmotic control of luminescence and growth in Photobacterium leiognathi from ponyfish light organs. Arch. Microbiol. 141:44-50.

Dunlap, PV. 1989. Regulation of luminescence by cyclic AMP in cya-like and crp-like mutants of Vibrio fischeri. J. Bacteriol. 171:1199-1202.

Dunlap, PV, and A Kuo. 1992. Cell density-dependent modulation of the Vibrio fischeri luminescence system in the absence of autoinducer and LuxR protein. J. Bacteriol. 174:2440-2448.

Dunn, DK, GA Michaliszyn, IG Bogacki and EA Meighen. 1973. Conversion of aldehyde to acid in the bacterial bioluminescent reaction. Biochem. 12:4911-4918.

Eberhard, A. 1972. Inhibition and activation of bacterial luciferase. J. Bacteriol. 109:1101-1105.

Eberhard, A, AL Burlingame, C Eberhard, GL Kenyon, KH Nealson and NJ Oppenheimer. 1981. Structural identification of autoinducer of Photobacterium fischeri luciferase. Biochem. 20:2444-2449.

Engebrecht, J, K Nealson and M Silverman. 1983. Bacterial bioluminescence: isolation and genetic analysis of functions from Vibrio fischeri. Cell 32:773-781.

Engebrecht, J, and M Silverman. 1984. Identification of genes and gene products necessary for bacterial bioluminescence. Proc. Natl. Acad. Sci. USA 81:4154-4158. 
Engebrecht, J, and M Silverman. 1987. Nucleotide sequence of the regulatory locus controlling expression of bacterial genes for bioluminescence. Nucleic Acids Res. 15:10455-10467.

Fontecave, M, R Eliasson and P Reichard. 1987. NAD(P)H:flavin oxidoreductase of Escherichia coli. J. Biol. Chem. 262:12325-12331.

Foran, DR, and WM Brown. 1988. Nucleotide sequence of the LuxA and LuxB genes of the bioluminescent marine bacterium Vibrio fischeri. Nucleic Acids Res. 16:777.

Fridovich, I. 1978. The biology of oxygen radicals. Science 201:875-880.

Friedrich, WF, and EP Greenberg. 1983. Glucose repression of luminescence and luciferase in Vibrio fischeri. Arch. Microbiol. 134:87-91.

Giese, AC. 1943. Studies on the nutrition of dim and bright variants of a species of luminous bacteria. J. Bacteriol. 46:323-331.

Guerrero, MA, and JC Makemson. 1989. The cytochromes of luminous bacteria and their coupling to bioluminescence. Curr. Microbiol. 18:67-73.

Hastings, JW, S-C Tu, JE Becvar and RP Presswood. 1979. Bioluminescence from the reaction of $\mathrm{FMN}, \mathrm{H}_{2} \mathrm{O}_{2}$ and long chain aldehyde with bacterial luciferase. Photochem. Photobiol. 29:383-387.

Imlay, JA, and S Linn. 1988. DNA damage and oxygen radical toxicity. Science 240:1302-1309.

Kanfer, S, and NJ Turro. 1981. Reactive forms of oxygen, p. 47-64. DL Gilbert (ed.), Oxygen and living processes. Springer-Verlag, New York.

Kasai, S, S Fujii, R Miura, S Odani, T Nakaya and K Matsui. 1990. Structure of $\mathrm{FP}_{390}$ including its prosthetic group (Q-flavin): physiological significance of light emitting reaction in luminous bacteria. Flavins and flavoproteins 1990.

Keynan, A, and JW Hastings. 1961. The isolation and characterization of dark mutants of luminescent bacteria. Biol. Bull. 121:375.

Keynan, A, C Veeder and JW Hastings. 1963. Studies on the survival of dark and bright mutants of luminescent bacteria in sea water. Biol. Bull. 125:382.

Kurfurst, M, S Ghisla and JW Hastings. 1983. Bioluminescence emission from the reaction of luciferase-flavin mononucleotide radical with $\mathrm{O}_{2}^{-}$. Biochem. 22:15211525 .

Makemson, JC. 1986. Luciferase-dependent oxygen consumption by bioluminescent vibrios. J. Bacteriol. 165:461-466.

Makemson, JC, and JW Hastings. 1986. Luciferase-dependent growth of cytochrome-deficient Vibrio harveyi. FEMS Microbiol. Ecol. 38:79-85.

Makemson, JC, and AS Gordon. 1989. Total energy flux in a marine bioluminescent bacterium. FEMS Microbiol. Lett. 57:161-166.

McElroy, WD, JW Hastings, V Sonnenfield and J Coulombre. 1953. The requirement of riboflavin phosphate for bacterial luminescence. Science 118:385-386.

McElroy, WD, and HH Seliger. 1962. Origin and evolution of bioluminescence, p. 91-101. M Kasha and B Pullman (ed.), Horizons in biochemistry. Academic Press, Inc, New York.

McFall-Ngai, MJ, and EG Ruby. 1991. Symbiont recognition and subsequent morphogenesis as early events in an animal-bacterial mutualism. Science 254:14911494.

Nealson, KH, and A Markovitz. 1970. Mutant analysis and enzyme subunit complementation in bacterial bioluminescence in Photobacterium fischeri. J. Bacteriol. 104:300-312.

Nealson, KH, and JW Hastings. 1979. Bacterial bioluminescence: its control and ecological significance. Microbiol. Rev. 43:496-518. 
Riendeau, D, and E Meighen. 1970. Evidence for a fatty acid reductase catalyzing the synthesis of aldehydes for the bacterial bioluminescent reaction. J. Biol. Chem. 254:7488-7490.

Rogers, P, and WD McElroy. 1955. Biochemical characteristics of aldehyde and luciferase mutants of luminous bacteria. Proc. Natl. Acad. Sci. USA 41:67-70.

Rosson, RA, and KH Nealson. 1981. Autoinduction of bacterial bioluminescence in a carbon limited chemostat. Arch. Microbiol. 129:299-304.

Ruby, EG, and MJ McFall-Ngai. 1992. A squid that glows in the night: development of an animal-bacterial mutualism. J. Bacteriol. 174:4865-4870.

Ruby, EG, and JG Morin. 1979. Luminous enteric bacteria of marine fishes: a study of their distribution, densities, and dispersion. Appl. Environ. Microbiol. 38:406411.

Ruby, EG, and KH Nealson. 1976. Symbiotic association of Photobacterium fischeri with the marine luminous fish Monocentris japonica: a model of symbiosis based on bacterial studies. Biol. Bull. 151:574-586. 21:355-361.

Seliger, HH. 1975. The origin of bioluminescence. Photochem. Photobiol.

Seliger, HH. 1987. The evolution of bioluminescence in bacteria. Photochem. Photobiol. 45:291-297.

Simon, R, M O'Connell, M Labes and A Puhler. 1986. Plasmid vectors for the genetic analysis and manipulation of rhizobia and other gram-negative bacteria. Meth. Enzymol. 118:640-659.

Spyrou, G, E Haggard-Ljungquist, M Krook, H Jornvall, E Nilsson and P Reichard. 1991. Characterization of the flavin reductase gene (fre) of Escherichia coli and construction of a plasmid for overproduction of the enzyme. J. Bacteriol. 173:36733679.

Swartzman, E, S Kapoor, AF Graham and EA Meighen. 1990. A new Vibrio fischeri lux gene precedes a bidirectional termination site for the lux operon. J. Bacteriol. 172:6797-6802.

Ulitzur, S, A Reinhertz and JW Hastings. 1981. Factors affecting the cellular expression of bacterial luciferase. Arch. Microbiol. 129:67-71.

Watanabe, T, and T Nakamura. 1976. Studies on luciferase from Photobacterium phosphoreum. VIII. FMN- $\mathrm{H}_{2} \mathrm{O}_{2}$ initiated bioluminescence and the thermodynamics of the elementary steps of the luciferase reaction. J. Biochem. 79:489495.

Yanisch-Perron, C, J Vieira and J Messing. 1985. Improved M13 phage cloning vectors and host strains: nucleotide sequences of the M13mp18 and pUC19 vectors. Gene 33:103-119.

Zenno, S, K Saigo, H Kanoh and S Inouye. 1994. Identification of the gene encoding the major NAD(P)H-flavin oxidoreductase of the bioluminescent bacterium Vibrio fischeri ATCC 7744. J. Bacteriol. 176:3536-3543.

Zenno, S, and K Saigo. 1994. Identification of the genes encoding NAD(P)Hflavin oxidoreductases that are similar in sequence to Escherichia coli Fre in four species of luminous bacteria: Photorhabdus luminescens, Vibrio fischeri, V. harveyi, and V. orientalis. J. Bacteriol. 176:3544-3551. 
Chapter 3. Multiple $\mathrm{N}$-acyl-L-homoserine lactone autoinducers of luminescence in the marine symbiotic bacterium Vibrio fischeri

This chapter has appeared in the Journal of Bacteriology 176(24):7558-7565. What follows is a copy of the galley proofs. On the sixth page of the proofs, first column of text, " $\delta_{1}, \delta_{\mathrm{H}}=4.42$ " should read as " $\gamma_{1}, \delta_{\mathrm{H}}=4.42$ ". 


\title{
Multiple $N$-Acyl-L-Homoserine Lactone Autoinducers of Luminescence in the Marine Symbiotic Bacterium Vibrio fischeri†
}

\author{
ALAN KUO, ${ }^{1}$ NEIL V. BLOUGH, ${ }^{2} \ddagger$ AND PAUL V. DUNLAP ${ }^{1 *}$ \\ Biology Department ${ }^{1}$ and Chemistry Department, ${ }^{2}$ Woods Hole Oceanographic Institution, Woods Hole, Massachusetts 02543
}

Received 24 August 1994/Accepted 14 October 1994

\begin{abstract}
In Vibrio fischeri, the synthesis of $N$-3-oxohexanoyl-L-homoserine lactone, the autoinducer for population density-responsive induction of the luminescence operon (the lux operon, luxICDABEG), is dependent on the autoinducer synthase gene luxI. Gene replacement mutants of $V$. fischeri defective in luxI, which had been expected to produce no autoinducer, nonetheless exhibited lux operon transcriptional activation. Mutants released into the medium a compound that, like $N$-3-oxohexanoyl-L-homoserine lactone, activated expression of the lux system in a dose-dependent manner and was both extractable with ethyl acetate and labile to base. The luxI-independent compound, also like $N$-3-oxohexanoyl-L-homoserine lactone, was produced by $V$. fischeri cells in a regulated, population density-responsive manner and required the transcriptional activator LuxR for activity in the lux system. The luxI-independent compound was identified as $N$-octanoyl-L-homoserine lactone by coelution with the synthetic compound in reversed-phase high-pressure liquid chromatography, by derivatization treatment with 2,4-dinitrophenylhydrazine, by mass spectrometry, and by nuclear magnetic resonance spectroscopy. A locus, ain, necessary and sufficient for Escherichia coli to synthesize $N$-octanoyl-Lhomoserine lactone was cloned from the $V$. fischeri genome and found to be distinct from luxI by restriction mapping and Southern hybridization. $N$-Octanoyl-L-homoserine lactone and ain constitute a second, novel autoinduction system for population density-responsive signalling and regulation of lux gene expression, and possibly other genes, in $V$. fischeri. A third $V$. fischeri autoinducer, $N$-hexanoyl-L-homoserine lactone, dependent on luxI for its synthesis, was also identified. The presence of multiple chemically and genetically distinct but cross-acting autoinduction systems in $V$. fischeri indicates unexpected complexity for autoinduction as a regulatory mechanism in this bacterium.
\end{abstract}

Autoinduction is an intercellular signalling and gene regulatory mechanism for population density-responsive control of luminescence in Vibrio fischeri, a bacterium that occurs at high population density in light-organ symbiosis (e.g., $10^{10}$ to $10^{11}$ cells $\left.\mathrm{ml}^{-1}\right)$ and other habitats (23). Autoinducer ( $N$-3-oxohexanoyl-L-homoserine lactone [ $\mathrm{N}$-3-oxohexanoyl-L-HSL]) is a self-produced, membrane-permeable compound that accumulates as $V$. fischeri population density increases $(10,20)$. At threshold concentrations, autoinducer, via the autoinducer receptor and transcriptional activator LuxR, triggers transcription of the luminescence (lux) operon, luxICDABEG, which contains genes for autoinducer synthase (luxI) and luminescence enzymes $(13,14,30)$.

Besides $V$. fischeri, other species of proteobacteria that are symbionts or pathogens of higher organisms have recently been found to produce $N$-acyl-L-HSL autoinducers structurally similar or identical to the $V$. fischeri autoinducer. For example, $\mathrm{N}$-3-hydroxybutanoyl-L-HSL mediates autoinduction of luminescence in Vibrio harveyi, $N$-3-oxooctanoyl-L-HSL mediates autoinduction of conjugation in Agrobacterium tumefaciens, and $N$-3-oxohexanoyl-L-HSL and $N$-3-oxododecanoyl-L-HSL mediate autoinduction of virulence determinants in Erwinia carotovora and Pseudomonas aeruginosa, respectively $(2,4,25$, 32 ). In many cases, the genes for the autoinducer synthase and transcriptional activator exhibit substantial sequence similarity

\footnotetext{
* Corresponding author. Mailing address: Biology Department, Redfield Laboratory, 86 Water St., Woods Hole Oceanographic Institution, Woods Hole, MA 02543. Phone: (508) 457-2000, ext. 3209. Fax: (508) 457-2195. Electronic mail address: pdunlap@whoi.edu. $\uparrow$ Contribution 8833 from Woods Hole Oceanographic Institution.

$\ddagger$ Present address: Department of Chemistry and Biochemistry, University of Maryland, College Park, MD 20742.
}

to $l u x I$ and luxR, respectively, of $V$. fischeri $(16,17,24,26,27)$. Recently, evidence has been obtained for an HSL-based signal of starvation in Escherichia coli (19). The diversity of species that use autoinduction and the chemical and genetic similarities of their autoinduction systems indicate that autoinduction is an evolutionarily conserved signalling and regulatory mechanism of general importance in proteobacteria.

In this report, we demonstrate that $V$. fischeri produces a second, novel autoinducer, $N$-octanoyl-L-HSL, that activates lux operon transcription via LuxR. The synthesis of $\mathrm{N}$-octanoyl-L-HSL is directed by a novel autoinducer synthase locus, ain, that is distinct from luxI. A third $V$. fischeri autoinducer, $N$-hexanoyl-L-HSL, dependent on luxI for its synthesis, was also identified. The presence of multiple chemically and genetically distinct autoinduction systems in $V$. fischeri indicates unexpected complexity for autoinduction as a signalling and gene regulatory mechanism within a single bacterium.

\section{MATERIALS AND METHODS}

Bacterial strains, plasmids, culture conditions, and physiological assays. The strains used in this study are derivatives of E. coli $\mathrm{K}-12$ and $V$. fischeri $\mathrm{MJ}-1$ and are listed in Table $1 . V$. fischeri MJ-100, a spontaneously nalidixic acid-resistant $\left(\mathrm{Nx}^{\mathrm{r}}\right)$ derivative of MJ-1 (8), and its derivatives were maintained on solid LBS medium (8) with $20 \mu \mathrm{g}$ of nalidixic acid $\mathrm{ml}^{-1}$. E. coli S17-1 is a strain capable of conjugatively transferring the mobilizable chloramphenicol resistance $\left(\mathrm{Cm}^{\mathrm{r}}\right)$ plasmid pSUP102 to a wide range of recipients (29), including $V$. fischeri $(6,8)$. E. coli strains were maintained on solid LB medium (1) with appropriate antibiotics to ensure plasmid maintenance.

Growth conditions, cell density and luminescence assays, and the light-measuring equipment and standard were as 
TABLE 1. Bacterial strains and plasmids used in this study

\begin{tabular}{|c|c|c|}
\hline Strain or plasmid & Relevant characteristics ${ }^{a}$ & Source or reference \\
\hline \multicolumn{3}{|l|}{ Strains } \\
\hline \multicolumn{3}{|l|}{ E. coli $\mathrm{K}-12$} \\
\hline JM83 & $\Delta($ lac-pro $A B)$ & 31 \\
\hline PD100 & $z a h-735:: \operatorname{Tn} 10 \Delta($ argF-lac $) U 169, \mathrm{Tc}^{\mathrm{r}}$ & 7 \\
\hline S17-1 & RP4 $\mathrm{tra}^{+}$ & 29 \\
\hline \multicolumn{3}{|l|}{ V. fischeri } \\
\hline MJ-1 & $\mathrm{Lux}^{+}$ & 28 \\
\hline MJ-100 & $\mathrm{MJ}-1, \mathrm{Nx}^{\mathrm{r}}$ & 8 \\
\hline MJ-203 & MJ-100, $\Delta l u x A$ (168-bp XhoI-NheI in-frame deletion) & This study \\
\hline MJ-207 & MJ-100, $\Delta l u x R I C D(\sim 3.5-\mathrm{kbp}$ PstI-BglII deletion) & This study \\
\hline MJ-208 & MJ-100, $\Delta l u x R$ (450-bp PstI-XbaI in-frame deletion) & This study \\
\hline MJ-211 & MJ-100, $\Delta l u x I$ ( $\sim 250$-bp nonpolar deletion) & This study \\
\hline \multicolumn{3}{|l|}{ Plasmids } \\
\hline pSUP102 & $\mathrm{pACYC184}, \mathrm{RP} 4 \mathrm{mob}^{+}, \mathrm{Cm}^{\mathrm{r}} \mathrm{Tc}^{\mathrm{r}}$ & 29 \\
\hline pJE202 & pBR322 with $\sim 8.8-\mathrm{kbp}$ SalI fragment from $V$. fischeri DNA (luxR luxICDABEG), Ap ${ }^{\mathrm{r}}$ & 13 \\
\hline pNL121 & pSUP102 with $\sim 8.8-\mathrm{kbp}$ Sall lux fragment of pJE202, $\mathrm{Cm}^{\mathrm{r}}$ & 8 \\
\hline pPD749 & Ptac-luxR, lacI $I^{4}, \mathrm{Ap}^{\mathrm{r}}$ & 7 \\
\hline pJR551 & $\begin{array}{l}\text { pACYC184 with luxR::Mu } \Delta\left(c \text { nerAB) dI1681 }\left(\operatorname{lac} Z Y A \mathrm{Km}^{s}\right) \text { and luxICDABEG with a nonpolar point }\right. \\
\text { mutation in luxI, } \mathrm{Cm}^{\mathrm{r}}\end{array}$ & 9 \\
\hline pAI002 & pSUP102 with $\sim 10.5$-kbp fragment from $V$. fischeri, ain ${ }^{+}, \mathrm{Cm}^{r}$ & This study \\
\hline pAIO04 & pBR322 with $\sim 2.7-\mathrm{kbp}$ HindIII $V$. fischeri DNA fragment, ain $^{+}, \mathrm{Ap}^{r}$ & This study \\
\hline pAK211 & pNL121 with $\sim 250$-bp nonpolar deletion in luxI & This study \\
\hline pAK411 & pBR322 with 8.5-kbp lux fragment of pAK211 & This study \\
\hline pAK208 & pNL121 with 450-bp in-frame PstI-XbaI deletion in luxR & This study \\
\hline pAK408 & pBR322 with $\sim 8.3$-kbp SalI fragment of pAK208 & This study \\
\hline
\end{tabular}

${ }^{a} \mathrm{Ap}^{r}$, ampicillin resistant; $\mathrm{Km}^{2}$, kanamycin sensitive; $\mathrm{Tc}^{r}$, tetracycline resistant.

previously described (8). V. fischeri was inoculated into liquid LBS or ASH medium (8) to an $A_{660}<0.01$. Liquid cultures of $E$. coli were handled similarly except that LB medium (1) with $50 \mathrm{mM}$ Tris ( $\mathrm{pH} 7.5)$ and an appropriate antibiotic was used.

For the measurement of autoinducer activity, filter-sterilized supernatants of high-density cultures $\left(A_{660}\right.$ of 1.5 in LBS for $V$. fischeri and 2.0 for $E$. coli) (i.e., conditioned media) were mixed $1: 1$ with autoinducer assay medium (an LB-Tris medium) (9). Alternatively, supernatants were extracted with acidified ethyl acetate $(100 \mu \mathrm{l}$ of glacial acetic acid in 1 liter of ethyl acetate) and dried as described previously (10) and then redissolved in assay medium. Next, an exponential-phase culture $\left(A_{660}=0.3\right)$ of the autoinducer assay strain, $E$. coli PD100(pPD749, pJR551) (9), was added to a final $A_{660}$ of 0.01 , and subsequent luminescence and growth were monitored. The growth rates of the autoinducer assay strain within experiments were essentially similar. The responses of $V$. fischeri strains to an autoinducer were determined by inoculating the strain into a 1:1 mixture of unconditioned medium and medium conditioned by an appropriate autoinducer-producing strain.

Construction of $V$. fischeri lux mutants. Most of the deletions used in this study to construct $V$. fischeri lux mutants were generated in the subcloned lux genes (luxR and luxICDA$B E G)$ of pNL121 (8) by digestion with appropriate restriction enzymes (Fig. 1), blunt ending with Klenow fragment, ligating, transforming $E$. coli JM83, and selecting $\mathrm{Cm}^{\mathrm{r}}$ transformants. An exception was the nonpolar luxI deletion of pAK211, which was constructed by partial digestion of pNL121 with $S f c I$, removal of approximately 250 bp of luxI DNA with the Promega (Madison, Wis.) Erase-a-Base System, ligation, and screening for JM83 transformants that luminesced only in the proximity of $\mathrm{MJ}-203$, an autoinducerproducing derivative of $\mathrm{MJ}-100$ that contains a nonpolar deletion in $\operatorname{lu} x A$, the gene specifying the $\alpha$-subunit of the light-emitting enzyme luciferase (Fig. 1). Plasmids and $E$. coli strains were manipulated by using standard procedures (1).
V. fischeri lux mutants (Fig. 1) were then constructed by conjugating modified pNL121 from $\mathrm{S} 17-1$ to $\mathrm{MJ}-100$ by a previously described mating and transconjugant selection procedure (8) and screening the resulting $\mathrm{Nx}^{\mathrm{r}} \mathrm{Cm}^{\mathrm{s}}$ recombinant $V$. fischeri strains to confirm the mutant phenotype. For example, the nonpolar luxI deletion mutant MJ-211 was constructed by conjugating pAK211 into MJ-100 and screening for colonies that were Lux ${ }^{-}$except in proximity to MJ-203. Mutant genotypes and phenotypes were verified by physiological measurements, complementation tests, and Southern hybridizations.

Southern hybridizations. DNA was transferred from $1 \%$ agarose gels to Zeta-Probe blotting membrane by standard procedures (1) and probed and developed with the Boehringer Mannheim (Indianapolis, Ind.) nonradioactive DNA labeling and detection kit. Probes were prepared by labeling purified fragments by random priming. Hybridizations and high-stringency washes were performed at $65^{\circ} \mathrm{C}$.

RP HPLC of autoinducers. Synthetic $N$-acyl-L-HSLs, kindly provided by D. Lynn (University of Chicago), were dissolved in

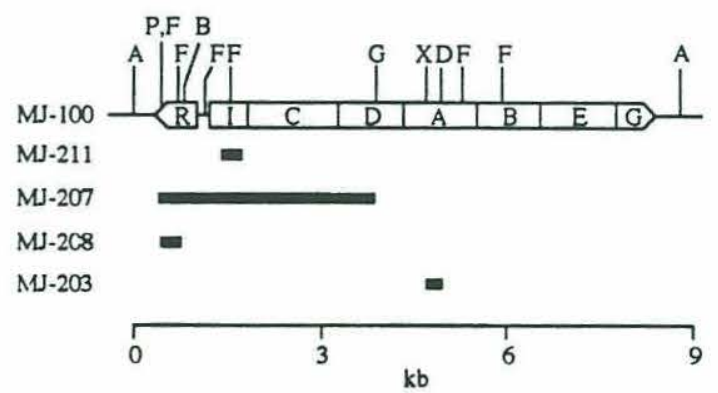

FIG. 1. The lux genes of $V$. fischeri and $V$. fischeri lux mutants constructed in this study. Solid bars indicate deletions. Restriction sites are denoted as follows: A, SalI; P, PstI; F, SfcI; B, XbaI; G, BglII; X. XhoI; D, NheI. Letters inside boxes indicate lux genes. 
ethanol and diluted into fresh medium. Samples were concentrated on an in-line $\mathrm{C}_{18}$ enrichment column and separated with a previously described reversed-phase high-pressure liquid chromatography (RP HPLC) system (21). Flow rate was $1 \mathrm{ml}$ $\mathrm{min}^{-1}$. Fractions were dried in a VR-I HetoVac with vacuum but without heat, dissolved in $10 \mu \mathrm{l}$ of ethanol, mixed with $3 \mathrm{ml}$ of autoinducer assay medium, and assayed for autoinducer activity with PD100(pPD749, pJR551) as described above. For gradient elutions, either $750 \mu \mathrm{l}$ of $l u x I$-conditioned medium, 3 $\mathrm{ml}$ of ain-conditioned medium, or an appropriate amount (1 $\mathrm{ng}$ to $2 \mu \mathrm{g})$ of a synthetic autoinducer compound $(N$ hexanoyl-L-HSL, $N$-3-oxohexanoyl-L-HSL, $N$-octanoyl-LHSL, N-3-oxooctanoyl-L-HSL, $N$-3-oxodecanoyl-L-HSL, or $N$-3-oxododecanoyl-L-HSL) was applied to the column. Mobile phase was composed of sodium phosphate $(10 \mathrm{mM}, \mathrm{pH} 7)$ and methanol, and the gradient was 0 to $100 \%$ (vol/vol) methanol over $8 \mathrm{~min}$. Fractions $(500 \mu \mathrm{l})$ were collected, and the luminescence of assay cultures was measured after a 2-h incubation. For isocratic separations, either $2 \mathrm{ml}$ of luxIconditioned medium, $500 \mu \mathrm{l}$ of ain-conditioned medium, or 5 $\mathrm{ng}$ of synthetic compound was applied. Mobile phase was composed of sodium phosphate and methanol. Fractions (250 $\mu \mathrm{l})$ were collected.

Purification of $V$. fischeri autoinducer-2 (AI-2). JM83(pAI004) ( ain $^{+}$; Table 1) was cultured at $28^{\circ} \mathrm{C}$ in $\mathrm{M} 9$ medium (1) supplemented with $0.8 \%$ glycerol, $1 \mathrm{mM} \mathrm{MgSO}_{4}, 230 \mathrm{mg}$ of L-proline liter ${ }^{-1}$, and $150 \mathrm{mg}$ of ampicillin liter ${ }^{-1}$ to an $A_{660}>3$, after which cells were removed from the medium by centrifugation in a Sorvall GS- 3 rotor at $4^{\circ} \mathrm{C}$ and $16,000 \times g$ for $30 \mathrm{~min}$. Then a peristaltic pump was used to pass 4 liters of culture supernatant through two in-series $60-\mathrm{ml}$ Varian Mega Bond Elut $\mathrm{C}_{18}$ columns at a flow rate of $2 \mathrm{ml} \mathrm{min}^{-1}$ at $4^{\circ} \mathrm{C}$. Columns were eluted with the following series of mixtures of water and increasing amounts (vol/vol) of methanol: fraction $1,100 \mathrm{ml}$ of $0 \%$ methanol; fraction $2,30 \mathrm{ml}$ of $25 \%$ methanol; fraction 3,20 $\mathrm{ml}$ of $50 \%$ methanol; fraction $4,10 \mathrm{ml}$ of $75 \%$ methanol; fraction $5,10 \mathrm{ml}$ of $75 \%$ methanol; fraction $6,10 \mathrm{ml}$ of $100 \%$ methanol; fraction $7,40 \mathrm{ml}$ of $100 \%$ methanol. Respective fractions from the two columns were pooled, and $10 \mu \mathrm{l}$ of each pooled fraction was assayed for autoinducer activity, which was found to be present in fractions 5 and 6 . These two fractions were pooled, rotoevaporated to dryness at $42^{\circ} \mathrm{C}$, redissolved in $10 \%$ methanol, filtered, and eluted isocratically with $40 \%$ phosphate buffer-60\% methanol by the HPLC system described above. Autoinducer-containing fractions were pooled, dried, dissolved in water, and eluted isocratically by RP HPLC with $50 \%$ phosphate buffer-50\% methanol. The resulting fractions were assayed for autoinducer activity, which occurred as a single peak at 10 to $13 \mathrm{~min}$. Active fractions were dried, dissolved in $200 \mu \mathrm{l}$ of water, and extracted twice with $200 \mu \mathrm{l}$ of acidified ethyl acetate. The resulting highly purified material was pooled, dried again, and stored at $-20^{\circ} \mathrm{C}$.

Mass spectrometry and NMR spectroscopy. For mass spectrometry, samples were analyzed with a VG AutoSpec-Q mass spectrometer by utilizing a desorption chemical ionization probe and electron impact ionization. Magnet scanning was at 3.4. $\mathrm{s}^{\text {decade }}$ d $^{-1}$ from 310 to $41 \mathrm{Da}$. Low-resolution spectra $(M / \Delta M=4,000)$ were acquired in the centroid mode, whereas high-resolution spectra $(M / \Delta M>10,000)$ were acquired in the continuum mode. For nuclear magnetic resonance (NMR) spectroscopy, ${ }^{1} \mathrm{H}$ spectra of samples dissolved in a deuterated solvent (methanol or chloroform) were obtained with a Bruker AC-300 NMR spectrometer.

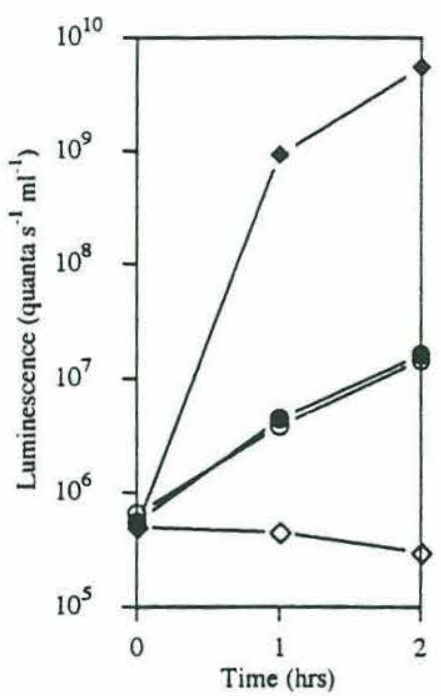

FIG. 2. Synthesis of autoinducer activity by luxI mutants of $V$. fischeri. Cell-free culture supernatants of MJ-100 $\left(l u x^{+}\right)$and two luxI deletion mutants, MJ-211 and MJ-207, were assayed for autoinducer. The medium was not conditioned $(\diamond)$ or was conditioned by MJ-100 $(\diamond)$, MJ-207 (O), or MJ-211 (•).

\section{RESULTS}

Production of autoinducer activity by $l u x I$ mutants of $V$. fischeri. Previously, in a study of lix gene regulation with lux::lacZ (Mu dI) gene replacement mutants of $V$. fischeri, we observed that a mutant defective in luxI, expected to produce no autoinducer, nonetheless exhibited lux operon transcriptional activation (8). To examine the basis for that activation, we constructed a $V$. fischeri luxI deletion mutant, MJ-211, containing an approximately 250 -bp nonpolar internal deletion in luxI (Fig. 1). The nonpolar nature of the deletion permitted transcription initiated from the luxICDABEG promoter to be monitored by luminescence, and the absence of foreign DNA (i.e., E. coli lacZYA and other genes of $\mathrm{Mu}$ dI present in lux::lacZ fusion mutants) avoided possible complications in interpreting results. Consistent with earlier results, luminescence in MJ-211 exhibited substantial lux operon transcriptional activation in the absence of added autoinducer. To determine if the luxI mutant actually produced autoinducer activity, cell-free supernatants of medium conditioned by the growth of MJ-211 were examined by a sensitive assay for autoinducers that activate expression of the $V$. fischeri luminescence system (9). Medium conditioned by MJ-211 activated lux operon expression (Fig. 2), suggesting that $V$. fischeri produced a second, luxI-independent autoinducer activity. To exclude the unlikely possibility that the remaining approximately 300 bp of luxI DNA in MJ-211 retained autoinducer synthase function, we constructed another mutant, MJ-207, in which the entire luxI gene and flanking sequences were removed (Fig. 1). Medium conditioned by MJ-207 gave results identical to those of MJ-211 (Fig. 2), demonstrating that the second autoinducer activity was independent of luxI. The autoinducer assay system did not respond to media conditioned by luminous bacteria closely related to $V$. fischeri (Photobucterium leiognathi LN-1a and $V$. harveyi B-392) or medium conditioned by $E$. coli JM83, indicating that the putative second autoinducer activity was die specifically to $V$. fischeri and not to a general conditioning effect.
The possibility, however, that the putative luxI-independent 


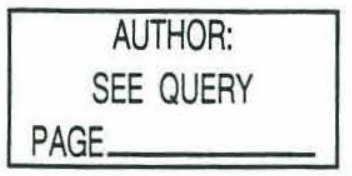

$a$

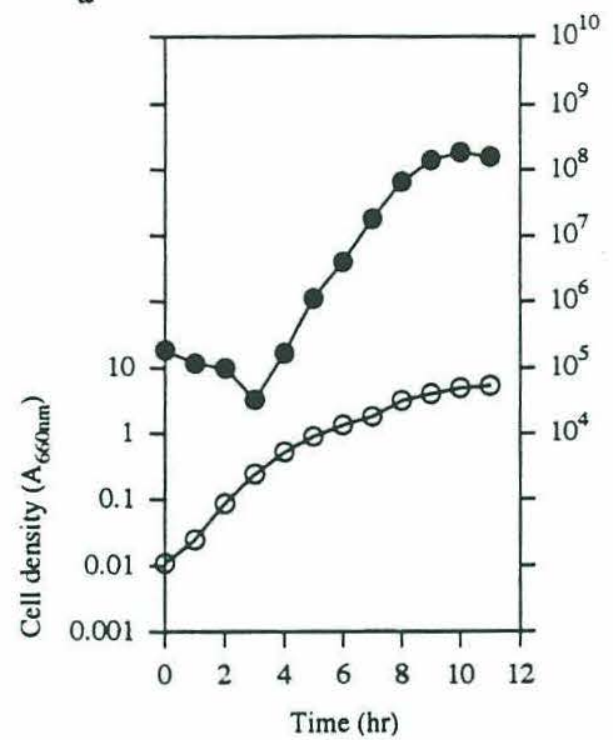

$b$

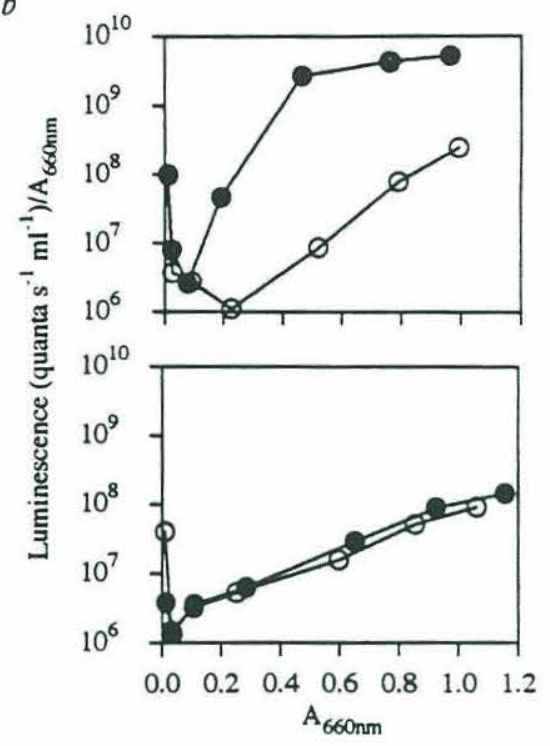

FIG. 3. Regulated synthesis of the luxI-independent autoinducer by $V$. fischeri and requirement of LuxR for lux operon transcriptional activation by the luxI-independent autoinducer. (a) Cells of $V$. fischeri MJ-211 ( $\Delta l u x I)$ were inoculated into $50 \mathrm{ml}$ of ASH broth, and cell density $(\bigcirc)$ and autoinducer activity $(\bullet)$ were monitored during culture growth. Autoinducer levels were measured as the luminescence response of autoinducer assay strain PD100(pPD749, pJR551) by using 2-ml samples of cell-free growth medium of the MJ-211 culture at each time point (see Materials and Methods). (b) Responses of luxI deletion mutant MJ-211 (upper panel) and luxR deletion mutant MJ-208 (lower panel) to the luxI-independent autoinducer activity. Open symbols denote responses to unconditioned medium, and solid symbols denote responses to medium conditioned by MJ-207.

autoinducer activity did not result from the synthesis of a second autoinducer but from a spurious conditioning effect on the autoinducer assay system specific to $V$. fischeri existed. For example, $V$. fischeri cells might have released into the medium a compound, such as an iron chelator, that led to a change in the copy number of the lux gene-containing plasmids (5) in the $E$. coli autoinducer assay strain or a compound that activated transcription from plasmid-borne promoter sequences which continued on into the lux operon. To rigorously exclude this possibility, we used an approach modeled after that employed to extract and chemically characterize the first $V$. fischeri autoinducer, $N$-3-oxohexanoyl-L-HSL (V. fischeri AI-1) (10). We found the luxI-independent autoinducer activity, like AI-1, to be extractable from conditioned medium with acidified ethyl acetate. Furthermore, the luxI-independent activity, extracted and concentrated by rotoevaporation, was active in a dosedependent manner and was destroyed by incubation at $\mathrm{pH} 12$ for $10 \mathrm{~min}$, like AI-1 (data not shown). Sensitivity to treatment with base suggested that the compound contained a lactone ring (10). Chemical similarities with AI-1 indicated that the luxI-independent activity was likely to be an autoinducer and not a spurious conditioning effect. This conclusion was supported by two additional similarities with AI-1, regulated synthesis of the luxI-independent activity and its requirement of LuxR for activity in the lux system, as described below.

Regulated synthesis of the luxI-independent autoinducer activity. In $V$. fischeri, the synthesis of AI-1 is regulated. The presence of luxI as part of the autoinducer-controlled lux operon results in an autocatalytic, positive-feedback loop for AI-1 synthesis, which leads to a rapid increase in the level of AI- 1 once lux operon induction is triggered $(5,11,13,15)$. To determine if synthesis of the luxI-independent autoinducer activity also might be regulated, we assayed the cell-free supernatant of an culture MJ-211 for luxI-independent autoinducer activity during growth. The level of activity was low initially and remained constant during the first few hours of culture growth. After the culture attained an $A_{660}$ of approximately 0.3 to 0.5 , however, the level of activity increased rapidly, at a rate faster than the rate of increase in cell density (Fig. 3a). These results suggest that the production of the luxI-independent autoinducer activity, like the production of AI- 1 , is inducible.

Requirement of LuxR for activity of the luxI-independent autoinducer. The experiments described above were conducted with $V$. fischeri and $E$. coli strains that contained an intact $l u x R$ gene, leaving open the possibility that the activation of lux operon transcription by the luxI-independent autoinducer, like activation of lux operon transcription by AI-1, required LuxR. To test this possibility, we examined the effect of medium conditioned by MJ-207 on luminescence in MJ-208 (Fig. 1), a $V$. fischeri strain with a deletion in luxR. Medium conditioned by MJ-207 stimulated luminescence in MJ-211 ( $\Delta l u x I)$ but had no effect on luminescence in MJ-208 (Fig. 3b), which demonstrated that the luxI-independent autoinducer activated lux operon transcription via LuxR. The above results, as well as the known limited tolerance of LuxR for autoinducer compounds structurally different from AI-1 (12), led us to conclude that the luxI-independent compound was likely to be an $N$-acyl-L-HSL chemically similar to AI- 1 . For these reasons, we termed the compound $V$. fischeri AI-2.

A genetic locus that directs the synthesis of AI-2. The production of AI-2 by luxI deletion mutants indicated that another autoinducer synthase gene was present in the $V$. fischeri chromosome. To isolate the locus containing that gene, we transformed a plasmid-borne MJ-1 chromosomal library (6) into JM83(pAK411), which bears the lux genes with the same 250-bp nonpolar deletion in luxI as MJ-211 (Table 1). By conferring luminescence on cells in the presence of an autoinducer, pAK411 served as a reporter for DNA fragments that directed the synthesis of autoinducers active in the $V$. fischer 

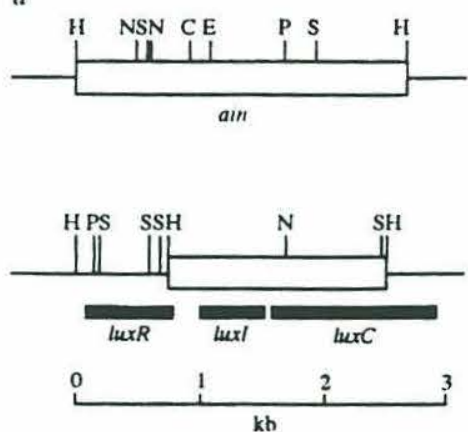

$b$

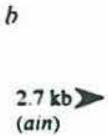

$1.8 \mathrm{~kb}\rangle$ (luxl)

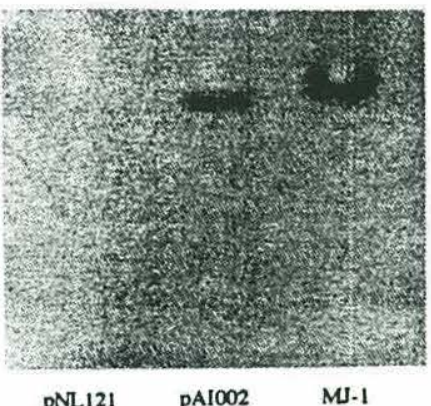

PNL121 PAI002 MJ-1

FIG. 4. Restriction map and Southern hybridization analysis of the novel $V$. fischeri autoinducer synthesis locus ain. The 2.7-kbp HindIII fragment containing ain was subcloned from the 10.5 -kbp insert of pAI002, isolated from a genomic library of MJ-1 DNA that had been inserted into the BamHI site of pSUP102 (6). (a) Physical maps of ain and luxI. Restriction sites are denoted as follows: H, HindIII; N, NsiI; S, SspI; C, ClaI; E, EcoRV; P, PstI. Black bars indicate lux genes. Open boxes indicate the 2.7- and 1.8-kbp HindIII fragments used as ain and luxI probes, respectively, in hybridization experiments. (b) Blot of HindIII digests of pNL121, pAI002, and MJ-1 genomic DNA, all probed with the 2.7-kbp ain fragment. In the reciprocal experiment, the 1.8-kbp luxI probe hybridized to same-sized HindIII fragments of pNL121 and MJ-1 DNA but did not hybridize to pAI002 (data not shown).

luminescence system. Two such fragments were found. Of approximately 50,000 transformant colonies screened for luminescence, 12 emitted high levels of light, and each of these was found by restriction analysis to have received a fragment containing luxI. Three others, however, emitted a low level of light that was consistent with the lower activation of luminescence by $\mathrm{AI}-2$ in the autoinducer assay (Fig. 2); each had received a $10.5-\mathrm{kbp}$ DNA fragment that by preliminary restriction analysis was distinct from luxI. This fragment contained a locus, designated ain (autoinducer), that was necessary and sufficient for JM83 to produce AI-2 (see below).

By subcloning, the ain locus was resolved to a 2.7-kbp HindIII fragment of the original $10.5-\mathrm{kbp}$ clone. The detailed restriction map of the $2.7-\mathrm{kbp}$ fragment differed unambiguously from that of the luxI region (Fig. 4a), and ain and luxI did not cross-hybridize (Fig. 4b), confirming that the two loci were distinct. The original $10.5-\mathrm{kbp}$ ain clone did not, however, restore luminescence to JM83(pAK408), with a lux gene plasmid with a deletion in luxR. Therefore, the $10.5-\mathrm{kbp}$ fragment did not express a protein that could substitute for LuxR in the $V$. fischeri luminescence system.

Chemical identity of AI-2. To chemically characterize AI-2, we fractionated media conditioned by $E$. coli and $V$. fischeri by RP HPLC and assayed fractions for autoinducer activity. From medium conditioned by JM83 containing ain, AI-2 was recovered in a fraction that eluted later (i.e., was more hydrophobic) than AI-1 from medium conditioned by JM83 containing luxI (Fig. 5a), indicating that AI-2 and AI-1 were chemically distinct compounds. Medium conditioned by MJ-207 yielded only AI-2, whereas medium conditioned by MJ-100 yielded AI-1, AI-2, and a second luxI-dependent autoinducer compound, AI-3 (data not shown). Furthermore, a $V$. fischeri ain gene replacement mutant failed to produce AI-2 but produced AI-1 and AI-3 (18). Thus, in E. coli as well as $V$. fischeri, the synthesis of AI-2 was dependent on the ain locus.

To chemically identify AI-2, we compared AI-2 chromatographically with several synthetic $N$-acyl-L-HSLs. Under RP HPLC gradient elution conditions, AI-2 separated unambiguously from most of the synthetic $N$-acyl-L-HSLs examined, including $N$-3-oxohexanoyl-L-HSL (AI-1), $N$-3-oxooctanoyl-LHSL (the $A$. tumefaciens autoinducer), and $N$-3-oxododecanoyl-L-HSL (the $P$. aeruginosa autoinducer) (Fig. 5a). A fourth previously identified autoinducer, $N$-3-hydroxybutanoyl-
L-HSL (the $V$. harveyi autoinducer), is a more hydrophilic compound that does not bind to the RP HPLC C ${ }_{18}$ columns (4) used here. Fractions of medium conditioned by $E$. coli containing ain in which the $V$. harveyi compound eluted if present (i.e., $0 \%$ methanol) exhibited no activity in the autoinducer assay. However, AI- 2 did coelute under the gradient conditions employed with two synthetic compounds, $N$-octanoyl-L-HSL, which was shown previously to activate expression of the $V$. fischeri luminescence system and to interfere with the activity of AI-1 (12), and N-3-oxodecanoyl-L-HSL (Fig. 5a).

To differentiate between these two candidate compounds, a higher-resolution isocratic elution system that unambiguously separated them was used. Under these conditions, AI-2 was indistinguishable from $N$-octanoyl-L-HSL but distinct from $N$-3-oxodecanoyl-L-HSL (Fig. 5b). These results suggested that AI-2 was $N$-octanoyl-L-HSL.

As $N$-octanoyl-L-HSL, AI-2 presumably lacked a 3-oxo group. Since most other known autoinducers contain a 3-oxo group, we sought to directly confirm the absence of this group in AI-2. We used a keto-group detection procedure that involved derivatization with 2,4-dinitrophenylhydrazine and separation and detection of the resulting hydrazones by RP HPLC and UV absorbance (22). To our knowledge, this is the first application of this method to studies of autoinducer chemical structure. Each of these $N$-3-oxoacyl-L-HSLs was detected as its corresponding hydrazone by this analysis, but AI- 2 was not detected, confirming its lack of a 3-oxo group (data not shown). We concluded that AI-2 is $N$-octanoyl-L-HSL, an $N$-acyl-LHSL compound that is structurally related to but distinct from other known autoinducers.

To confirm the identification of AI-2 as $N$-octanoyl-L-HSL. we used mass spectrometry to compare AI-2 purified from medium conditioned by the growth of JM83(pAI004) (see Materials and Methods) with synthetic $N$-octanoyl-L-HSL. The low-resolution mass spectrum of AI-2, with a molecular ion at $m / z=227.2$, was essentially identical to that of synthetic $N$-octanoyl-L-HSL, with minor contaminants (Fig. 6). The monotonically decreasing peaks at 156.1, 170.1, 184.1, 198.1, and 212.1 were consistent with a simple unbranched alkyl chain, confirming the absence of a 3-oxo or 3-hydroxy group. High-resolution mass spectrometry revealed that the $\mathrm{m} / \mathrm{z}$ of the molecular ion was 227.1513, which corresponded to the elemental composition of $\mathrm{N}$-octanoyl-L-HSL, $\mathrm{C}_{12} \mathrm{H}_{21} \mathrm{NO}_{3}$ (calcu- 

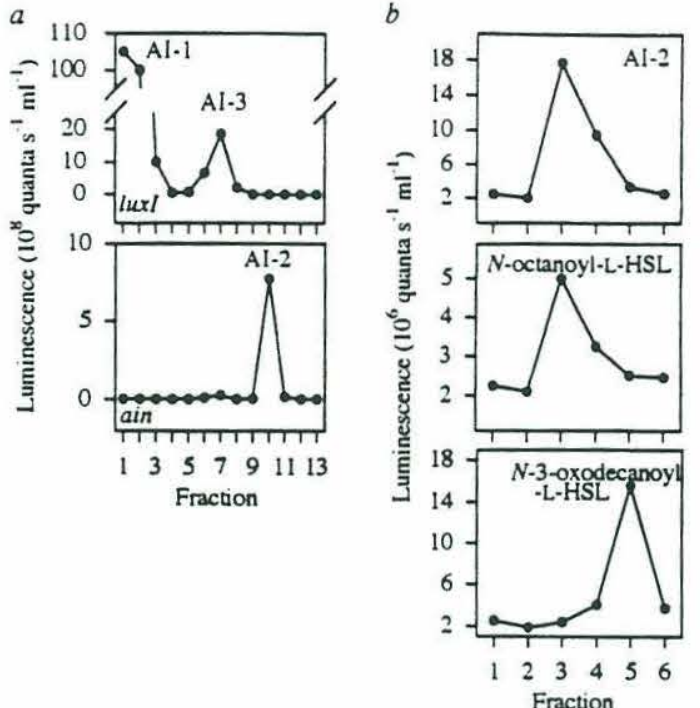

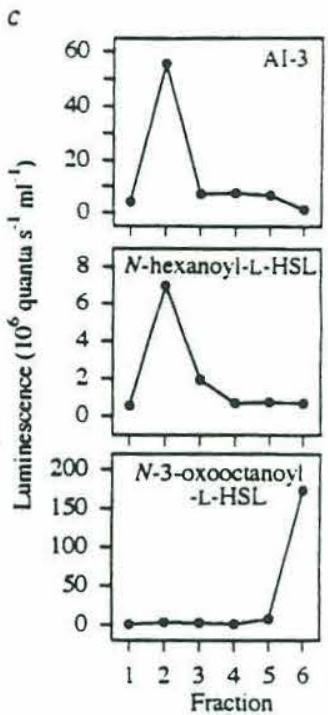

FIG. 5. Chromatographic identification of the novel ain-dependent autoinducer, AI-2, and a second luxI-dependent autoinducer, AI-3. (a) Gradient elution profiles of media conditioned by either luxI-expressing strain JM83(pJE202) (upper panel) or ain-expressing strain JM83(pAI004) (lower panel) and subjected to a methanol gradient. Synthetic $N$-acyl-L-HSLs eluted as follows: $N$-3-oxohexanoyl-L-HSL, fraction $2 ; N$-hexanoylL-HSL and $N$-3-oxooctanoyl-L-HSL, fraction 7; $N$-octanoyl-L-HSL and $N$-3-oxodecanoyl-L-HSL, fraction $10 ; N$-3-oxododecanoyl-L-HSL, fraction 12. (b) Isocratic separation (30\% phosphate buffer-70\% methanol) of JM83(pAI004)-conditioned medium and synthetic $N$-octanoyl-L-HSL and $\mathrm{N}$-3-oxodecanoyl-L-HSL. (c) Isocratic elution (47\% phosphate buffer-53\% methanol) of JM83(pJE202)-conditioned medium and synthetic $N$-hexanoyl-L-HSL and $N$-3-oxooctanoyl-L-HSL.

lated $m / z=227.1521)$. The $m / z$ of the base peak, 143.0576 , also observed in mass spectra of $\mathrm{AI}-1$ and the $P$. aeruginosa autoinducer $(2,10,25)$, corresponded to the rearrangement product, $\mathrm{C}_{6} \mathrm{H}_{9} \mathrm{NO}_{3}$ (calculated $m / z=143.0582$ ).

To further confirm the structure of AI-2, we subjected the purified compound to NMR spectroscopy. The ${ }^{1} \mathrm{H}$ NMR spectrum of AI-2 matched that of synthetic $N$-octanoyl-L-HSL. The peak assignments of AI-2 in deuterated methanol were consistent with an unbranched octanoyl moiety for the following carbon designations (Fig. 7): a, $\delta_{\mathrm{H}}=2.20, \mathrm{t}, 2 \mathrm{H} ; \mathrm{b}, \delta_{\mathrm{H}}=$ $1.59, \mathrm{t}, 2 \mathrm{H} ; \mathrm{c}, \delta_{\mathrm{H}}=1.29$, broad s, $8 \mathrm{H} ; \mathrm{d}, \delta_{\mathrm{H}}=0.87, \mathrm{t}, 3 \mathrm{H}$. Observed peaks diagnostic of HSL were as follows: $\alpha, \delta_{\mathrm{H}}=$ $4.55, \mathrm{~m}, 1 \mathrm{H} ; \beta_{1}, \delta_{\mathrm{H}}=2.50, \mathrm{~m}, 1 \mathrm{H} ; \beta_{2}, \delta_{\mathrm{H}}=2.25, \mathrm{~m}, 1 \mathrm{H} ; \delta_{1}, \delta_{\mathrm{H}}$ $=4.42, \mathrm{~m}, 1 \mathrm{H} ; \gamma_{2}, \delta_{\mathrm{H}}=4.26, \mathrm{~m}, 1 \mathrm{H}$.

The biological activity of AI-2 also matched that of $N$ octanoyl-L-HSL. Over the concentration range tested, 10 to $1,000 \mathrm{nM}$, the autoinducer assay system responded identically to purified AI-2 and synthetic N-octanoyl-L-HSL (data not shown).

Chemical identity of a third $V$. fischeri autoinducer. Conducting RP HPLC analyses of conditioned media, we found that $V$. fischeri produced a third autoinducer activity, AI-3. AI-3 exhibited by RP HPLC a hydrophobicity that was intermediate between those of $N$-3-oxohexanoyl-L-HSL and $N$ octanoyl-L-HSL, indicating it was chemically distinct from AI-1 and AI-2. JM83 containing luxI produced this activity (Fig. 5a), but JM83 containing the lux genes with a deletion in luxI did not. Furthermore, neither JM83 containing only ain nor MJ207 produced AI-3. Thus, AI-3, like AI-1, was dependent on luxI for its synthesis. The RP HPLC gradient elution profile of AI-3 was consistent with it being either $N$-hexanoyl-L-HSL, which had been previously shown to activate expression of the $V$. fischeri luminescence system and to inhibit the activity of AI-1 (12), or N-3-oxooctanoyl-L-HSL, the A. tumefaciens autoinducer (Fig. 5a). Under a higher-resolution isocratic elution
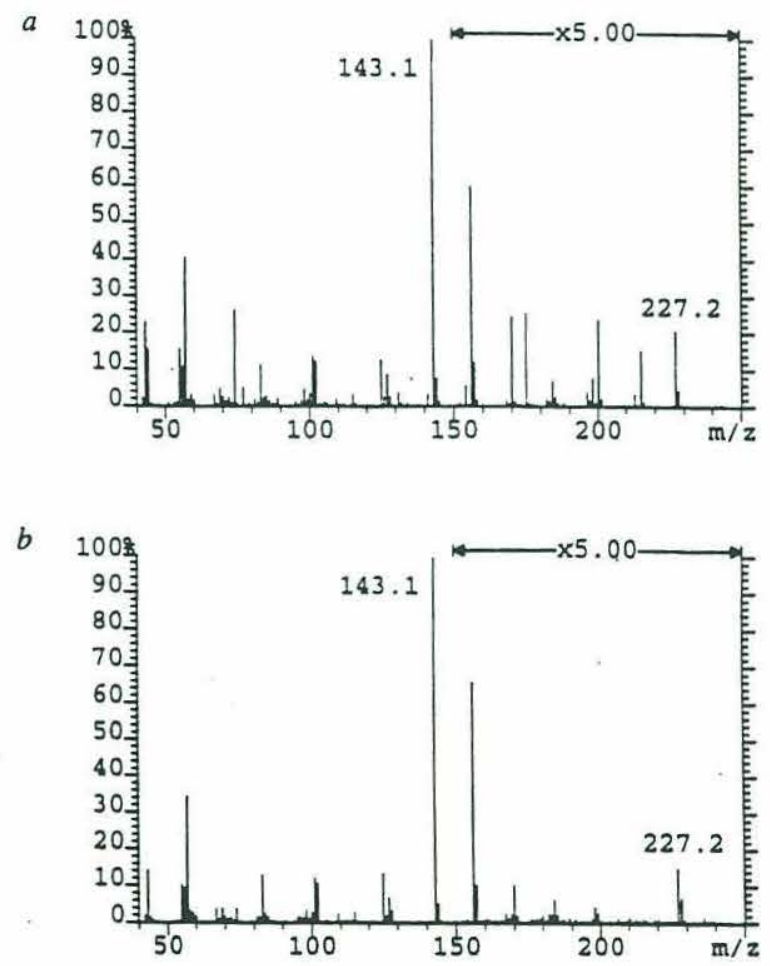

FIG. 6. Mass spectrometric analysis of $V$. fischeri AI-2. Low-resolution mass spectra of AI-2 purified from cell-free supernatant of $E$. coli JM83(pAID04) (a) and synthetic $N$-octanoyl-L-HSL (b). Peaks corresponding to the molecular ion $(m / z=227.2)$ and rearrangement product $\mathrm{C}_{6} \mathrm{H}_{9} \mathrm{NO}_{3}(m / z=143.1)$ are indicated. AI- 2 was purified as described in Materials and Methods. 


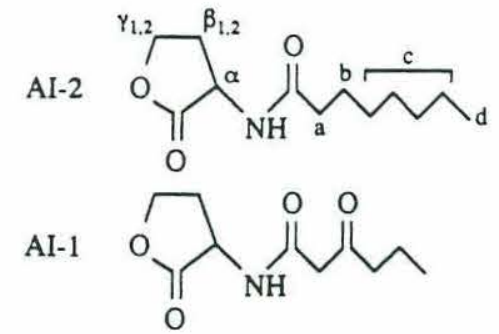

FIG. 7. Structural comparison of $V$. fischeri AI-2 ( $N$-octanoyl-LHSL) and AI-1 ( $N$-3-oxohexanoyl-L-HSL). Carbon designations refer to proton assignments from NMR spectra described in the text.

regimen, the coelution of AI-3 with the synthetic compound identified it as $N$-hexanoyl-L-HSL (Fig. $5 \mathrm{c}$ ). Thus, $V$. fischeri cells produced three chemically distinct autoinducers with activity in the lux system, AI-1 ( $N$-3-oxohexanoyl-L-HSL) and AI-3 ( $N$-hexanoyl-L-HSL), both of which are dependent on luxI for synthesis, and AI-2 ( $N$-octanoyl-L-HSL), whose synthesis is dependent on the novel locus ain. The relative activities of autoinducer-containing RP HPLC fractions of medium conditioned by MJ-100 were $1.000,0.033$, and 0.167 for AI- $1, \mathrm{AI}-2$, and AI-3, respectively.

\section{DISCUSSION}

In this study, we have identified a novel autoinducer of luminescence, $N$-octanoyl-L-HSL (AI-2), that is produced by the marine symbiotic bacterium $V$. fischeri and have isolated from the $V$. fischeri genome a novel locus, ain, that is involved in the synthesis of AI-2. This is the first report in which a second autoinducer from a bacterial species has been chemically identified and the gene directing its synthesis has been isolated. The ain locus and AI-2, acting via LuxR, constitute a third level of population density-responsive control of lux gene expression in $V$. fischeri, one that could supplement or inhibit transcriptional control by $N$-3-oxohexanoyl-L-HSL (AI- 1 ) and enhance the mechanistically undefined effect of autoinducerLuxR-independent modulation (8). We also have identified a second previously unrecognized autoinducer of luminescence in $V$. fischeri, $N$-hexanoyl-L-HSL (AI-3), whose synthesis, like that of AI-1, is dependent on luxI. Therefore, population density-responsive control of lux gene expression in $V$. fischeri is substantially more complex than previously envisioned.

The construction of $V$. fischeri mutants with defects in luxI, which eliminated the synthesis of AI-1 by these strains, led to the detection of AI-2, and isolation of the ain locus was facilitated by the use of a lux gene-containing plasmid with a nonpolar deletion in luxI, which served as a reporter for DNA fragments that directed the synthesis of autoinducers active in the $V$. fischeri luminescence system. These approaches may find applications with other autoinducer-utilizing bacteria to detect the presence of multiple autoinducers and to isolate the genes involved in the synthesis of them.

In this regard, other bacteria are likely to contain more than one autoinducer synthase gene and to synthesize more than one autoinducer. In $V$. harveyi, genetic evidence for an activity in addition to $N$-3-hydroxybutanoyl-L-HSL controlling luminescence has been obtained, although neither the chemical structure of the second activity nor the gene responsible for its synthesis has been identified (3). Furthermore, A. tumefaciens and $P$. aeruginosa apparently synthesize more than one autoinducer activity $(25,32)$.

Like autoinducers identified from other species of bacteria
(2, 4, 25, 32), $V$. fischeri AI-2 and AI-3, as $N$-acyl-L-HSLs, are structurally similar to $V$. fischeri AI-1 (Fig. 7). Besides the chemical similarity of autoinducers, in many cases, the genes encoding the autoinducer synthases and autoinducer receptor proteins from these other bacteria exhibit sequence similarity to $V$. fischeri luxI and $l u x R$, respectively $(16,17,24,26,27)$. The ain locus, however, exhibits no obvious sequence similarity to luxI (18), suggesting that it arose independently. With respect to a possible AI-2-specific transcriptional activator analogous or homologous to $\operatorname{lux} R$, we know at this point only that the original $10.5-\mathrm{kbp}$ ain fragment did not restore luminescence to $E$. coli carrying a lux plasmid with a deletion in luxR, indicating that this fragment does not express a protein that can substitute for LuxR in the $V$. fischeri luminescence system. The putative protein might not be expressed by $E$. coli or might not recognize the lux operator, or its gene might be incomplete on the 10.5 -kbp fragment or occur elsewhere in the $V$. fischeri chromosome.

The total amounts of each of the three autoinducers produced by $V$. fischeri were such that they exhibited activity in the luminescence system as AI-1 > AI-3 > AI-2, which is consistent with $\mathrm{AI}-1$ as the primary autoinducer of luminescence. Besides controlling luminescence in $V$. fischeri, the different autoinducers encoded by the two autoinducer synthase genes also might function either separately or cooperatively to control various other cellular responses to the high population densities this bacterium encounters in light-organ symbiosis and other habitats (23). On the basis of the smaller effect of $\mathrm{AI}-2$ on luminescence compared with those of AI-1 and AI-3, one possibility is that the activation of luminescence by AI- 2 is incidental to its principal function, that of controlling a set(s) of genes distinct from those involved in light production. Identification of these genes and a transcriptional activator specific to AI-2 would add substantial insight into cellular responses to high population density in $V$. fischeri.

A striking feature of the $V$. fischeri luminescence system is the versatility of LuxR and LuxI seen in this study. LuxR recognized a wide range of chemically distinct $N$-acyl-L-HSLs, including the three different compounds produced by $V$. fischeri (AI-1, AI-2, and AI-3) (Fig. 5), the chemically distinct autoinducers produced by $A$. tumefaciens and $P$. aeruginosa, and three other compounds ( $N$-3-oxodecanoyl-L-HSL, $N$-decanoyl-L-HSL, and $N$-nonanoyl-L-HSL) (data not shown). A reasonable explanation for this versatility is that LuxR recognizes both of the main structural elements of autoinducers, the HSL and hydrophobic acyl moiety, but its level of activity is strongly influenced by the length and composition of the acyl group (12). Similarly, LuxI catalyzed a critical step in the synthesis of two distinct autoinducers that differed only in the structure of the acyl group. This versatility presumably reflects the ability of LuxI to recognize two alternative fatty acyl substrates, as well as reflecting the presence of those substrates in $V$. fischeri and $E$. coli. The versatility of LuxR and LuxI, together with our demonstration of a second autoinducer system in $V$. fischeri, implies that autoinduction of luminescence and other bacterial population density-responsive activities may be the summation of an unexpectedly complex network of multiple cross-acting regulatory elements.

\section{ACKNOWLEDGMENTS}

We thank D. Lynn for the generous gift of synthetic autoinducers, S. Caron for technical assistance with RP HPLC, C. Johnson for conducting the mass spectrometry and NMR spectroscopy experiments, and L. Gilson for comments on the manuscript.

This work was supported by the Woods Hole Oceanographic Institution Ocean Ventures Fund (A.K.), Office of Naval Research 


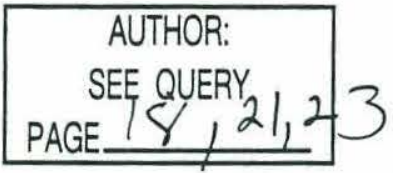

J. BACTERIOL.

grant N00014-89-J-1260 (N.V.B.), and National Science Foundation grants MCB 91-04653 and MCB 94-08266 (P.V.D.).

\section{REFERENCES}

1. Ausubel, F. M., R. Brent, R. E. Kingston, D. D. Moore, J. A. Smith, J. G. Seidman, and K. Struhl. 1987. Current protocols in molecular biology. John Wiley, New York.

2. Bainton, N. J., P. Stead, S. R. Chhabra, B. W. Bycroft, G. P. C. Salmond, G. S. A. B. Stewart, and P. Williams. 1992. N-(3Oxohexanoyl)-L-homoserine lactone regulates carbapenem antibiotic production in Enwinia carotova. Biochem. J. 288:997-1004.

3. Bassler, B. L., M. Wright, R. E. Showalter, and M. R. Silverman 1993. Intercellular signalling in Vibrio harveyi: sequence and function of genes regulating expression of luminescence. Mol. Microbiol. 9:773-786.

4. Cao, J., and E. A. Meighen. 1989. Purification and structural identification of an autoinducer for the luminescence system of Vibrio harveyi. J. Biol. Chem. 264:21670-21676.

5. Dunlap, P. V. 1992. Mechanism for iron control of the Vibrio fischeri luminescence system: involvement of cyclic AMP and cyclic AMP receptor protein and modulation of DNA level. J. Biolumin. Chemilumin. 7:203-214.

6. Dunlap, P. V., and S. M. Callahan. 1993. Characterization of a periplasmic $3^{\prime}: 5^{\prime}$-cyclic nucleotide phosphodiesterase gene, $c p d P$, from the marine symbiotic bacterium Vibrio fischeri. J. Bacteriol. 175:4615-4624.

7. Dunlap, P. V., and E. P. Greenberg. 1988. Control of Vibrio fischer lux gene transcription by a cyclic AMP receptor protein-LuxR protein regulatory circuit. J. Bacteriol. 170:4040-4046.

8. Dunlap, P. V., and A. Kuo. 1992. Cell density-dependent modulation of the Vibrio fischeri luminescence system in the absence of autoinducer and LuxR protein. J. Bacteriol. 174:2440-2448.

9. Dunlap, P. V., and J. M. Ray. 1989. Requirement for autoinducer in transcriptional negative autoregulation of the Vibrio fischeri luxR gene in Escherichia coli. J. Bacteriol. 171:3549-3552.

10. Eberhard, A., A. L. Burlingane, C. Eberhard, G. L. Kenyon, K. H. Nealson, and N. J. Oppenheimer. 1981. Structural identification of autoinducer of Photobacterium fischeri luciferase. Biochemistry 20:2444-2449.

11. Eberhard, A., T. Longin, C. A. Widrig, and S. J. Stranick. 1991. Synthesis of the lux gene autoinducer in Vibrio fischeri is positively autoregulated. Arch. Microbiol. 155:294-297.

12. Eberhard, A., C. A. Widrig, P. McBath, and J. B. Schineller. 1986. Analogs of the autoinducer of bioluminescence in Vibrio fischeri. Arch. Microbiol. 146:35-40.

13. Engebrecht, J., K. Nealson, and M. Silverman. 1983. Bacterial bioluminescence: isolation and genetic analysis of functions from Vibrio fischeri. Cell 32:773-781.

14. Engebrecht, J., and M. Silverman. 1984. Identification of genes and gene products necessary for bacterial bioluminescence. Proc. Natl. Acad. Sci. USA 81:4154-4158.

15. Friedrich, W. F., and E. P. Greenberg. 1983. Glucose repression of luminescence and luciferase in Vibrio fischeri. Arch. Microbiol. 134:87-91.
16. Fuqua, W. C., and S. C. Winans. 1994. A LuxR-LuxI type regulatory system activates Agrobacterium $\mathrm{Ti}$ plasmid conjugal transfer in the presence of a plant tumor metabolite. J. Bacteriol. 176:2796-2806.

17. Gambello, M. J., and B. H. Iglewski. 1991. Cloning and characterization of the Pseudomonas aeruginosa las $R$ gene, a transcriptional activator of elastase expression. J. Bacteriol. 173:3000-3009.

18. Gilson, L., A. Kuo, and P. V. Dunlap. Unpublished data.

19. Huisman, G. W., and R. Kolter. 1994. Sensing starvation: a homoserine lactone-dependent signalling pathway in Escherichia coli. Science 265:537-539.

20. Kaplan, H. B., and E. P. Greenberg. 1985. Diffusion of autoinducer is involved in regulation of the Vibrio fischeri luminescence system. J. Bacteriol. 163:1210-1214.

21. Kieber, D. J., and N. V. Blough. 1990. Determination of carboncentered radicals in aqueous solution by liquid chromatography with fluorescence detection. Anal. Chem. 62:2275-2283.

22. Kieber, D. J., and K. Mopper. 1986. Trace determination of $\alpha$-keto acids in natural waters. Anal. Chim. Acta 183:129-140.

23. Nealson, K. H., and J. W. Hastings. 1992. The luminous bacteria, p. 625-639. In A. Balows, H. G. Trüper, M. Dworkin, W. Harder, and K.-H. Schleifer (ed.), The prokaryotes, 2nd ed. SpringerVerlag, Berlin.

24. Passador, L., J. M. Cook, M. J. Gambello, L. Rust, and B. H. Iglewski. 1993. Expression of Pseudomonas aeruginosa virulence genes requires cell-to-cell communication. Science 260:1127-1130.

25. Pearson, J. P., K. M. Gray, L. Passador, K. D. Tucker, A. Eberhard, B. H. Iglewski, and E. P. Greenberg. 1994. Structure of the autoinducer required for expression of Pseudomonas aeruginosa virulence genes. Proc. Natl. Acad. Sci. USA 91:197-201.

26. Piper, K. R., S. B. von Bodman, and S. K. Farrand. 1993. Conjugation factor of Agrobacterium tumefaciens regulates Ti plasmid transfer by autoinduction. Nature (London) 362:448-450.

27. Pirhonen, M., D. Flego, R. Heikinheimo, and E. T. Palva. 1993. A small diffusible signal molecule is responsible for the global control of virulence and exoenzyme production in the plant pathogen Envinia carotovora. EMBO J. 12:2467-2476.

28. Ruby, E. G., and K. H. Nealson. 1976. Symbiotic association of Photobacterium fischeri with the marine luminous fish Monocentris japonica: a model of symbiosis based on bacterial studies. Biol. Bull. (Woods Hole) 141:574-586.

29. Simon, R., M. O'Connell, M. Labes, and A. Pühler. 1986. Plasmid vectors for the genetic analysis and manipulation of rhizobia and other gram-negative bacteria. Methods Enzymol. 118:640-659.

30. Swartzman, E., S. Kapoor, A. F. Graham, and E. A. Meighen. 1990. A new Vibrio fischeri lux gene precedes a bidirectional termination site for the lux operon. J. Bacteriol. 172:6797-6802.

31. Yanisch-Perron, C., J. Vieira, and J. Messing. 1985. Improved M13 phage cloning vectors and host strains: nucleotide sequences of the M13mp18 and pUC19 vectors. Gene 33:103-119.

32. Zhang, Lo, P. J. Murphy, A. Kerr, and M. E. Tate. 1993. Agrobacterium conjugation and gene regulation by $\mathrm{N}$-acyl-L-homoserine lactones. Nature (London) 362:446-448. 


\title{
Chapter 4. Negative regulation of luminescence by $\mathbf{N}$-octanoyl-L-homoserine lactone, a Vibrio fischeri autoinducer
}

\begin{abstract}
The symbiotic bacterium Vibrio fischeri synthesizes three different cell-cell signalling molecules, or autoinducers, that individually interact with LuxR to activate transcription of the luminescence genes. The autoinducer with highest activity, AI-1 $(\mathrm{N}$ 3-oxohexanoyl-L-homoserine lactone), requires luxI for its synthesis, while the autoinducer with lowest activity, AI-2 ( $N$-octanoyl-L-homoserine lactone) requires ain for its synthesis. To determine the role of AI-2 in autoinduction, ain and ain luxI null mutants of $V$. fischeri were constructed. Light emission by the ain luxI mutant was very low but was stimulated by exogenous AI-2, confirming the ability of AI-2 to induce luminescence. However, the ain mutant exhibited a more rapid induction of luminescence relative to the wild-type strain. Also, induction in both the ain mutant and the wild-type was inhibited by physiological concentrations of exogenous AI-2. These results suggested that AI-2 is an inhibitor of luminescence induction. The cloned luminescence genes, which are functional in Escherichia coli, were used to show that the inhibitory property of AI-2 can be at least partly attributed to interference with AI-1mediated induction of luminescence, but not to repression of luxR transcription. Thus AI2 , a minor inducer of luminescence, is also an inhibitor of AI-1 activity, and so mediates an additional level of control of luminescence.
\end{abstract}




\section{INTRODUCTION}

Autoinduction is a cell density-responsive intercellular signal and gene regulatory system first described in luminescent bacteria (Nealson et al 1970). Though subsequently discovered to regulate diverse cellular functions in diverse proteobacteria, including Agrobacterium tumefaciens and Pseudomonas aeruginosa (Zhang et al 1993, Pearson et al 1994), the mechanism of autoinduction is best understood in the marine light organ symbiont Vibrio fischeri, where it regulates luminescence. In a log-phase batch culture, luminescence per cell at first decreases, then rises rapidly $10^{3}-4$-fold as the culture approaches stationary phase. This cell density-dependent activation of luminescence operon (luxICDABEG) transcription requires luxI and luxR (Engebrecht et al 1983). LuxI is the putative synthase of a membrane-permeable signal molecule (the autoinducer, $\mathrm{N}-3$ oxohexanoyl-L-homoserine lactone, $N$-3-oxohexanoyl-L-HSL), and LuxR is putatively both the autoinducer receptor and the activator of lux transcription (Eberhard et al 1981, Engebrecht and Silverman 1984). The lux operator, to which LuxR presumably binds, is located between luxR and the luxICDABEG operon, which are divergently transcribed (Engebrecht et al 1983, Devine et al 1989). The putative AI-1-LuxR complex both activates transcription of $l u x I C D A B E G$ and represses transcription of $l u x R$. This LuxR autorepression is probably effected by steric hindrance of Crp (cyclic AMP receptor protein)-mediated activation of luxR transcription (Dunlap and Greenberg 1988, Dunlap and Ray 1989, Shadel et al 1991).

The above model was established through study of $V$. fischeri genes cloned into Escherichia coli. Subsequent studies using $V$. fischeri mutants confirmed all elements of the model examined, but also revealed novel aspects of luminescence regulation. For example, the $V$. fischeri lux operon exhibits a modulation that is independent of and underlies autoinduction (Dunlap and Kuo 1992). Also, V. fischeri synthesizes three different autoinducers, called AI-1 ( $N$-3-oxohexanoyl-L-HSL), AI-2 ( $N$-octanoyl-L-HSL), and AI-3 ( $N$-hexanoyl-L-HSL) (Kuo et al 1994). As with AI-1, synthesis of AI-2 is induced in a cell density-dependent manner. Also like AI-1, AI-2 interacts with LuxR to stimulate luminescence in E. coli and $V$. fischeri. Unlike AI-1, AI-2 is dependent not on luxI for its synthesis but on the distinct autoinducer synthesis locus ain.

Total AI-2 autoinducer activity in dense cultures of $V$. fischeri is only one-thirtieth that of AI-1 (Kuo et al 1994), implying that AI-2 is likely to make a very minor contribution to autoinduction. To rigorously demonstrate this suggestion, I constructed ain (AI-2-) mutants of $V$. fischeri. Here I use these mutants to show that AI-2 primarily 
inhibits rather than supplements autoinduction, and that this inhibiton can be attributed to inhibition of AI-1 activity. 


\section{MATERIALS AND METHODS}

Strains and plasmids. MJ-100 is a spontaneously nalidixic acid (Nx)-resistant isolate of the wild-type $V$. fischeri strain MJ-1 (Dunlap and Kuo 1992, Ruby and Nealson 1976). MJ-211 is a nonpolar luxI deletion mutant derived from MJ-100 (Kuo et al 1994). It synthesizes AI-2 but not AI-1 or AI-3, and thus emits a low but visible amount of light that appears to be induced in a cell density-dependent manner (Fig. 1a). Other $V$. fischeri mutants are described below and in Table 1. E. coli PD100(pJR551,pPD749) is the basis for the most sensitive autoinducer assay of which we know (Dunlap and Ray 1989). E. coli JM83 (Yanisch-Perron et al 1985) was used for most cloning manipulations, which followed standard procedures (Ausubel et al 1987).

pAK411 contains the lux locus from MJ-1 but with a nonpolar deletion in luxI (identical to that of MJ-211), and cloned into the ampicillin resitance (Apr), $\operatorname{Inc}(\mathrm{pMB} 1$ ) plasmid pBR322 (Kuo et al 1994). pAK411 allows JM83 to luminesce, but only in the presence of a source of autoinducer. pJR551 contains the lux region cloned into the chloramphenicol resistance $\left(\mathrm{Cm}^{\mathrm{r}}\right)$, Inc(p15A) plasmid pACYC184, with a nonpolar mutation in luxI and a luxR::lacZ operon fusion (Dunlap and Ray 1989). pAK011 is a $11.8 \mathrm{~kb} B g l \mathrm{II}$ fragment from pJR551, containing $l u x I^{-}$and $l u x R:$ :lacZ, cloned into the BamHI site of pSUP102, a $\mathrm{mob}^{+}$derivative of pACYC184 (Simon et al 1986). pPD749 has luxR under the control of the lactose-inducible high-expression promoter $\mathrm{P}_{t a c}$ (Dunlap and Greenberg 1988). pAI009 is a $2.7 \mathrm{~kb}$ HinDIII fragment containing ain cloned from MJ-1 into pSUP102, and directs synthesis of AI-2 in JM83 (Gilson et al). Other plasmids were constructed using standard procedures (Ausubel et al 1987) and are described below and in Table 1. The neo cassette was the $1.8 \mathrm{~kb}$ BamHI-HinDIII fragment from Mu dI 1734 (Castilho et al 1984) and conferred kanamycin resistance $\left(\mathrm{Km}^{\mathrm{r}}\right)$ on $E$. coli and neomycin resistance $\left(\mathrm{Nm}^{\mathrm{r}}\right)$ on $V$. fischeri.

Culture techniques. E. coli was cultured on LB medium with $50 \mathrm{mM}$ Tris (pH 7.5). V. fischeri was maintained on LBS (Dunlap 1989) plates with $\mathrm{Nx}$, while liquid cultures were grown in ASH medium without antibiotics (Dunlap and Kuo 1992). Growth was monitored by measuring absorbance at $660 \mathrm{~nm}\left(A_{660}\right)$ while luminescence was measured as described previously (Dunlap and Kuo 1992). $\beta$-galactosidase activity was assayed using standard procedures (Miller 1992) with four replicates (range < 10\%). Autoinducer activity was assayed by measuring the luminescence response of PD100(pJR551,pPD749) in autoinducer assay medium, as described previously (Kuo et al 1994, Dunlap and Ray 1989). Except where indicated otherwise, antibiotics were used 
Table 1. Strains and plasmids used in this study.

Strain or

Plasmid Relevant genotypic and phenotypic characters

Source

Strains

V. fischeri

MJ-1 Lux ${ }^{+}$

MJ-100 MJ-1, Nx

MJ-211 MJ-100, $\Delta l u x I$ ( 250 bp nonpolar deletion)

MJ-215 MJ-211, ain- (2 bp insertion)

MJ-216 MJ-100, ain::neo (1.8 kb Nm cassette)

E. coli

JM83 $\Delta$ (lac-pro)

PD100 zah-735::Tn10A (argF-lac)U169, Tc ${ }^{\mathrm{r}}$

Ruby and Nealson 1976

Dunlap and Kuo 1992

Kuo et al 1994

This study

This study

Yanisch-Perron et al 1985

Dunlap and Greenberg 1988

Plasmids

pPD749 $\mathrm{P}_{\text {tac }}$-luxR, lacI $\mathrm{q}, \mathrm{Ap}^{\mathrm{r}}$

Dunlap and Greenberg 1988

pJR551 pACYC184 with luxR:Mu $\triangle(c, n e r A B)$ dI1681

Dunlap and Ray 1989b

(lacZYA, $\mathrm{Km}^{\mathrm{s}}$ ) and $l u x I C D A B E$ with a nonpolar

mutation in luxI, $\mathrm{Cm}^{\mathrm{r}}$

pSUP102 pACYC184 with RP4 $\mathrm{mob}^{+}, \mathrm{Cm}^{\mathrm{r}} \mathrm{Tc} \mathrm{c}^{\mathrm{r}}$

Simon et al 1986

pAK011 pSUP102 with $11.8 \mathrm{~kb}$ BglII fragment from pJR551,

This study

luxR::lacZ luxI- lux $C^{+}$

pAK411 pBR322 with luxRICDABE fragment with $\sim 250 \mathrm{bp}$

Kuo et al 1994

nonpolar deletion in luxI, Ap ${ }^{r}$

pAI009 pSUP102 with ain

Gilson et al

pAI014 pAI009 with ain::neo, $\mathrm{Km}^{\mathrm{r}}$

This study

pAI015 pAI009 with 2 bp insertion in ain

This study 
at the following concentrations: $\mathrm{Nx}, 20 \mathrm{mg} \mathrm{l}^{-1} ; \mathrm{Ap}, 150 \mathrm{mg} \mathrm{l}^{-1} ; \mathrm{Cm}, 34 \mathrm{mg} \mathrm{l}^{-1} ; \mathrm{Km}, 20 \mathrm{mg}$ ${ }^{-1} ; \mathrm{Nm}, 200 \mathrm{mg} \mathrm{l}^{-1}$.

Genetic and chemical methods. $V$. fischeri autoinducer synthesis mutants were constructed using the $V$. fischeri gene transfer procedure described previously (Dunlap and Kuo 1992): generally, the targeted $V$. fischeri genes were cloned into pSUP102, engineered in JM83, verified by restriction analysis, and introduced to a $\mathrm{Nx}^{\mathrm{r}} V$. fischeri strain. The desired $\mathrm{Nx}^{\mathrm{r}} \mathrm{Cm}^{\mathrm{s}}$ recombinants were identified with an appropriate screen, and confirmed by Southern hybridizations following established procedures (Kuo et al 1994), and suitable phenotypic tests (see below). In the case of autoinducer synthesis mutants, conditioned media were assayed for autoinducer activity. Where distinction between the different $V$. fischeri autoinducers was required, autoinducer assays were applied to fractions of conditioned media separated by high-pressure liquid chromatography (HPLC), as described previously (Kuo et al 1994). Where a culture was treated with exogenous AI-1 or AI-2, synthetic N-3-oxohexanoyl-L-HSL or $N$-octanoylL-HSL, respectively, was dissolved in chloroform, added to the culture tube, and dried before addition of culture medium and bacteria.

Construction of ain mutants. The ain $^{-}$plasmid pAI015 was constructed by digesting pAI009 with ClaI (one site in ain, one site in vector; Gilson et al), blunt-ending, gel-purifying singly-cut plasmid, and ligating. The resulting plasmid theoretically has a frameshifting $2 \mathrm{bp}$ insertion in ain. JM83(pAI015) was $\mathrm{Cm}^{r} \mathrm{AI}^{-}$. The $V$. fischeri ain $\Delta l u x I$ double mutant MJ-215 was constructed by introducing pAI015 to MJ-211 and screening for $\mathrm{Nx}^{\mathrm{r}} \mathrm{Cm}^{\mathrm{s}}$ recombinants that emitted no light detectable by eye. Southern analysis confirmed that MJ-215 lacks the ClaI site in ain. MJ-215 synthesized no autoinducer activity detectable by the PD100(pJR551,pPD749) assay, but responded to exogenous AI-1 or AI-2 by emitting light (Fig. 1b). Finally, the luminescence defect of MJ-215 was rescued by introduction of pAI009 but not of pSUP102 or pAI015.

The ain::neo plasmid pAI014 was constructed by partially digesting pAI009 with ClaI, blunt-ending, purifying singly-cut plasmid by low melting-point agarose gel electrophoresis, and ligating with a neo cassette. JM83(pAI014) was $\mathrm{Cm}^{r} \mathrm{Km}^{r} \mathrm{AI}^{-}$. The $V$. fischeri ain::neo mutant MJ-216 was constructed by introducing pAI014 to MJ-100 and screening for $\mathrm{Nx}^{\mathrm{r}} \mathrm{Cm}^{\mathrm{s}} \mathrm{Nm}^{\mathrm{r}}$ recombinants. Southern analysis confirmed that MJ-216 lacks the ClaI site but possesses a $1.8 \mathrm{~kb}$ insert in ain. Autoinducer assays of HPLC fractions of conditioned medium confirmed that MJ-216 synthesizes AI-1 and AI-3 but not AI-2. 


\section{RESULTS}

Mutation of both ain and luxI abolishes induction of luminescence. To assess the role of AI-2 in regulation of luminescence, I constructed a ain luxI double mutant of $V$. fischeri and observed its luminescence phenotype. The ain luxI mutant MJ-215 did not synthesize a detectable autoinducer activity and correspondingly emitted a very low level of light which was never induced (Fig. 1a), implying that $V$. fischeri synthesizes no autoinducers capable of inducing the lux operon other than AI-1, -2 , and -3 , and that the limited induction observed in the luxI mutant MJ-211 is due to its synthesis of AI-2. Also, luminescence in MJ-215 was stimulated by exogenous AI-2 (Fig. 1b). Growth rate of MJ-215 was indistinguishable from that of MJ-100 and MJ-211. These results confirm that AI- 2 is an autoinducer of luminescence, though one with less than $0.02 \mathrm{x}$ the specific activity of AI-1 (Table 2).

Mutation of ain alone accelerates induction. To assess the contribution of AI-2 to autoinduction in the presence of the other autoinducers, I constructed a mutant deficient in AI-2 alone by inserting a neo cassette into ain. The resulting mutant MJ-216 was Lux+; MJ-216 colonies were visually indistinguishable from those of MJ-100. However, the two strains differed in their kinetics of luminescence; in log-phase batch cultures, induction of luminescence appeared to take place earlier and more quickly in MJ-216 than in MJ-100 (Figure 2a). This surprising result suggested that AI-2 might inhibit rather than induce luminescence in $V$. fischeri, but did not exclude the possibility that the neo insertion might cause abnormal luminescence kinetics. My previous experience with chromosomal insertion mutants has led me to caution that exogenous DNAs can have gross and poorly understood effects on the growth physiology of $V$. fischeri (Kuo 1994). Indeed, MJ-216 grew significantly more slowly than did MJ-100 (at mid-exponential phase, doubling times of MJ-100 and MJ-216 were 40 and $130 \mathrm{~min}$, respectively). Given the wild-type growth rate of the ain luxI mutant MJ-215, as well as the lack of effect of exogenous AI-2 on the growth rates of any $V$. fischeri strain tested (see below), I conclude that AI-2 itself does not affect growth physiology.

Exogenous AI-2 inhibits autoinduction. To determine if the accelerated induction of MJ-216 was due to the lack of AI-2 rather than the presence of exogenous DNA, induction was examined in the presence of exogenous AI-2. AI-2 inhibited luminescence of MJ-216 without altering growth rate (data not shown), implying that absence of AI-2 is responsible for part if not all of the accelerated autoinduction phenotype of MJ-216 (Fig. 2a). Exogenous AI-2 similarly inhibited autoinduction in the ain $^{+}$luxI $F^{+}$strains MJ-100 and MJ-1 in a dose-dependent manner (Fig. 2b). Inhibition 

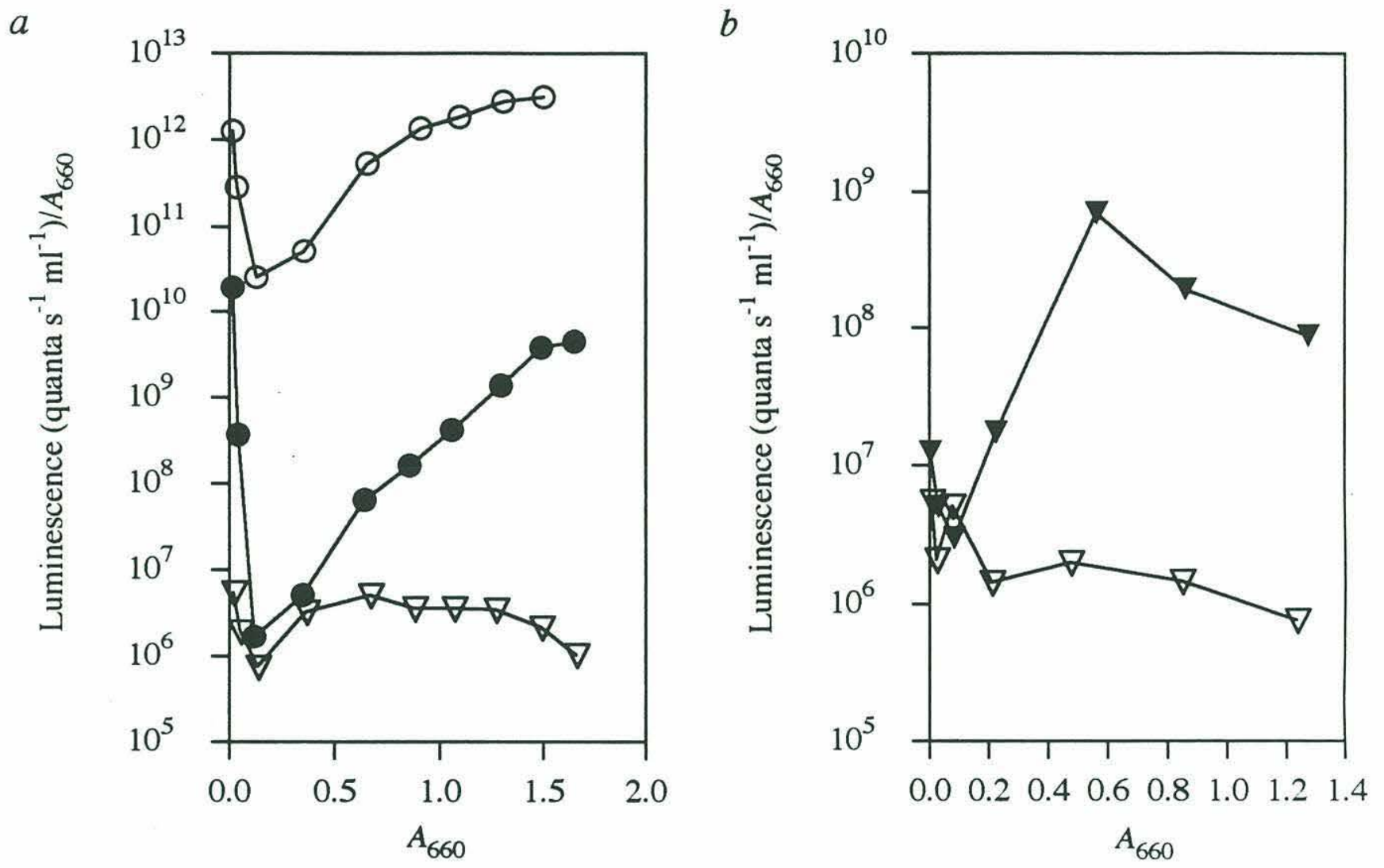

Fig. 1. The autoinducer mutant MJ-215. a. Comparison between MJ-100 (0), the luxI mutant MJ-211 ( $)$, and the ain luxI mutant MJ-215 ( $\nabla)$. b. Luminescence of MJ-215 in the absence $(\nabla)$ and the presence $(\nabla)$ of $170 \mathrm{ng} \mathrm{ml}^{-1} \mathrm{AI}-2$. 
$a$

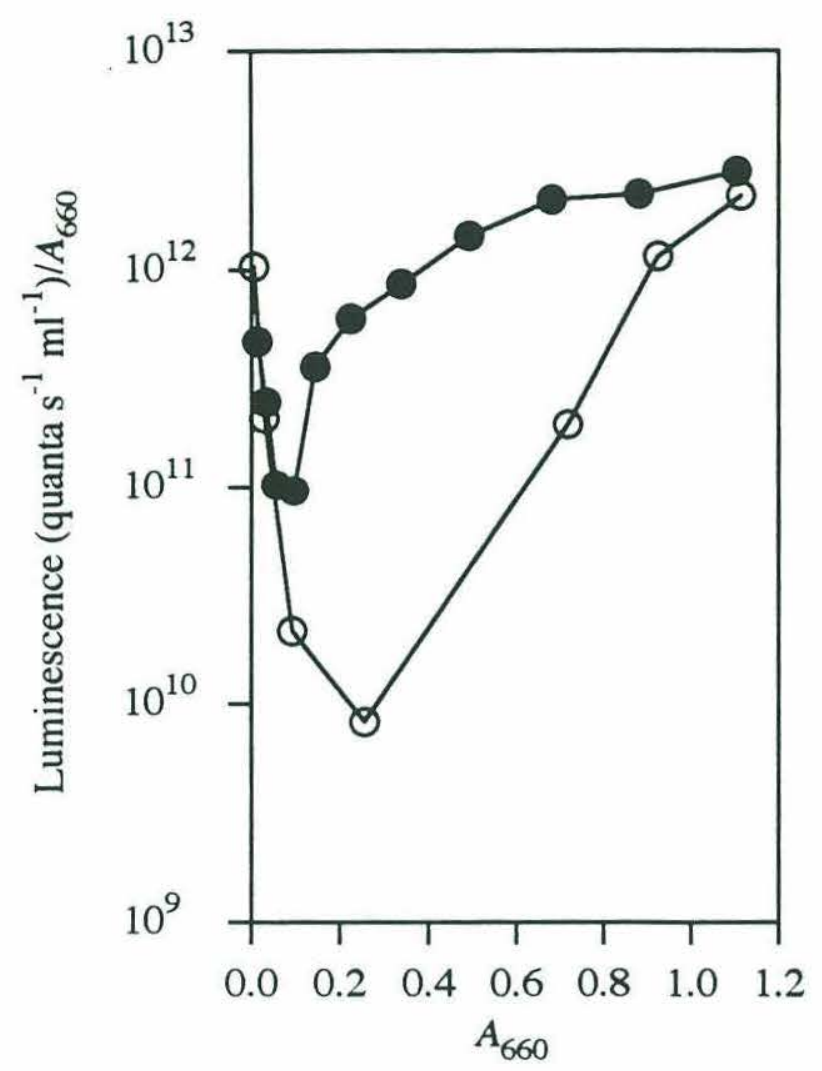

b

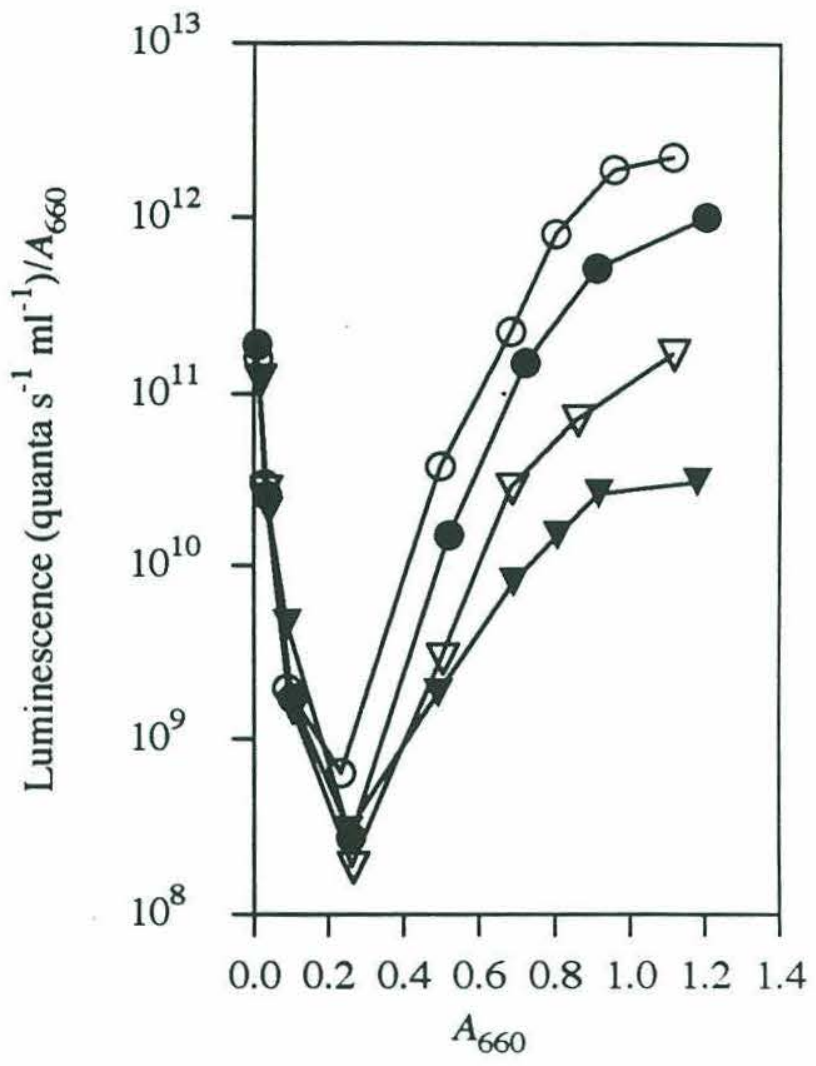

Fig. 2. Inhibition of autoinduction by ain and AI-2. a. Comparison between the ain ${ }^{+}$ strain MJ-100 (O) and the ain mutant MJ-216(0). b. Autoinduction in the wild-type strain MJ-1 in the presence of $0(0), 1.7(\bullet), 17(\nabla)$, and $170(\nabla) \mathrm{ng} \mathrm{ml}^{-1}$ exogenous AI-2. 
was observed with doses well within the range of AI-2 concentrations synthesized by $V$. fischeri (a dense culture of MJ-211 contained activity equivalent to $\sim 15 \mathrm{ng} \mathrm{ml}^{-1} \mathrm{AI}-2$; data not shown). In none of these strains was growth rate affected by any concentration of AI-2. These AI-2 addition experiments, together with the MJ-216 phenotype, demonstrate that AI-2 is an inhibitor of autoinduction.

AI-2 inhibits activity of exogenous AI-1. While the above results demonstrate that AI-2 inhibits autoinduction, they do not demonstrate the mechanism of that inhibition. Given the structural and functional similarities between the $V$. fischeri autoinducers, AI-2 might occupy the same putative binding site on LuxR as does AI-1; it seems reasonable to propose that AI-2 inhibition requires AI-2-LuxR interaction. If so, AI-2 should inhibit AI-1 activity in an E. coli system containing only LuxR, exogenous $\mathrm{AI}-1$, and $l u x C D A B E$ as a target for AI-1-LuxR activation. E. coli JM83 was first transformed with the $\triangle l u x I$ plasmid pAK411, which carries both luxR and luxCDABE, and then was treated with a fixed arbitrary amount of AI-1 $\left(10 \mathrm{ng} \mathrm{ml}^{-1}\right)$ and a range of amounts of AI-2 (from 0 to $333 \mathrm{ng} \mathrm{ml}^{-1}$ ). Induction of luminescence by AI-1 was reduced by AI-2 in a dose-dependent manner (Fig. 3a). This demonstration of AI-2mediated inhibition in an E. coli system shows that LuxR, AI-1, and luxICDABE are the only elements necessary to observe AI-2-mediated inhibition. Qualitatively similar results were obtained with the ain luxI mutant MJ-215 treated with a fixed amount of AI1 and a range of amounts of AI-2 (Fig. 3b).

AI-2 does not repress transcription of $l u x R$. Since AI-2, like AI-1, induces luminescence via LuxR, I hypothesized that AI-2, also like AI-1, represses transcription of luxR via LuxR; such repression might contribute to AI-2-mediated inhibition of autoinduction. To detect such repression, I used the luxR::lacZ operon fusion plasmid pJR551 to directly measure luxR transcription in an E. coli system. Because pJR551

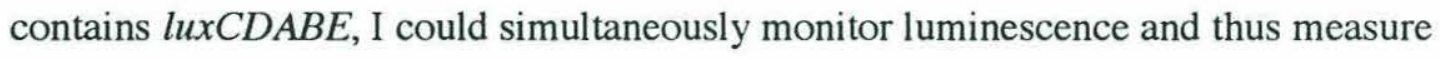
autoinducer activity. pPD749, which contains luxR fused to an exogenous promoter and thus expresses $l u x R$ unregulated by AI-1-LuxR, was also present in the $E$. coli system. By measuring $\beta$-galactosidase activities of $E$. coli PD100(pJR551,pPD749) with and without exogenous autoinducers, I demonstrated that AI-1 represses luxR but AI-2 does not. LuxR autorepression was not observed even with a concentration of AI-2 that stimulated luminescence to the same degree as AI-1 (Table 2). This shows that the level of luxICDABEG transcriptional activation is not linearly related to the level of luxR transcriptional repression. Qualitatively similar results were obtained by mobilizing the luxR::lacZ operon fusion plasmid pAK011 into the ain luxI mutant MJ-215, and then measuring luxR transcription in the presence of exogenous autoinducers (Table 2). 

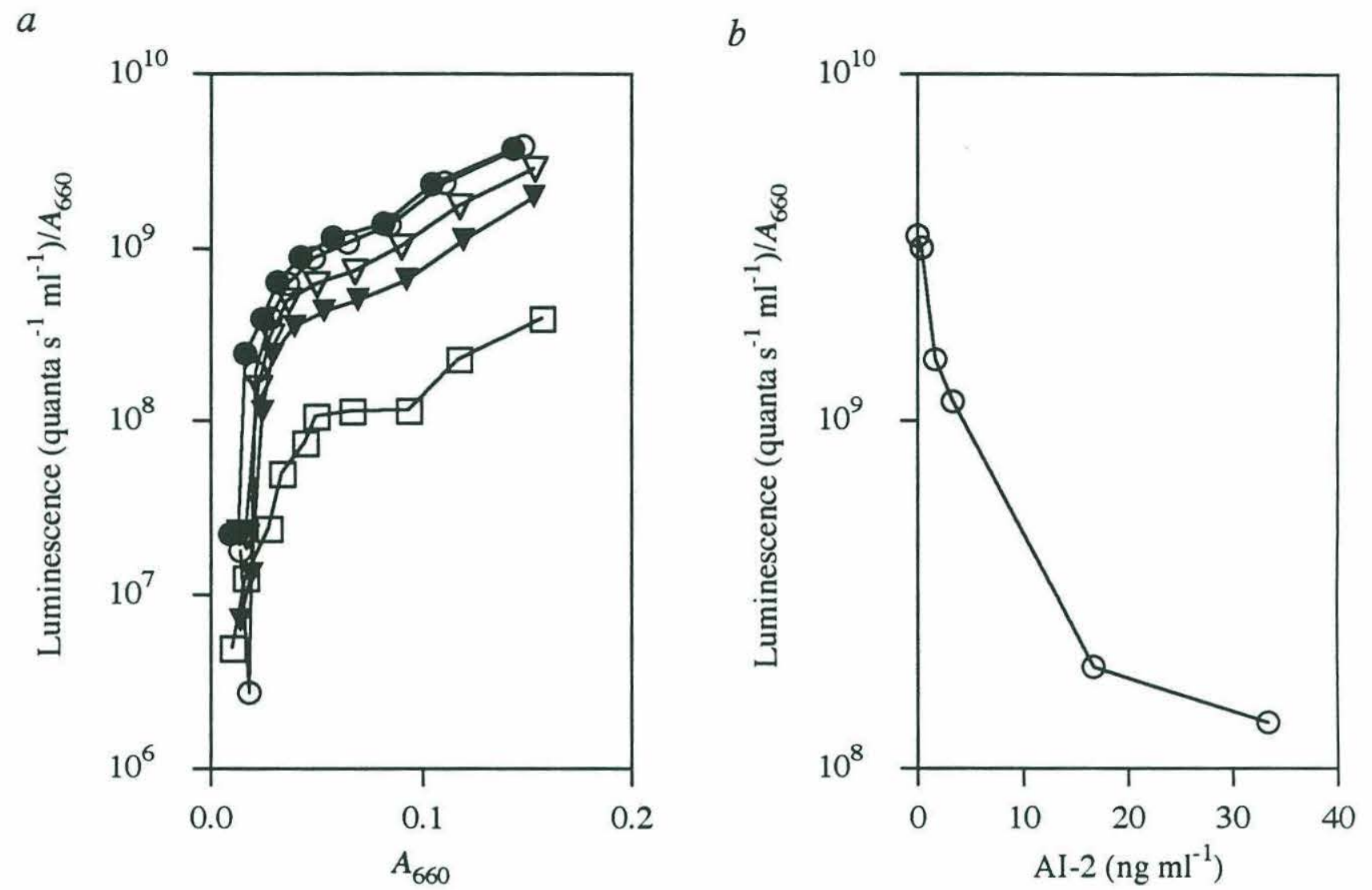

Fig. 3. Inhibition of AI-1 activity by AI-2. In each experiment cultures were treated with $10 \mathrm{ng} \mathrm{ml}^{-1} \mathrm{AI}-1$ and a range of AI-2 concentrations. $a$. Inhibition of AI-1 activity in $E$. coli JM83(pAK411,pSUP102), which has a nonpolar deletion in luxI. AI-2 was added to $0(0), 0.33(\bullet), 3.3(\nabla), 33(\nabla)$, and $330(\square) \mathrm{ng} \mathrm{ml}^{-1}$. b. Inhibition of AI-1 activity in the ain luxI mutant $\mathrm{MJ}-215$. AI-1 was added to each culture to $10 \mathrm{ng} \mathrm{ml}^{-1}$, and luminescence was measured at $A_{660}=0.1$. 
Table 2. Effect of AI-2 on transcription of luxR::lacZ operon fusions on plasmids pJR551 and pAK011 in E. coli and $V$. fischeri, respectively.

Luminescence $\quad \beta$-galactosidase activity

Strain $^{a}$

Additions ${ }^{b} \quad$ quanta s$^{-1} \mathrm{ml}^{-1} A_{660}{ }^{-1}$

Miller units

E. coli

PD100(pJR551,pPD749)

None

$2.22 \times 10^{8}$

310

AI-1

$8.12 \times 10^{11}$

190

AI-2

$7.36 \times 10^{11}$

320

V. fischeri

MJ215(pAK011)

None

$2.31 \times 10^{7}$

670

AI-1

$7.84 \times 10^{10}$

500

AI-2

$1.98 \times 10^{10}$

720

${ }^{a} E$. coli was grown in autoinducer assay medium (Dunlap and Ray 1989) to $A_{660}=1.0$.

$V$. fischeri was grown in ASH medium with $17 \mathrm{mg} \mathrm{l}^{-1} \mathrm{Cm}$ to $A_{660}=1.1$.

${ }^{b}$ To $E$. coli, autoinducers were added to $33 \mathrm{ng} \mathrm{ml}^{-1}$ (AI-1) or $1.6 \mu \mathrm{g} \mathrm{ml}^{-1}$ (AI-2). To $V$.

fischeri, autoinducers were added to $67 \mathrm{ng} \mathrm{ml}^{-1}$ (AI-1) or $1.7 \mu \mathrm{g} \mathrm{ml}^{-1}$ (AI-2). 
To determine whether AI-2 represses luxR transcription when simultaneously inhibiting AI-1-mediated induction of luxICDABEG transcription, I measured luxR transcription from the luxR::lacZ fusion plasmid pAK011 in the presence of AI-1, AI-2, LuxR, and luxCDABE. JM83(pAK411,pAK011) was treated with $10 \mathrm{ng} \mathrm{ml}^{-1} \mathrm{AI}-1$ and $333 \mathrm{ng} \mathrm{ml-1} \mathrm{AI-2,} \mathrm{luminescence} \mathrm{was} \mathrm{monitored} \mathrm{until} \mathrm{significant} \mathrm{inhibition} \mathrm{of} \mathrm{AI-1}$ activity was observed (at $A_{660}=0.27$, induction of luminescence was inhibited by AI-2 to $12 \%$ of the level without AI-2), and $\beta$-galactosidase activity was measured. Under such conditions, no repression of $l u x R$ transcription was observed (Table 3), demonstrating that the level of AI-2-mediated inhibition of AI-1 activity is not related to the level of luxR transcription. I conclude that AI-2 does not inhibit autoinduction by repressing luxR. 
Table 3. Effect of AI-2 on AI-1-mediated induction of luminescence from pAK411 and on transcription of a $l u x R:$ :lacZ fusion on pAK011 in a single cell ${ }^{a}$.

\begin{tabular}{ccc} 
& Luminescence & $\beta$-galactosidase activity \\
Additions $^{b}$ & quanta s $~^{-1} \mathrm{mr}^{-1} A_{660}$ & Miller units \\
\hline
\end{tabular}

None

$$
8.04 \times 10^{6}
$$

53

AI-1

$4.30 \times 10^{8}$

52

AI-2

$1.01 \times 10^{7}$

53

$\mathrm{AI}-1$ and $\mathrm{AI}-2$

$5.37 \times 10^{7}$

53

aJM83(pAK411,pAK011) was grown to $A_{660}=0.27$.

${ }^{b}$ Autoinducers were added to $10 \mathrm{ng} \mathrm{ml}^{-1}$ (AI-1) or $333 \mathrm{ng} \mathrm{ml}^{-1}$ (AI-2). 


\section{DISCUSSION}

I have demonstrated that an autoinducer of luminescence, AI-2, inhibits the AI-1mediated autoinduction of luminescence in $V$. fischeri, and that this inhibition can be attributed to inhibition of AI-1 activity but not to repression of luxR transcription. I have also shown that in the absence of AI-1, -2 , and -3 , all autoinduction is abolished, revealing the autoinducer-independent modulation of luminescence described previously (Fig. 1a; Dunlap and Kuo 1992).

The wild-type growth rate of the ain luxI mutant MJ-215 and the lack of effect of exogenous AI-2 on growth rates of all strains tested lead me to conclude that neither ain nor AI-2 regulates growth. Thus the aberrantly long doubling time of the ain::neo mutant MJ-216 must be ascribed to its insert DNA. Similar affects have been previously observed with other exogenous DNAs inserted into the lux region of $V$. fischeri (Kuo 1994). Given the frequent and routine insertion of selectable markers in genetic studies, the effect of exogenous DNA reported here may serve as a cautionary note.

My demonstration that AI-2 has an inhibitory activity is consistent with the report that a number of synthetic $N$-acyl-L-HSLs, including $N$-octanoyl-L-HSL, both stimulated luminescence and inhibited AI-1 activity in the natural autoinducer-deficient $V$. fischeri strain B-61 (Eberhard et al 1986). Because the nature of the autoinducer deficiency of B61 is unknown, it is not possible to use B-61 to examine the mechanisms underlying the observed inhibition. The use of defined autoinducer mutants and E. coli systems in this study has allowed me to examine potential mechanisms of inhibition as well as to demonstrate the presence of the inhibition in wild-type $V$. fischeri.

It is not yet understood why AI-2 has a lower specific activity than does AI-1. A simple explanation is that AI-1 and AI-2 have different binding affinities for LuxR, but that AI-1-LuxR and AI-2-LuxR are functionally equivalent. This explanation is consistent with the current model for autoinduction and LuxR autorepression, where AI1-LuxR binds to the lux operator to simultaneously stimulate transcription from the luxICDABE operon and sterically prevent Crp-mediated activation of luxR transcription (Dunlap and Greenberg 1988, Dunlap and Ray 1989, Shadel et al 1991). I thus predicted that AI-2, which interacts with LuxR to stimulate luminescence (Kuo et al 1994), would similarly repress $l u x R$ transcription. I saw no such repression by $1.6 \mu \mathrm{g} \mathrm{ml}^{-1} \mathrm{AI}-2$, which induces luxICDABE to a level comparable to that of $33 \mathrm{ng} \mathrm{ml}^{-1} \mathrm{AI}-1$, which is sufficient for significant repression of $l u x R$. Thus AI-2 can induce luminescence without simultaneously repressing luxR transcription. Therefore I suspect that the current model for LuxR action is overly simple. Also, I conclude that AI-1-LuxR and AI-2-LuxR 
cannot be functionally equivalent. AI-1-LuxR and AI-2-LuxR must differ in their abilities to repress luxR, or to activate luxICDABEG, or both.

The proposal that AI-1-LuxR and AI-2-LuxR are functionally different provides an explanation for the seemingly contradictory finding that a molecule with demonstrable luminescence-inducing activity, $\mathrm{AI}-2$, can also inhibit autoinduction of luminescence. My results are consistent with a mechanism of inhibition where AI- 1 and AI- 2 compete for the same putative binding site on LuxR, and where AI-2-LuxR is a significantly less potent activator of luxICDABEG transcription than is AI-1-LuxR. Because of the lower activity of AI-2-LuxR, substitution of some AI-1 molecules with AI-2 at LuxR results in lower total expression of luxICDABEG per cell. Because luxI expression is lowered, AI2 also inhibits the synthesis of AI-1, and thus further decreases the rate of induction of luminescence. Because AI-2 itself activates a low level of luxICDABEG transcription, AI-2 never eliminates autoinduction or luminescence altogether.

The above model invokes only the autoinducers and LuxR, and no other regulatory elements, for its operation. However, the model requires the assumption that availability of AI-binding sites limits the amount of luxICDABEG transcription; such a limitation has not been experimentally demonstrated. Other possible mechanisms for inhibition have not been excluded, including the logical possibilities that AI-2 might degrade AI-1, block LuxI activity, inactivate LuxR, inhibit LuxR synthesis posttranscriptionally, or even interfere with the luminescence reactions. Also, the model leaves unanswered the question as to how AI-1-LuxR and AI-2-LuxR differ. LuxR has been proposed to act as a multimer (Choi and Greenberg 1992), and the putative interaction between the DNA-binding "helix-turn-helix" motif of LuxR with the palindromic lux operator is reminiscent of some regulatory proteins that bind operator DNA more or less effectively depending on their dimerization state (Gussin et al 1983). I speculate that AI-1-LuxR and AI-2-LuxR differ in their state of multimerization.

This model of autoinducer interactions contrasts sharply with the model proposed for the V. harveyi autoinducers (Bassler and Silverman 1994). In the latter, two autoinducers bind to distinct cognate receptors ( $\mathrm{LuxN}$ and LuxPQ), each of which inactivates a single DNA-binding repressor of luxCDABE transcription (LuxO). My model does not preclude the existence in $V$. fischeri of a system analogous to that of $V$. harveyi, but none of the three $V$. fischeri autoinducers is known to derepress a repressor of luminescence.

The demonstration of a functional role of AI-2 in regulation of luminescence leaves unknown the functional role of AI-3. Total AI-3 activity in $V$. fischeri is intermediate between that of AI-1 and AI-2, and AI-3 is also a $N$-acyl-L-HSL (Kuo et al 
1994). It seems reasonable to suppose that AI-3, like AI-2, serves as an inhibitor of autoinduction. It should be noted that an inhibitory role for either AI-2 or AI-3 does not exclude the possibility that these multiple autoinducers might serve other regulatory roles in the cell.

The synthesis by $V$. fischeri of an inhibitor of autoinduction leads me to suggest that fine-tuned control of the rate of luminescence induction is significant to the bacterium. It is possible that, during the rapid changes in population density that luminous bacteria presumably experience when moving from high density environments such as the light organ symbiosis ( $10^{6-10}$ cells ml-1; Nealson and Hastings 1991) to the surrounding water column $\left(10^{3-4} \mathrm{cells} \mathrm{ml}^{-1}\right)$ and back, the rate of lux autoinduction is optimized by the interactions between AI-1 and AI-2. That an autoinduction system may be modulated by an additional regulatory factor is not unprecedented; modA is a negative regulator of the A. tumefaciens autoinduction system that is presently regarded as a secondary or modulating element (Hwang et al 1994). However, the activity of ModA has so far not been shown to require an extracellular autoinducer. Nevertheless, the evolution of negative regulatory elements that inhibit autoinduction, such as AI-2 and perhaps ModA, points to the importance to bacteria of controlling the rate of autoinduction events during transitions between different population density states. 


\section{ACKNOWLEDGEMENTS}

I thank N. Blough for use of his HPLC system and D. Lynn for his supply of synthetic autoinducers.

This work was partially supported by the Woods Hole Oceanographic Institution Molecular Biology Fund.

\section{REFERENCES}

Ausubel, F. M., R. Brent, R. E. Kingston, D. D. Moore, J. A. Smith, J. G. Seidman, and K. Struhl. 1987. Current protocols in molecular biology. John Wiley, New York.

Bassler, B. L., M. Wright, and M. R. Silverman. 1994. Multiple signalling systems controlling expression of luminescence in Vibrio harveyi: sequence and function of genes encoding a second sensory pathway. Mol. Microbiol. 13:273-286.

Castilho, B. A., P. Olfson, and M. J. Casadaban. 1984. Plasmid insertion mutagenesis and lac gene fusion with mini-Mu bacteriophage transposons. J. Bacteriol. 158:488-495.

Choi, S. H., and E. P. Greenberg. 1992. Genetic evidence for multimerization of LuxR, the transcriptional activator of Vibrio fischeri luminescence. Mol. Mar. Biol. Biotechnol. 1:408-413.

Devine, J. H., G. S. Shadel, and T. O. Baldwin. 1989. Identification of the operator of the lux regulon from the Vibrio fischeri strain ATCC7744. Proc. Natl. Acad. Sci. USA 86:5688-5692.

Dunlap, P. V., and E. P. Greenberg. 1988. Control of Vibrio fischeri lux gene transcription by a cyclic AMP receptor protein-LuxR protein regulatory circuit. J. Bacteriol. 170:4040-4046.

Dunlap, P. V. 1989. Regulation of luminescence by cyclic AMP in cya-like and crp-like mutants of Vibrio fischeri. J. Bacteriol. 171:1199-1202.

Dunlap, P. V., and J. M. Ray. 1989. Requirement for autoinducer in transcriptional negative autoregulation of the Vibrio fischeri luxR gene in Escherichia coli. J. Bacteriol. 171:3549-3552.

Dunlap, P. V., and A. Kuo. 1992. Cell density-dependent modulation of the Vibrio fischeri luminescence system in the absence of autoinducer and LuxR protein. J. Bacteriol. 174:2440-2448.

Eberhard, A., A. L. Burlingame, C. Eberhard, G. L. Kenyon, K. H. Nealson, and N. J. Oppenheimer. 1981. Structural identification of autoinducer of Photobacterium fischeri luciferase. Biochem. 20:2444-2449.

Eberhard, A., C. A. Widrig, P. McBath, and J. B. Schineller. 1986. Analogs of the autoinducer of bioluminescence in Vibrio fischeri. Arch. Microbiol. 146:35-40.

Engebrecht, J., K. Nealson, and M. Silverman. 1983. Bacterial bioluminescence: isolation and genetic analysis of functions from Vibrio fischeri. Cell 32:773-781.

Engebrecht, J., and M. Silverman. 1984. Identification of genes and gene products necessary for bacterial bioluminescence. Proc. Natl. Acad. Sci. USA 81:41544158.

Gilson, L., A. Kuo, and P. V. Dunlap. Manuscript in preparation.

Gussin, G. N., A. D. Johnson, C. O. Pabo and R. T. Sauer. 1983. Repressor and Cro protein: structure, function, and role in lysogenization, p. 93-121. In R. W. Hendrix, J. W. Roberts; F. W. Stahl and R. A. Weisberg (ed.), Lambda II. Cold Spring Harbor Laboratory, Cold Spring Harbor. 
Hwang, I., D. M. Cook, and S. K. Farrand. 1994. A new regulatory element involved in modulating Ti plasmid conjugal transfer, abstr.H-115, p. 220. Abstr. 94th Gen. Meet. Am. Soc. Microbiol. 1994.

Kuo, A., N. V. Blough, and P. V. Dunlap. 1994. Multiple $N$-acyl-L-homoserine lactone autoinducers of luminescence in the marine symbiotic bacterium Vibrio fischeri. J. Bacteriol. 176:7558-7565.

Miller, J. H. 1992. A short course in bacterial genetics. Cold Spring Harbor Laboratory, Cold Spring Harbor.

Nealson, K. H., T. Platt, and J. W. Hastings. 1970. Cellular control of the synthesis and activity of the bacterial luminescence system. J. Bacteriol. 104:313-322.

Nealson, K. H., and J. W. Hastings. 1991. The luminous bacteria. In A. Balows, H. G. Truper, M. Dworkin, W. Harder and K.-H. Schleifer (ed.), The prokaryotes, 2nd ed. Springer-Verlag, New York.

Pearson, J. P., K. M. Gray, L. Passador, K. D. Tucker, A. Eberhard, B. H. Iglewski, and E. P. Greenberg. 1994. Structure of the autoinducer required for expression of Pseudomonas aeruginosa virulence genes. Proc. Natl. Acad. Sci. USA 91:197-201.

Shadel, G. S., and T. O. Baldwin. 1991. The Vibrio fischeri LuxR protein is capable of bidirectional stimulation of transcription and both positive and negative regulation of the $l u x R$ gene. J. Bacteriol. 173:568-574.

Simon, R., M. O'Connell, M. Labes, and A. Puhler. 1986. Plasmid vectors for the genetic analysis and manipulation of rhizobia and other gram-negative bacteria. Meth. Enzymol. 118:640-659.

Yanisch-Perron, C., J. Vieira, and J. Messing. 1985. Improved M13 phage cloning vectors and host strains: nucleotide sequences of the M13mp18 and pUC19 vectors. Gene 33:103-119.

Zhang, L., P. J. Murphy, A. Kerr, and M. E. Tate. 1993. Agrobacterium conjugation and gene regulation by $N$-acyl-L-homoserine lactones. Nature 362:446-448. 


\section{Chapter 5. Concluding remarks}

In this study I have used a mutational approach in $V$. fischeri to investigate novel aspects of luminescence and autoinduction. This was the first attempt to use defined lux mutants to determine the physiological role of luminescence. Also, these mutants potentially lend insight into the functions of $\operatorname{lu} G \mathrm{a}$ and the unidentified yellow extracellular pigment. Finally, I have employed these mutants to demonstrate the existence of a second autoinducer system, to isolate and identify the autoinducer, and to generate evidence for the second autoinducer's function in $V$. fischeri. I will discuss my ruminations on these observations in the remainder of this chapter. First, however, I wish to emphasize the importance of constructing mutations in $V$. fischeri. Until recently, all genetic studies of $V$. fischeri biology were restricted to the cloned lux genes in E. coli. By constructing $V$. fischeri mutants, I have encountered aspects of $V$. fischeri biology that could not have been observed using cloned genes in E. coli. Even more instructively, I have belatedly learned that an experimental "dialogue" between the mutants and the cloned genes, where results in one system are tested in the other system and vice versa, is productive and rewarding (and fun). My hope is that this and the few other studies

utilizing $V$. fischeri mutants will provoke broader use of genetic techniques to more completely understand this bacterium, both in its own right and as a model for studies of luminescence, autoinduction, and symbiosis.

\section{Luminescence}

The lux mutants described in Chapter 2 confirmed most of the classical model for luminescence established in E. coli (the exception is autoinduction, discussed below), demonstrated that luminescence does not play an obviously significant role in bacterial growth, and provided a means to assess luminescence as a functional adaptation. In the last capacity, the lux mutants were used to test the hypothesis that luciferase is a defense against $\mathrm{H}_{2} \mathrm{O}_{2}$ toxicity. The lack of difference in $\mathrm{H}_{2} \mathrm{O}_{2}$ sensitivity between the lux mutants and the wild-type is inconsistent with the hypothesis. Many of the other "adaptationist stories" proposed for luminescence could be similarly examined with these mutants. Thus the hypothesis that luciferase serves to defend the cell against some other form of oxidative stress (or any other kind of stress) could be tested by subjecting the luciferase mutant to the stress. The notion that luciferase is an alternative electron acceptor to cytochrome oxidase could be examined by growing the luciferase mutant under conditions where cytochrome oxidase is not functional, such as iron depletion, or 
under $\mathrm{O}_{2}$ tensions too low for cytochrome oxidase function but high enough for luciferase function (luciferase has a higher affinity for $\mathrm{O}_{2}$ than does cytochrome oxidase; Hastings 1952, Yonetani 1963). The idea that luminescence serves to lure potential host animals could be addressed by observing captive host behavior with respect to free-living mutant bacteria. The proposal that the purpose of the luminescence reaction is to generate the fatty acyl product could be investigated by following the fates of radiolabeled aldehydes when assimilated by the aldehyde mutant.

\section{Pigmentation}

The distribution of pigment phenotypes among the lux mutants generated in Chapter 2 points to a link between $\operatorname{lux} G$ and the extracellular yellow pigment of $V$. fischeri. However, such a link is not rigorously demonstrated without construction of a $V$. fischeri strain with mutation in luxG alone. E. coli JM83 with the cloned lux genes on pNL121 does not appear to synthesize the pigment; whether this is due to an unknown alteration in luxG on pNL121 (the luxG in question has not been sequenced) or to a lack of a necessary substrate in $E$. coli is unknown.

LuxG has sequence similarity to Fre, an E. coli $\mathrm{NAD}(\mathrm{P}) \mathrm{H}$ :flavin oxidoreductase that reduces the ferric iron of ribonucleotide reductase, a necessary step in deoxyribonucleotide synthesis (Fontecave et al 1987, Spyrou et al 1991, Andrews et al 1992). Specifically, three of four regions located at the active site are conserved between Fre and LuxG (Zenno and Saigo 1994). Thus it has been suggested that LuxG catalyzes the flavin reduction necessary for luminescence (Andrews 1992). However, none of the six $\mathrm{NAD}(\mathrm{P}) \mathrm{H}$ :flavin oxidoreductases so far purified from luminous bacteria are encoded by LuxG, though four (including one of the two from $V$. fischeri) are homologues of Fre (Zenno et al 1994, Zenno and Saigo 1994, Lei et al 1994). I know of no successful demonstration of flavin or iron reductase activity that is regulated by autoinducer, or is dependent on LuxG.

Similarly, the nature and function of the pigment are unknown. Its solubility in water and flourescence in ultraviolet have led to the suggestion that it is riboflavin (Giese 1943). The functional significance of an extracellular flavin is, however, unclear. Alternatively, the yellow color is reminiscent of a phenazine. Phenazines have a heterocyclic structure and redox functionality analogous to those of flavins (Morrison et al 1978). In this light, it is intriguing that two Pseudomonas sp. have been shown to synthesize extracellular phenazine antibiotics in a cell density-dependent manner, each requiring a luxR homologue for production (Ochsner et al 1994, Pierson et al 1994). 
Interestingly, genes involved in the synthesis of riboflavin are located $3^{\prime}$ to the luxG genes of Photobacterium sp. (Lee and Meighen 1992, Lee et al 1994). However, the $V$. fischeri lux $G$ is followed by a transcriptional terminator that serves both the luxICDABEG operon and a convergently transcribed open reading frame (Swartzman et al 1990). Intriguingly, the latter has sequence similarity to the Bacillus subtilis riboflavin synthesis gene ribG (Lee et al 1993), but its transcriptional orientation is difficult to reconcile with the autoinducer-dependence of pigmentation (Chapter 2).

On a more theoretical level, it is not obvious how a flavin reductase might be involved in synthesis of a flavin. Elucidation of the enzymatic steps of riboflavin synthesis is not yet complete (Richter et al 1993, Lee et al 1994), but none of the known steps is obviously analogous to the reduction of ribonucleoside diphosphates to deoxyribonucleotides. Even if a luxG-specific mutation in $V$. fischeri results in pigment deficiency, LuxG is not necessarily a synthase of the pigment; alternatively, LuxG may influence pigment production through an indirect effect on intermediary metabolism. A variant altered in metabolic acidification was also altered in pigmentation (Giese 1943), and this pigment defect was rescued by strong buffer. It was unclear whether the acids were destroying the pigment directly, or were adversely affecting pigment production by reducing cellular metabolism or viability. In my own work I have not observed correlations amongst lux mutants between acidification of medium and pigmentation (data not shown).

\section{Autoinduction}

While the luxI and $l u x R$ mutants of Chapter 3 confirmed the primary role of AI-1 in inducing expression of the lux operon, as well as repression of $l u x R$, they also revealed the presence of a second and separate autoinducer system in $V$. fischeri. The second autoinducer activity, AI-2, was shown to be $N$-octanoyl-L-HSL. Synthesis of AI-2 was directed by ain, which bears sequence similarity to $V$. harveyi luxM (see below) but not $V$. fischeri luxI. AI-2 was capable of interacting with LuxR to stimulate expression of luxICDABEG, but not to repress luxR. However, the ain mutants of Chapter 4 showed that the overall effect of $\mathrm{AI}-2$ on regulation of luminescence is to inhibit induction of luxICDABEG by AI-1, thus slowing autoinduction. Finally, LuxI synthesized a third molecule AI-3 ( $N$-hexanoyl-L-HSL) capable of inducing the lux operon via LuxR.
A. $\mathbf{A I}-2$ 
AI-2 lowers the rate of induction of luminescence by AI-1, and thus modifies the autoinduction response. As to the purpose of inhibition, we can only speculate that the rapidity of autoinduction is relevant to its adaptive role. These results do not exclude the possibility that AI-2 regulates functions other than luminescence (see below).

The ain locus has been mapped and sequenced by L. Gilson; a single gene ainS is necessary for synthesis of AI-2 (Gilson et al). The carboxyl terminus of AinS has sequence similarity with $V$. harveyi LuxM (Bassler et al 1993) and not LuxI, while the amino terminus bears no resemblance to either LuxLM or LuxI. The fact that genes as divergent as luxI and ainS direct the production of structurally similar $N$-acyl-HSLs in $E$. coli lends support to the notion that autoinducer synthesis is catalyzed by a single step, probably formation of the peptide bond; presumably LuxI and AinS utilize the same homoserine lactone substrate but different fatty acyl substrates. Verification of this notion awaits purification of active autoinducer synthases.

The dissimilarity of LuxI and AinS also supports the notion that the structures of autoinducers are products of convergent evolution, and thus that the $N$-acyl-L-HSL motif is of adaptive significance to these bacteria, as proposed in Chapter 1. V. fischeri is the only example of a bacterium with both the LuxI- and AinS-types of putative autoinducer synthase; I would not be surprised if both types were to be discovered in $V$. harveyi, $P$ aeruginosa, and A tumefaciens.

Sequencing revealed another open reading frame immediately 3' to ainS (Gilson et al). This gene possesses its own candidate promoter and ribosome-binding site. The sequence of the first fifth of the protein is known, and is similar to that of $V$. harveyi LuxN and LuxQ. Since LuxN and LuxQ are putative autoinducer receptors (Bassler et al 1994), the ainS-linked gene is an obvious candidate for an AI-2 receptor gene and has been named ainR (Gilson et al). If so, presence of this gene has no effect on either stimulation of luminescence (pAI002 containing ainR failed to complement a $\Delta l u x R$ plasmid in E. coli in Chapter 3; other data not shown) or on AI-2-mediated inhibition of autoinduction (data not shown). It is possible that ainR is either insufficient to transduce the AI-2 signal to a response, or is not functional in E. coli. Alternatively, ainR together with AI-2 might regulate some unknown target other than lux. However, S. Callahan and I have so far not detected radiolabeled AI-2-regulated polypeptides on polyacrylamide gels (data not shown).

B. AI-3 
The ability of luxI to direct the synthesis of two distinct autoinducers, AI-1 and AI-3, is striking. The same autoinducers are also recognized by LuxR. The fact that luxI is involved in the synthesis of two structurally similar molecules lends further credence to the notion that LuxI catalyzes a single peptide bond-formation step. Presumably there exist in both $E$. coli and $V$. fischeri at least two distinct pools of potential fatty acyl substrates for LuxI.

I have not explored AI-3 in depth, and so cannot state whether AI-3 is a supplementary autoinducer to AI-1, inhibits like AI-2, or performs yet another function. It should be possible to examine some of these propositions following the approach already used for investigating AI-2 function in Chapter 4. Given LuxI synthesized significantly less AI-3 activity than AI-1 activity (Chapter 3), it is possible that AI-3 merely represents an inefficiency, a product of imprecision in LuxI substrate recognition. Alternatively, AI-3 may be the product of LuxI utilization of an alternative fatty acyl pool, to be used when the 3-oxohexanoyl pool for AI-1 synthesis is limiting.

\section{LuxR}

Like AI-1, AI-2 induces luxICDABEG transcription, but unlike AI-1, AI-2 appears not to repress $l u x R$ transcription (Chapter 4). This result is inconsistent with the current model for autoinduction and LuxR autorepression, which views LuxR binding to the lux operator as the proximal cause for both $\operatorname{luxICDABEG}$ activation and $l u x R$ repression. The behavior of AI-2 logically separates luxICDABEG activation from luxR repression, implying that LuxR-operator binding is itself not sufficient for one or both effects.

The putative domain for LuxR multimerization overlaps two hydrophobic regions and the putative autoinducer-binding domain, suggesting that autoinducer-binding may promote multimerization (Choi and Greenberg 1992). I speculate that the autoinducer itself mediates dimerization, by acting as a bridge between the homoserine lactone binding site in one LuxR monomer and a hydrophobic pocket in another LuxR monomer, and that this dimerization is required for $l u x R$ repression but not for low levels of luxICDABEG activation. The "original" helix-turn-helix DNA-binding protein, $\lambda$ repressor, binds weakly to its palindromic operator as a monomer and binds several orders of magnitude more strongly as a dimer (Gussin et al 1983). Similarly, monomeric LuxR may bind to its palindromic operator too weakly to repress $l u x R$. In effect, the autoinducer-binding domain is identical to the dimerization domain, and AI-1 is a "dimerization factor". In this model, the differences in repression activity between AI-1 
and AI-2 are due entirely to their differing abilities to mediate dimerization, which is a consequence of their differing fatty acyl structures. If one supposes that dimerization and stronger DNA binding also promote greater luxICDABEG activation, then this model can also explain differences in luxICDABEG inducing activity between different $N$-acyl-LHSLs.

Definitive establishment of AI-LuxR and LuxR-LuxR interactions awaits purification of active LuxR, but it may be possible to use existing $E$. coli systems to test the above-described dimerization model. I suggest using the Choi and Greenberg (1992) genetic dominance system as a logical starting point. Choi and Greenberg report genetic dominance of the putative autoinducer-binding domain of LuxR over intact LuxR with respect to induction of luminescence (by AI-1). This observation can be explained by LuxR dimerization, or by titration of the autoinducer. My model predicts that 1) genetic dominance should be similarly observed with respect to repression of $l u x R$ transcription and 2) no genetic dominance should be observed if AI-2 is supplied in lieu of AI-1. The second observation would be consistent with LuxR dimerization but not with autoinducer titration. Thus AI-2 might prove to be a useful probe for analyzing the mechanism of LuxR action. 


\section{REFERENCES}

Andrews, SC, D Shipley, JN Keen, JBC Findlay, PM Harrison and JR Guest. 1992. The haemoglobin-like protein (HMP) of Escherichia coli has ferrisiderophore reductase activity and its $\mathrm{C}$-terminal domain shares homology with ferredoxin NADP+ reductases. FEBS 302:247-252.

Bassler, BL, M Wright, RE Showalter and MR Silverman. 1993. Intercellular signalling in Vibrio harveyi: sequence and function of genes regulating expression of luminescence. Mol. Microbiol. 9:773-786.

Bassler, BL, M Wright and MR Silverman. 1994. Multiple signalling systems controlling expression of luminescence in Vibrio harveyi: sequence and function of genes encoding a second sensory pathway. Mol. Microbiol. 13:273-286.

Choi, SH, and EP Greenberg. 1992. Genetic evidence for multimerization of LuxR, the transcriptional activator of Vibrio fischeri luminescence. Mol. Mar. Biol. Biotechnol. 1:408-413.

Fontecave, M, R Eliasson and P Reichard. 1987. NAD(P)H:flavin oxidoreductase of Escherichia coli. J. Biol. Chem. 262:12325-12331.

Giese, AC. 1943. Studies on the nutrition of dim and bright variants of a species of luminous bacteria. J. Bacteriol. 46:323-331.

Gilson, L, A Kuo and PV Dunlap. Manuscript in preparation.

Gussin, GN, AD Johnson, CO Pabo and RT Sauer. 1983. Repressor and Cro protein: structure, function, and role in lysogenization, p. 93-121. RW Hendrix, JW Roberts, FW Stahl and RA Weisberg (ed.), Lambda II. Cold Spring Harbor Laboratory, Cold Spring Harbor.

Hastings, JW. 1952. Oxygen concentration and bioluminescence intensity. I. Bacteria and fungi. J. Cell. Comp. Physiol. 39:1-30.

Lee, CY, and EA Meighen. 1992. The lux genes in Photobacterium leiognathi are closely linked with genes corresponding in sequence to riboflavin synthesis genes. Biochem. Biophys. Res. Comm. 186:690-697.

Lee, CY, RB Szittner, CM Miyamoto and EA Meighen. 1993. The gene convergent to luxG in Vibrio fischeri codes for a protein related in sequence to RibG and deoxycytidylate deaminase. Biochim. Biophys. Acta 1143:337-339.

Lee, CY, DJ O'Kane and EA Meighen. 1994. Riboflavin synthesis genes are linked with the lux operon of Photobacterium phosphoreum. J. Bacteriol. 176:21002104.

Lei, B, M Liu, S Huang and S-C Tu. 1994. Vibrio harveyi NADPH-flavin oxidoreductase: cloning, sequencing and overexpression of the gene and purification and characterization of the cloned enzyme. J. Bacteriol. 176:3552-3558.

Morrison, MM, ET Seo, JK Howie and DT Sawyer. 1978. Flavin model systems. 1. The electrochemistry of 1-hydroxyphenazine and pyocyanine in aprotic solvents. J. Am. Chem. Soc. 100:207-211.

Ochsner, UA, AK Koch, A Fiechter and J Reiser. 1994. Isolation and characterization of a regulatory gene affecting rhamnolipid biosurfactant synthesis in Pseudomonas aeruginosa. J. Bacteriol. 176:2044-2054.

Pierson, LS, 3rd, VD Keppenne and DW Wood. 1994. Phenazine antibiotic biosynthesis in Pseudomonas aureofaciens 30-84 is regulated in response to cell density. J. Bacteriol. 176:3966-3974.

Richter, G, H Ritz, G Katzenmeier, R Volk, A Kohnle, F Lottspeich, D Allendorf and A Bacher. 1993. Biosynthesis of riboflavin: cloning, sequencing, mapping, and expression of the gene coding for GTP cyclohydrolase II in Escherichia coli. J. Bacteriol. 175:4045-4051.

Spyrou, G, E Haggard-Ljungquist, M Krook, H Jornvall, E Nilsson and P Reichard. 1991. Characterization of the flavin reductase gene (fre) of Escherichia coli 
and construction of a plasmid for overproduction of the enzyme. J. Bacteriol. 173:36733679.

Swartzman, E, S Kapoor, AF Graham and EA Meighen. 1990. A new Vibrio fischeri lux gene precedes a bidirectional termination site for the lux operon. J. Bacteriol. 172:6797-6802.

Zenno, S, K Saigo, H Kanoh and S Inouye. 1994. Identification of the gene encoding the major NAD(P)H-flavin oxidoreductase of the bioluminescent bacterium Vibrio fischeri ATCC 7744. J. Bacteriol. 176:3536-3543.

Zenno, S, and K Saigo. 1994. Identification of the genes encoding NAD(P)Hflavin oxidoreductases that are similar in sequence to Escherichia coli Fre in four species of luminous bacteria: Photorhabdus luminescens, Vibrio fischeri, V. harveyi, and $V$. orientalis. J. Bacteriol. 176:3544-3551.

Yonetani, T. 1963. The a-type cytochromes, p. 41-79. PD Boyer, H Lardy and K Myrback (ed.), The enzymes. Vol. 8. Academic Press, New York. 